Universidade de São Paulo

Instituto de Química de São Carlos

\title{
Nitrosilo complexos de rutênio(II) como captores de radicais de interesse biológico
}

\author{
Gustavo Metzker
}

Dissertação apresentada ao Instituto de Química de São Carlos, da Universidade de São Paulo, como um dos requisitos para a obtenção do título de Mestre em Ciências. Área de concentração: Química Analítica

Orientador: Prof. Dr. Douglas Wagner Franco

São Carlos

2009 
Aos meus pais, Antonio e Carmen e ao meu irmão Fabrício, pelo apoio constante e por acreditarem em mim. Sem vocês, eu não teria chegado até aqui.
A minha namorada Paula, por me "aguentar" durante esses dois anos e pelo carinho. 
De cada coisa em particular, pergunte:

O que é em si mesma?

Qual a sua natureza?

Marcus Aurelius Antoninus Augustus

(121 d.C - 180 d.C) 


\section{Agradecimentos}

Ao Prof. Dr. Douglas Wagner Franco pela orientação, amizade e pelos ensinamentos, não só no tocante da química.

Ao Prof. Dr. Daniel Rodrigues Cardoso pelas discussões, importante ajuda nos experimentos e pela amizade.

Ao Prof. Dr. Benedito dos Santos Lima Neto pelas discussões e pela amizade.

Ao Prof. Dr. Luiz Alberto Avaca e ao Msc. Gustavo Stoppa Garbellini pela disponibilidade na realização dos experimentos voltamétricos utilizando eletrodo de diamante dopado com boro.

Aos colegas do Laboratório de Química Inorgânica e Analítica e do Laboratório da Química da Aguardente do IQSC-USP pela harmoniosa convivência.

A "velha guarda" da turma de bacharelado do IQSC-USP (2003).

Aos amigos Raphael e Pietro pelas discussões e por compartilharem os momentos bons e difíceis durante esses dois anos de mestrado.

A minha tia Apparecida pelo incentivo.

Aos amigos Gisélia e Luiz Fernando pelos bons momentos vividos e pela amizade

A Veroneide por se mostrar sempre pronta a ajudar.

Aos funcionários da biblioteca do IQSC, principalmente a Bernadete e Eliana por se mostrarem sempre prontas a ajudar.

Ao Instituto de Química de São Carlos e a Universidade de São Paulo pela oportunidade.

A FAPESP pelo auxílio financeiro (Processo 06/05877-4). 


\section{Sumário}

Lista de Figuras

Lista de Tabelas $\quad$ iii

Abreviaturas

Estruturas Químicas $\quad$ v

Resumo vi vi vis

Abstract vii

I - Introdução 1

1.1 - Radicais e sua participação em processos fisiológicos 1

1.2 - Mecanismos de neutralização de radicais 3

1.3 - Óxido Nítrico 4

1.3.1 - Óxido nítrico e fisiologia humana 4

1.3.2 - Óxido nítrico e o seu duplo papel no estresse oxidativo 5

1.3.3 - Óxido nítrico como antioxidante: reações e implicações 6

1.4 - Metais de transição: aplicações como fármacos e transportadores de 8 óxido nítrico

II - Objetivos e Justificativa 11

III - Metodologia 12

$\begin{array}{ll}3.1 \text { - Instrumentação } & 12\end{array}$

3.1.1 - Espectrofotometria de UV-vis 12

3.1.2 - Medidas de eletrodo seletivo de NO 12

3.1.3 - Infravermelho (IV) 12

$\begin{array}{ll}3.1 .4 \text { - Voltametria cíclica } & 13\end{array}$

3.1.5 - Medidas de espectroscopia de ressonância paramagnética de 13 elétrons (RPE)

3.1.5.1 - Medidas de RPE a temperatura ambiente 13

3.1.5.2 - Medidas de RPE a baixa temperatura 14

3.1.6 - Experimentos utilizando fotólise por pulso de LASER 15

3.2 - Síntese e caracterização dos nitrosilo complexos de rutênio(II) 16

3.2.1 - Reagentes 16

3.2.2 - Caracterização dos compostos 17

3.2.3 - Via de síntese dos complexos trans-[Ru(NO)(NH$\left.)_{4}(\mathrm{~L})\right]\left(\mathrm{BF}_{4}\right)_{3}, \quad 17$ onde $\mathrm{L}=$ isn, 4-pic, nic, py, imN 
3.2.4 - Via de síntese complexo trans $-\left[\mathrm{Ru}(\mathrm{NO})\left(\mathrm{NH}_{3}\right)_{4}\left(\mathrm{P}(\mathrm{OEt})_{3}\right)\right]\left(\mathrm{PF}_{6}\right)_{3} \quad 18$

3.2.5 - Síntese complexo [Ru(NO)(Hedta)] 18

3.2.6 - Síntese complexo trans- $-\left[\mathrm{Ru}\left(\mathrm{H}_{2} \mathrm{O}\right)\left(\mathrm{NH}_{3}\right)_{4}\left(\mathrm{SO}_{2}\right)\right]\left(\mathrm{CF}_{3} \mathrm{SO}_{3}\right)_{2} \quad 19$

3.3 - Reações envolvendo o radical DPPH ${ }^{\bullet} \quad 19$

3.3.1 - Reagentes: procedência e pureza 19

3.3.2 - Preparo das soluções 20

3.4 - Reações envolvendo o radical hidroxila 20

3.4.1 - Reagentes: procedência e pureza 20

3.4 .2 - Preparação das soluções e protocolo de medida 21

3.5 - Medidas envolvendo radical superóxido $\left(\mathrm{O}_{2}^{-\bullet}\right) \quad 23$

3.5.1 - Geração do radical $\mathrm{O}_{2}^{-\bullet}$ pela via fotoquímica 23

3.5.2 - Geração do radical $\mathrm{O}_{2}^{-\bullet}$ pela via enzimática 24

3.5.3 - Protocolo de medida 25

3.5.4 - Detecção e quantificação do radical $\mathrm{O}_{2}^{-\bullet} 26$

$\begin{array}{ll}3.6 \text { - Medidas de cinética por competição } & 27\end{array}$

IV - Resultados e Discussão 29

4.1 - Comportamento voltamétrico dos nitrosilo complexos de rutênio(II) 29

4.1.1 - Aspectos Gerais 29

4.1.2 - Medidas voltamétricas utilizando eletrodos de diamante dopado 31

com boro para os complexos trans-[Ru(NO) $\left.\left(\mathrm{NH}_{3}\right)_{4}(\mathrm{~L})\right]^{3+}\left(\mathrm{L}=\right.$ nic, isn e $\left.\mathrm{P}(\mathrm{OEt})_{3}\right)$

e $[\mathrm{Ru}(\mathrm{NO})($ Hedta $)]$

4.2 - Experimentos envolvendo radical $\mathrm{DPPH}^{\bullet} \quad 36$

4.2.1 - Aspectos Gerais 36

4.2.2 - Reação entre os aquo complexos e o radical DPPH ${ }^{\bullet}$

4.3 - Experimentos envolvendo radical hidroxila $\left(\mathrm{OH}^{\bullet}\right)$

4.3.1 - Captação do radical hidroxila pelos nitrosilo complexos de 42 rutênio

4.3.2 - Aspectos da reação entre o radical $\mathrm{OH}^{\bullet}$ e os nitrosilo complexos utilizando RPE

4.3.3 - Monitoramento da reação entre o radical $\mathrm{OH}^{\bullet}$ e os nitrosilo complexos de $\mathrm{Ru}(\mathrm{II})$ utilizando eletrodo seletivo a NO

4.3.4 - Considerações sobre a reação entre os nitrosilo complexos e o radical $\mathrm{OH}^{\bullet}$ 
4.4 - Reações entre os nitrosilo complexos e o radical superóxido $\left(\mathrm{O}_{2}^{-{ }^{-}}\right)$

4.4.1 - Captação do radical $\mathrm{O}_{2}^{-\bullet}$ pelos nitrosilo complexos

4.4.2 - Estimativa da constante de velocidade entre o radical superóxido

e os nitrosilo complexos de rutênio(II)

4.4.3 - Liberação de $\mathrm{NO}^{0}$ após a reação entre o radical $\mathrm{O}_{2}^{-\bullet}$ e os nitrosilo complexos

4.4.4 - Sobre a formação de peroxinitrito $\left(\mathrm{ONOO}^{-}\right)$

4.4.5 - Considerações entre as reações entre o radical $\mathrm{O}_{2}^{-\bullet}$ e os nitrosilo 64 complexos de rutênio(II).

V- Considerações Finais

VI - Referências Bibliográficas $\quad 67$

VII - Apêndices 


\section{Lista de Figuras}

Figura 1 - Formação de radical livre superóxido $\left(\mathrm{O}_{2}^{-\bullet}\right)$ e de peróxido de 3 hidrogênio na cadeia transportadora de elétrons mitocondrial.

Figura 2 - Participação do NO como antioxidante nas reações envolvendo 6 espécies reativas de oxigênio e o íon Fe(II/III).

Figura 3 - Rota de síntese do complexo trans-[Ru(NO)(NH$\left.)_{4}(\mathrm{~L})\right]\left(\mathrm{BF}_{4}\right)_{3}$.

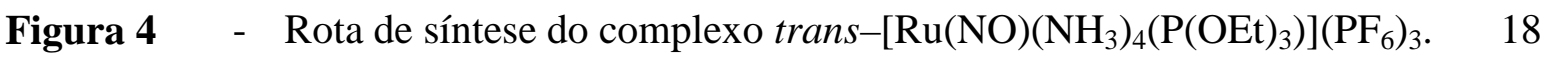

Figura 5 - Rota de síntese do complexo [Ru(NO)(Hedta)]. 18

Figura 6 - Rota de síntese do complexo trans- $\left[\mathrm{Ru}\left(\mathrm{H}_{2} \mathrm{O}\right)\left(\mathrm{NH}_{3}\right)_{4}\left(\mathrm{SO}_{2}\right)\right]\left(\mathrm{CF}_{3} \mathrm{SO}_{3}\right)_{2} . \quad 19$

Figura 7 - Espectro de RPE do aduto DMPO-OH resultante da reação entre o 23 radical hidroxila $\left(\mathrm{OH}^{\circ}\right)$ e o captador de spin DMPO.

Figura 8 - Espectro de UV-vis típico para detecção do radical superóxido $\left(\mathrm{O}_{2}^{-\bullet}\right), 27$ utilizando como sonda citocromo c.

Figura 9 - Reação de competição entre o citocromo c e os nitrosilo complexos. 27

Figura 10 - Voltamograma cíclico do complexo trans- $\left[\mathrm{Ru}(\mathrm{NO})\left(\mathrm{NH}_{3}\right)_{4} \mathrm{P}(\mathrm{OEt})_{3}\right]^{3+} . \quad 30$ $\mathrm{pH}=3,0 ; \mu=0,1 \mathrm{~mol} \mathrm{~L}{ }^{-1} ; \mathrm{T}=25^{\circ} \mathrm{C} ; \mathrm{V}=100 \mathrm{mV} \mathrm{s}^{-1}$; eletrodo de trabalho carbono vítreo.

Figura 11 - Voltamograma cíclico utilizando eletrodo de trabalho EDDB. 32 complexo trans- $\left[\mathrm{Ru}(\mathrm{NO})\left(\mathrm{NH}_{3}\right)_{4}(\mathrm{nic})\right]^{3+} . \mathrm{T}=25{ }^{\circ} \mathrm{C} ; \mathrm{pH}=3,0$; $\mu=0,1 \mathrm{~mol} \mathrm{~L}^{-1} \mathrm{CF}_{3} \mathrm{COOH} / \mathrm{CF}_{3} \mathrm{COONa} ; \mathrm{V}=100 \mathrm{mV} \mathrm{s}^{-1}$.

Figura 12 - Formação do radical $\mathrm{OH}^{\bullet}$ pela adsorção da água na superfície de 33 eletrodos submetidos a elevados potenciais anódicos.

Figura 13 - Voltamograma cíclico utilizando platina como eletrodo de trabalho $\mathrm{Pt} 34$ para o complexo trans- $\left[\mathrm{Ru}(\mathrm{NO})\left(\mathrm{NH}_{3}\right)_{4}(\text { nic })\right]^{3+} ; \mathrm{T}=25^{\circ} \mathrm{C} ; \mathrm{pH}=3,0$; $\mu=0,1 \mathrm{~mol} \mathrm{~L}^{-1} \mathrm{CF}_{3} \mathrm{COOH} / \mathrm{CF}_{3} \mathrm{COONa} ; \mathrm{V}=100 \mathrm{mV} \mathrm{s}^{-1}$.

Figura 14 - Principais mecanismos de desativação do radical DPPH.

Figura 15 - Espectro de UV-vis da reação entre o radical DPPH ${ }^{\bullet}$ e o complexo 38 $[\mathrm{Ru}(\mathrm{NO})($ Hedta $)] . \mathrm{T}=25^{\circ} \mathrm{C} ; \mathrm{pH}=3,0 ; 30$ minutos de reação.

Figura 16 - Variação do espectro de UV-vis da reação entre o radical DPPH e o complexo trans- $\left[\mathrm{Ru}(\mathrm{NO})\left(\mathrm{NH}_{3}\right)_{4}\left(\mathrm{P}(\mathrm{OEt})_{3}\right]^{3+} . \mathrm{T}=25^{\circ} \mathrm{C} ; \mathrm{pH}=3,0 ; 30\right.$ minutos de reação. $445 \mathrm{~nm}$ : ponto isosbéstico.

Figura 17 - Espectro de UV-vis da reação entre 0 complexo 41 trans $-\left[\mathrm{Ru}\left(\mathrm{H}_{2} \mathrm{O}\right)\left(\mathrm{NH}_{3}\right)_{4}\left(\mathrm{P}(\mathrm{OEt})_{3}\right)\right]^{2+}$ e o radical $\mathrm{DPPH}^{\bullet} . \mathrm{T}=25^{\circ} \mathrm{C} ; \mathrm{pH}$ $=3,0$. 
Figura 18 - Espectro de RPE da reação entre o complexo 42 trans $-\left[\mathrm{Ru}\left(\mathrm{NH}_{3}\right)_{4}\left(\mathrm{H}_{2} \mathrm{O}\right)\left(\mathrm{P}(\mathrm{OEt})_{3}\right)\right]^{2+}$ e o radical $\mathrm{DPPH}^{\bullet}$ gerando como produto trans $-\left[\mathrm{Ru}^{\mathrm{III}}\left(\mathrm{NH}_{3}\right)_{4}\left(\mathrm{H}_{2} \mathrm{O}\right)\left(\mathrm{P}(\mathrm{OEt})_{3}\right)\right]^{3+}$.

Figura 19 - Espectro de RPE da reação do complexo 44 trans-[Ru(NO) $\left(\mathrm{NH}_{3}\right)_{4}($ nic $\left.)\right]^{3+}$ e do captador de spin DMPO pelo radical hidroxila. $\mathrm{T}=25^{\circ} \mathrm{C} . \mathrm{CF}_{3} \mathrm{COOH} ; \mathrm{pH}=5,0$.

Figura 20 - Espectros de RPE em banda-X digitalizados para a reação entre o 48 radical $\mathrm{OH}^{\bullet}$ e os complexos trans- $[\mathrm{Ru}(\mathrm{NO})(\mathrm{Cl})($ ciclam $)] \mathrm{Cl}_{2}$ (A) e trans- $\left[\mathrm{Ru}(\mathrm{NO})\left(\mathrm{NH}_{3}\right)_{4}(\mathrm{isn})\right]^{3+}(\mathrm{B}) . \mathrm{T}=115 \mathrm{~K}, \mathrm{pH}=3,0 ; 35 \%$ etilenoglicol (v/v), 32 scans.

Figura 21 - Espectros de RPE banda-X digitalizados para a reação entre o radical 49 $\mathrm{OH}^{*}$ e os complexos trans-[Ru(NO)CiclamCl]Cl $\mathrm{Cl}_{2}$ (A) e trans- $\left[\mathrm{Ru}(\mathrm{NO})\left(\mathrm{NH}_{3}\right)_{4}(\mathrm{Isn})\right]^{3+}$ (B). $\mathrm{T}=10 \mathrm{~K}, \mathrm{pH}=3,0 ; 35 \%$ etilenoglicol (v/v), 8 scans.

Figura 22 - Geração do radical $\mathrm{O}_{2}^{\bullet}$ e a seqüência de reações de competição entre os nitrosilo complexos e a proteína citocromo c pelo radical $\mathrm{O}_{2}{ }^{-}$.

Figura 23 - Espectro de UV-vis da reação de competição entre o complexo 53 trans-[Ru(NO) $\left.\left(\mathrm{NH}_{3}\right)_{4}(\mathrm{imN})\right]^{3+}$ e a proteína citocromo c pelo radical $\mathrm{O}_{2}^{-\bullet} \cdot \mathrm{T}=25^{\circ} \mathrm{C} ; \mathrm{pH}=5,0$.

Figura 24 - Gráfico da porcentagem de captação do radical superóxido versus o 55 potencial de redução $\mathrm{NO}^{+} / \mathrm{NO}^{0}$.

Figura 25 - Gráfico da captação do radical $\mathrm{O}_{2}{ }^{\bullet}$ versus a concentração do 58 complexo trans- $\left[\mathrm{Ru}(\mathrm{NO})\left(\mathrm{NH}_{3}\right)_{4}\left(\mathrm{P}(\mathrm{OEt})_{3}\right)\right]^{3+}$. $\mathrm{k}_{2}$ é o valor da constante de velocidade obtida utilizando a Equação1.

Figura 26 - Cronoamperometria utilizando eletrodo seletivo à $\mathrm{NO}^{0}$ para 61 monitoramento da reação entre o complexo trans- $\left[\mathrm{Ru}(\mathrm{NO})\left(\mathrm{NH}_{3}\right)_{4}(\mathrm{isn})\right]^{3+}$ e o radical $\mathrm{O}_{2}{ }^{\bullet}$. Gráfico menor: mesma reação com o complexo [Ru(NO)Hedta] (a): adição da enzima xantina oxidase. $\mathrm{C}_{\mathrm{Ru}}=5,0 \times 10^{-4} \mathrm{~mol} \mathrm{~L}^{-1} ; \mathrm{pH}=7,2 ; \mathrm{T}=25^{\circ} \mathrm{C}$.

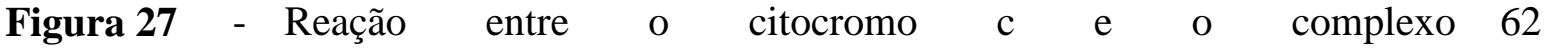
trans- $\left[\mathrm{Ru}(\mathrm{NO})\left(\mathrm{NH}_{3}\right)_{4}(\mathrm{imN})\right]^{3+}$ após a reação com $\mathrm{O}_{2}{ }^{-\bullet} \cdot \mathrm{T}=25{ }^{\circ} \mathrm{C}$; HTFA; $\mathrm{pH}=5,0$. 


\section{Lista de Tabelas}

Tabela 1 - Parâmetros utilizados para medidas de RPE a temperatura ambiente 14

Tabela 2 - Parâmetros utilizados nos experimentos de RPE a baixa temperatura 15

Tabela 3 - Protocolo utilizado para a reação com radical hidroxila 22

Tabela 4 - Protocolo utilizado para geração fotoquímica do radical superóxido 25

Tabela 5 - Protocolo utilizado para geração enzimática do radical superóxido 26

Tabela 6 - Potenciais de oxidação Ru(II)/Ru(III) para os complexos 35 trans-[Ru(NO) $\left.\left(\mathrm{NH}_{3}\right)_{4}(\mathrm{~L})\right]^{3+}$ e $[\mathrm{Ru}(\mathrm{NO})($ Hedta $)]$

Tabela 7 - Captação do radical $\mathrm{OH}^{\bullet}$ pelos complexos trans-[Ru(NO)(NH$\left.)_{4}(\mathrm{~L})\right]^{3+} \quad 45$ e $[\mathrm{Ru}(\mathrm{NO})($ Hedta) $]$

Tabela 8 - Eficiência de captação do radical $\mathrm{O}_{2}^{-\bullet}(\%)^{*}$ frente os complexos 54 trans-[Ru(NO) $\left.\left(\mathrm{NH}_{3}\right)_{4}(\mathrm{~L})\right]^{3+}$ e $[\mathrm{Ru}(\mathrm{NO})$ Hedta $]$ 


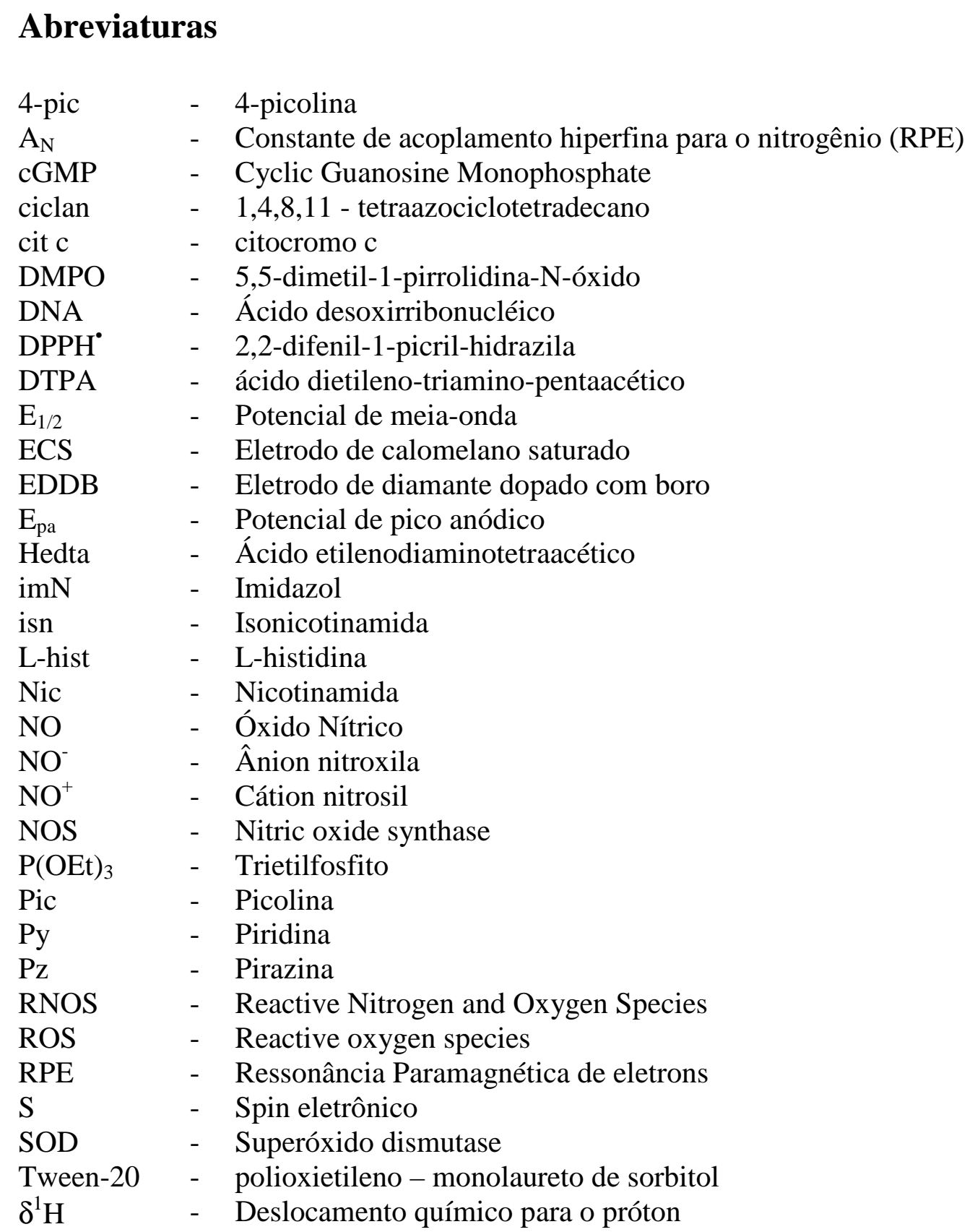




\section{Estruturas Químicas}

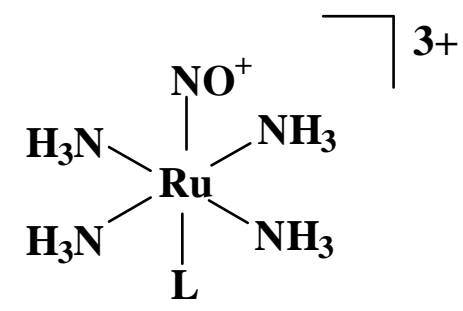

trans $-\left[\mathrm{Ru}(\mathrm{NO})\left(\mathrm{NH}_{3}\right)_{4}(\mathrm{~L})\right]^{3+}$<smiles>c1ccncc1</smiles>

Piridina (py)

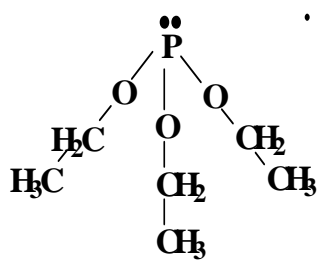

Trietilfosfito $\mathrm{P}(\mathrm{OEt})_{3}$<smiles>Cc1ccncc1</smiles>

4-Picolina (pic)<smiles>c1c[nH]cn1</smiles>

Imidazol (ImN)

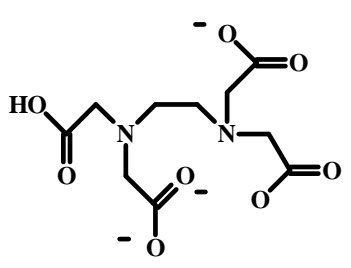

Hedta<smiles>NC(=O)c1cccnc1</smiles>

Nicotinamida (nic)<smiles>NC(=O)c1ccncc1</smiles>

Isonicotinamida (isn) 


\section{Resumo}

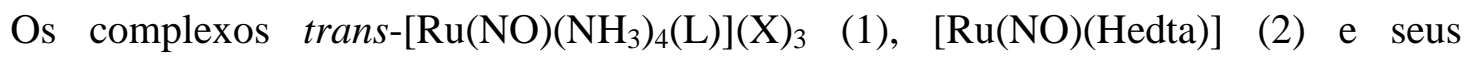
precursores sintéticos trans-[Ru( $\left.\left.\mathrm{H}_{2} \mathrm{O}\right)\left(\mathrm{NH}_{3}\right)_{4}(\mathrm{~L})\right](\mathrm{X})_{2}(3)$, trans- $\left[\mathrm{Ru}\left(\mathrm{SO}_{4}\right)\left(\mathrm{NH}_{3}\right)_{4}(\mathrm{~L})\right](\mathrm{X})(4)$, onde $\mathrm{L}=$ isn, nic, imN, 4-pic, py, $\mathrm{P}(\mathrm{OEt})$ e $\mathrm{X}=\mathrm{PF}_{6}{ }^{-}$e $\mathrm{BF}_{4}^{-}$, foram testados como captadores dos radicais livres $\mathrm{DPPH}^{*}, \mathrm{OH}^{\bullet}$ e $\mathrm{O}_{2}^{-\bullet}$ em meio aquoso. $\mathrm{O}$ potencial de oxidação do centro metálico nos complexos (1) foram estimados utilizando eletrodo de diamante dopado com boro como eletrodo de trabalho, estando situados em meio aquoso acima de 2,0 V vs. ECS $\left(\mathrm{C}_{\mathrm{H}+}=1,0 \times 10^{-3}, \mu=0,1 \mathrm{~mol} \mathrm{~L}^{-1}\right)$. Os complexos (1) e (2) mostraram-se incapazes de reagir com o radical DPPH', exceto o complexo trans-[Ru(NO) $\left.\left(\mathrm{NH}_{3}\right)_{4}\left(\mathrm{P}(\mathrm{OEt})_{3}\right)\right]^{3+}$, que reagiu apenas em grande excesso (50 vezes) em relação ao radical DPPH*. Os complexos (3) reagiram quando em excesso ou em proporção estequiométrica. O mecanismo pelo qual esta reação ocorre é predominantemente o de transferência de elétrons. $\mathrm{O}$ radical $\mathrm{OH}^{\bullet}$ foi captado pelos complexos (1), sendo provavelmente o mecanismo predominante o de transferência de elétrons pela oxidação do centro metálico $[\mathrm{Ru}(\mathrm{NO})]^{3+}$ a $[\mathrm{Ru}(\mathrm{NO})]^{4+}$, compatível com o potencial de oxidação do radical $\mathrm{OH}^{*}$ (acima de $2,8 \mathrm{~V} v$ s. ECS) reportado na literatura para este radical. As constantes de velocidade específica para estas reações foram estimadas como estando no intervalo de $10^{8}$ a $10^{10} \mathrm{M}^{-1} \mathrm{~s}^{-1}$. Não foi observada reação entre o radical $\mathrm{OH}^{\bullet}$ e os complexos (4). Os complexos (1) e (2) captam o radical $\mathrm{O}_{2}^{-}$pela redução do ligante $\mathrm{NO}^{+}$com constantes de velocidade específicas no intervalo de $2,0 \pm 1,0 \times 10^{4}$ a 4,2 $\pm 1,0 \times 10^{5} \mathrm{M}^{-1} \mathrm{~s}^{-1}$, em medidas efetuadas via cinética de competição com citocromo c. Após a redução, a liberação de NO foi acompanhada via eletrodo seletivo a NO e espectrofotometricamente pela reação do NO com o citocromo c. Nas condições experimentais utilizadas, não se observou a formação do íon peroxinitrito ( $\left.\mathrm{ONOO}^{-}\right)$. Os complexos (3) e (4) não reagiram com o radical $\mathrm{O}_{2}{ }^{\cdot}$. 


\begin{abstract}
The trans- $\left[\mathrm{Ru}(\mathrm{NO})\left(\mathrm{NH}_{3}\right)_{4}(\mathrm{~L})\right](\mathrm{X})_{3}(1),[\mathrm{Ru}(\mathrm{NO})($ Hedta $)]$ (2) complexes and their synthetic precursors trans- $\left[\mathrm{Ru}\left(\mathrm{H}_{2} \mathrm{O}\right)\left(\mathrm{NH}_{3}\right)_{4}(\mathrm{~L})\right](\mathrm{X})_{2}(3)$, trans- $\left[\mathrm{Ru}\left(\mathrm{SO}_{4}\right)\left(\mathrm{NH}_{3}\right)_{4}(\mathrm{~L})\right](\mathrm{X})$ (4) , with $\mathrm{L}=$ isn, nic, imN, 4-pic, py, $\mathrm{P}(\mathrm{OEt})$ e $\mathrm{X}=\mathrm{PF}_{6}{ }^{-}$and $\mathrm{BF}_{4}^{-}$, were tested as scavengers of the radicals $\mathrm{DPPH}^{\bullet}, \mathrm{OH}^{\bullet}$ e $\mathrm{O}_{2}^{-\bullet}$ in aqueous media. The redox potential of the metal center in the complexes (1) were obtained a using boron doped diamond electrode as working electrode. The redox potentials values for ruthenium nitrosyl complexes were higher than $+2,0 \mathrm{~V} v s$. SCE. The complexes (1) and (2) were unable to reduce the radical $\mathrm{DPPH}^{\circ}$, except the trans$\left[\mathrm{Ru}(\mathrm{NO})\left(\mathrm{NH}_{3}\right)_{4}\left(\mathrm{P}(\mathrm{OEt})_{3}\right)\right]^{3+}$ complex ion. The complexes (3) react with $\mathrm{DPPH}^{\bullet}$ in stoichometric proportion. Electron transfer from the oxidation of the ruthenium(II) center seems to be the reaction pathway. The $\mathrm{OH}^{\bullet}$ radical reacts with ruthenium nitrosyls complexes, predominantly oxidizing the metal center, and yielding the fragment $[\mathrm{Ru}(\mathrm{NO})]^{4+}$. This reaction is exothermic since the redox potential of the $\mathrm{OH}^{*}$ is around $+2.8 \mathrm{~V}$ vs. SCE. From competition kinetics the rate constant of this reaction were estimated in the range of $10^{8}$ to $10^{10} \mathrm{M}^{-1} \mathrm{~s}^{-1}$. Since the reaction between $\mathrm{OH}^{\bullet}$ radical and the complexes (4) was not observed, the hydrogen atom transfer mechanism for the scavenger of $\mathrm{OH}^{\bullet}$ by the nitrosyl complexes can be ruled out. The complexes (1) and (2) scavenge the radical $\mathrm{O}_{2}^{-\bullet}$ by the reduction of the coordinated nitrosyl with specific rate constants ranging from $2.0 \pm 1,0 \times 10^{4}$ to $4.2 \pm 1,0 \mathrm{x}$ $10^{5} \mathrm{M}^{-1} \mathrm{~s}^{-1}$ as probed by competitive kinetics using cytochrome $\mathrm{c}$. After reduction, nitric oxide dissociation was confirmed ampherometricaly using a selective NO electrode or spectrophotometrically using cytochrome c as probe. Reduction of the complexes (3) by superoxide ion was not observed and may suggest the coordinated nitrosonium as the reaction site for reduction.
\end{abstract}




\section{I - Introdução}

\section{1 - Radicais e sua participação em processos fỉsiológicos}

Radicais, por definição, são espécies que possuem um ou mais elétrons desemparelhados $(\mathrm{S} \neq 0)^{[1]}$. A maior reatividade destas espécies faz com que estas sejam de extrema importância em meio biológico, estando envolvidas em processos fisiológicos e patofisiológicos ${ }^{[2,3]}$.

Já no início da década de 60 , Gershman e Gilbert ${ }^{3}$ propuseram que a maioria dos danos causados em células do organismo humano seria fruto da reação destas com radicais, principalmente moléculas envolvendo oxigênio molecular ${ }^{[3,4]}$. Tais espécies seriam oriundas das reações nas quais o oxigênio molecular participa no processo respiratório celular principalmente na cadeia transportadora de elétrons. Dentre estas entidades químicas designadas espécies reativas do oxigênio ${ }^{[4,6]}$, ROS (Reactive Oxygen Species), podemos citar o íon superóxido $\left(\mathrm{O}_{2}^{-\bullet}\right)$, o peróxido de hidrogênio $\left(\mathrm{H}_{2} \mathrm{O}_{2}\right)$, e o radical hidroxila $\left(\mathrm{OH}^{\bullet}\right)$. Estes radicais por sua vez estão envolvidas também na formação de radicais lipídicos ${ }^{[7]}\left(\mathrm{L}^{\bullet}, \mathrm{LO}^{\bullet} \mathrm{e}\right.$ $\mathrm{LOO}^{\bullet}$, onde $\mathrm{L}=$ cadeias de hidrocarbonetos saturadas e/ou insaturadas).

Radicais que apresentam átomos de nitrogênio e oxigênio em sua composição são classificadas como espécies reativas de nitrogênio e oxigênio, RNOS (Reactive Nitrogen and Oxigen Species $)^{[8]}$. Dentre elas, podem-se destacar o peroxinitrito $\left(\mathrm{ONOO}^{-}\right)^{[8]}$ e o radical óxido nítrico $(\mathrm{NO})^{[8]}$.

O radical hidroxila é extremamente reativo, com elevado potencial de oxidação $\left(\mathrm{E}^{0} \approx+2,8 \mathrm{~V}\right)^{[9,10]}$. Formado em meio fisiológico pela reação de desproporcionamento do peróxido de hidrogênio na presença de traços de íons de metais de transição, principalmente 
íons de ferro e cobre no metabolismo aeróbico celular via reação de Fenton ${ }^{[11]}$ com constante de velocidade específica $\mathrm{k}_{\mathrm{f}}=53.0 \pm 0.7 \mathrm{M}^{-1} \mathrm{~s}^{-1[12]}$

$$
\begin{aligned}
& \mathbf{F e}(\mathrm{II})+\mathrm{H}_{2} \mathrm{O}_{2} \stackrel{\mathbf{k}_{\mathbf{f}}}{\longrightarrow} \mathbf{F e}(\mathrm{III})+\mathbf{O H}+\mathbf{O H} \text { (1) } \\
& \text { Reação 1 - Reação de formação do radical hidroxila (reação de Fenton) }
\end{aligned}
$$

Koppenol e colaboradores ${ }^{[9]}$ utilizando soluções modelo que mimetizavam o plasma sangüíneo demonstraram que o radical hidroxila pode ser gerado mesmo em sistemas onde o íon de ferro encontra-se quelado, como na presença de citrato e albumina, induzindo a formação de radical hidroxila.

O radical superóxido é um ânion radical formado pela adição de um elétron ao orbital $\pi^{*}$ do oxigênio molecular ${ }^{[13]}$. Pode agir como redutor ou oxidante, dependendo do $\mathrm{pH}$ e da composição do meio em que foi formado (reações 2 e 3$)^{[13]}$. Seu potencial na oxidação (reação 2) é de $-0,60 \mathrm{~V} v s$. ECS.

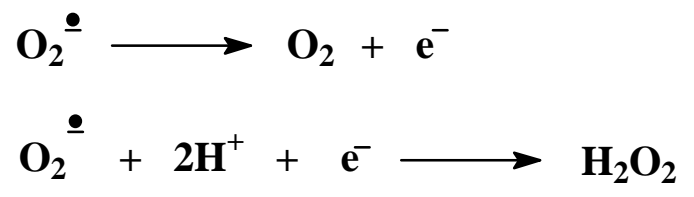

Reações 2 e 3 - Íon superóxido agindo como agente redutor ou oxidante $e^{[13]}$

O radical superóxido pode ser gerado no metabolismo aeróbico celular na cadeia transportadora de elétrons ${ }^{[6,14]}$ e também em situações de inflamação e isquemia ${ }^{[15]}$ sendo neutralizado por enzimas específicas como a superóxido dismutase (SOD). A Figura 1 ilustra a formação do radical superóxido durante a cadeia transportadora de elétrons da respiração aeróbica celular. 


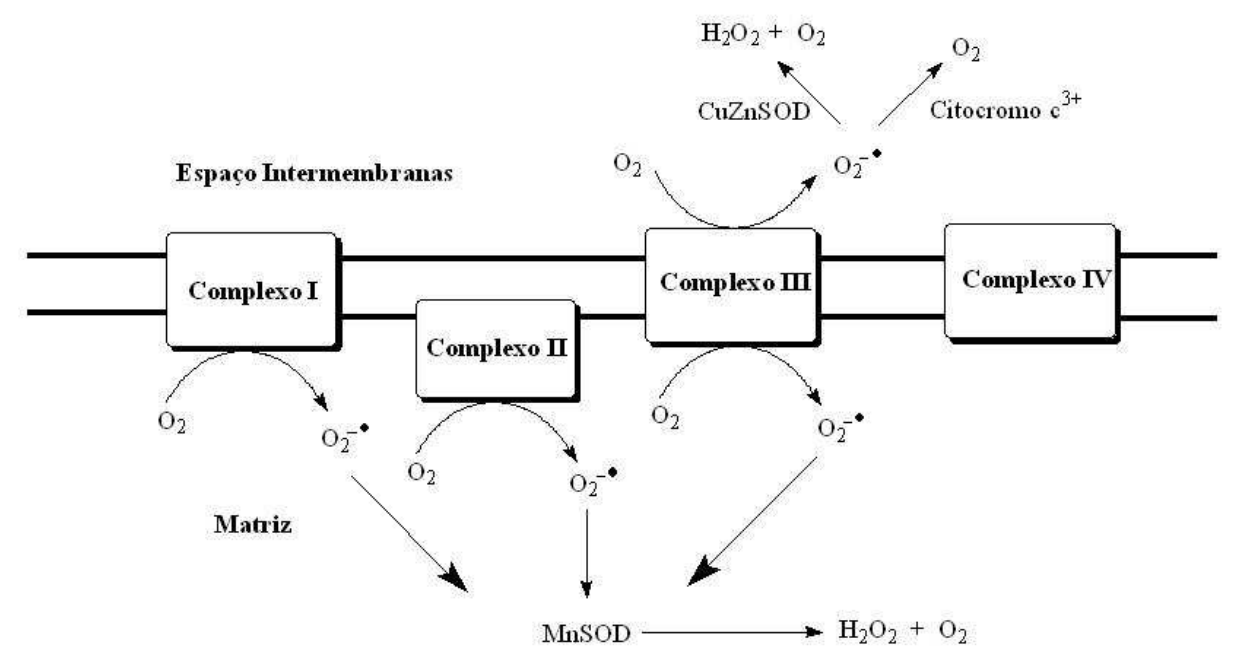

Figura 1 - Formação do radical superóxido $\left(\mathrm{O}_{2}^{-\bullet}\right)$ e de peróxido de hidrogênio na cadeia transportadora de elétrons mitocondrial ${ }^{[14]}$.

Os radicais $\mathrm{O}_{2}^{-\bullet}$ e $\mathrm{OH}^{\bullet}$ podem interagir com uma vasta gama de biomoléculas, formando outros radicais ou danificando estruturas importantes no nível celular ${ }^{[2,3,4]}$.

Foram intensamente investigadas as funções que estas espécies teriam na patofisiologia humana ${ }^{[3]}$. Descobriu-se que estas estão envolvidas numa série de doenças, dentre elas neurodegenerativas ${ }^{[16,17]}$ (Mal de Alzheimer e de Parkinson), arteriosclerose ${ }^{[18]}$ e câncer $^{[19]}$. Também ficou evidente que estes radicais estão envolvidos em processos de lise celular $^{[20]}$, danos ao $\mathrm{DNA}^{[20]}$ e na oxidação de lipídeos ${ }^{[7]}$ sendo, portanto um dos fatores causadores de uma gama tão grande de doenças. Em adição, os radicais são responsibilizados como uma das principais causas que levam ao envelhecimento ${ }^{[22]}$.

\section{2 - Mecanismos de neutralização de radicais}

Antioxidante pode ser definido como sendo uma substância que previne a formação de espécies oxidantes ou captam oxidantes produzidos sob condição de estresse oxidativo ${ }^{[4,22]}$.

Existem vários mecanismos fisiológicos para a desativação de radicais. Estes podem ser endógenos, utilizando enzimas específicas (superóxido-dismutase) e/ou proteínas e aminoácidos (cisteína, glutationa) ${ }^{[4,23]}$ e exógenos, conseqüência da ingestão de moléculas 
com capacidade antioxidante (ácido ascórbico, polifenóis derivados de alimentos) ${ }^{[15,23]}$. Porém, muitas vezes estes mecanismos não são capazes de conduzir a neutralização de todos os radicais formados, e como consequiência se observa um excesso de radicais em determinadas situações. A este processo se dá o nome de estresse oxidativo ${ }^{[22]}$ sendo considerado responsável pela maioria das doenças descritas anteriormente. Em situações de inflamação, o processo de estresse oxidativo é muito pronunciado, tornando o ambiente acometido bastante reativo e, portanto favorecendo a formação de radicais.

\section{3 - Óxido nítrico}

\subsection{1 - Óxido nítrico e fisiologia humana}

Moléculas que possuam habilidade de agirem como antioxidante em meio fisiológico têm merecido muita atenção nas últimas décadas ${ }^{[24]}$. Dentre elas, podemos destacar o óxido nítrico (NO). As funções fisiológicas do NO foram descritas pela primeira vez na década de 80, por Furchgott, Ignarro e Murad (ganhadores do Prêmio Nobel de Fisiologia de 1998), que relacionaram o óxido nítrico com o processo de vasodilatação ${ }^{[25]}$. Atualmente, sabe-se que o óxido nítrico é uma molécula chave no processo fisiológico humano, sendo responsável por várias funções dentre as quais: neurotransmissão ${ }^{[25]}$, vasodilatação e reperfusão ${ }^{[26]}$, atividade antimicrobiana $^{[27,28]}$, agente do sistema de defesa e de sinalização celular ${ }^{[24]}$. Recentemente o NO foi também relacionado como um antioxidante endógeno, devido sua elevada reatividade com outros radicais ${ }^{[24,29,30]}$. Torna-se então evidente a relevância de compostos que sejam doadores de NO e que permitam a liberação controlada desta molécula ${ }^{[31,32]}$. 


\subsection{2 - Óxido nítrico e o seu duplo papel no estresse oxidativo}

Dentre as possíveis moléculas que podem agir como antioxidante está o óxido nítrico $(\mathrm{NO})^{[29]}$. A produção endógena de NO pelo sistema fisiológico humano esta relacionada com três tipos de enzimas que o sintetizam. As NO sintases são classificadas como: nNOS (neural Nitric Oxide Synthase), iNOS (inducible Nitric Oxide Synthase) and eNOS (endothelial Nitric Oxide Synthase) $)^{[2,33]}$.

Este radical diatômico tem papel central na regulação do mecanismo de vasodilatação endotelial e em todas as funções onde a enzima cGMP (cyclic Guanosine Monophosphate) está envolvida ${ }^{[33]}$. Exogenamente, os níveis de NO podem ser supridos ou controlados via moléculas captadoras ou transportadoras de NO. Por estar presente em quantidades que variam de $1 \mathrm{nM}$ a $100 \mu \mathrm{M}$ no organismo humano, o NO pode desenvolver diversas funções. Além disso, por se tratar de um radical, o NO pode reagir rapidamente com outras espécies radicalares $^{[34]}$.

Desta forma, a investigação de suas reações com radicais e suas potencialidades terapêuticas têm merecido muita atenção ${ }^{[35]}$. Recentemente, foi demonstrado que o controle da concentração de óxido nítrico no meio fisiológico está diretamente ligado ao tipo de efeito que esta molécula pode gerar ${ }^{[34,36]}$. Concentrações de NO inferiores $1 \mu \mathrm{M}$ em tecidos induzem efeitos diretos, por não exigirem um fluxo contínuo de produção de NO, como reações com grupos heme de proteínas e ativação de enzimas ${ }^{[34]}$. Por outro lado, concentrações de NO acima de $1 \mu \mathrm{M}$ estão relacionadas com efeitos indiretos do NO e envolvem a formação de espécies reativas de oxigênio (radical superóxido e hidroxila) e também a formação de oxigênio molecular em excesso ${ }^{[36,37]}$.

Logo, dependendo da concentração NO em tecidos com elevado nível de estresse oxidativo (por exemplo, em tecidos inflamatórios e tecidos cancerosos) pode ocorrer uma 
diminuição destas inflamações e em alguns casos a extinção completa do quadro de estresse oxidativo ou o agravamento deste quadro pela produção de espécies altamente reativas em excesso $^{[29,34,37]}$. Novamente, torna-se evidente que o controle da concentração de NO no meio fisiológico é de extrema importância.

\subsection{3 - Óxido nítrico como antioxidante: reações e implicações}

O óxido nítrico pode apresentar função antioxidante, principalmente se consideradas suas reações envolvendo RNOS. A Figura 2 mostra como o NO pode participar na desativação de diversos processos fisiológicos potencialmente geradores de radicais.

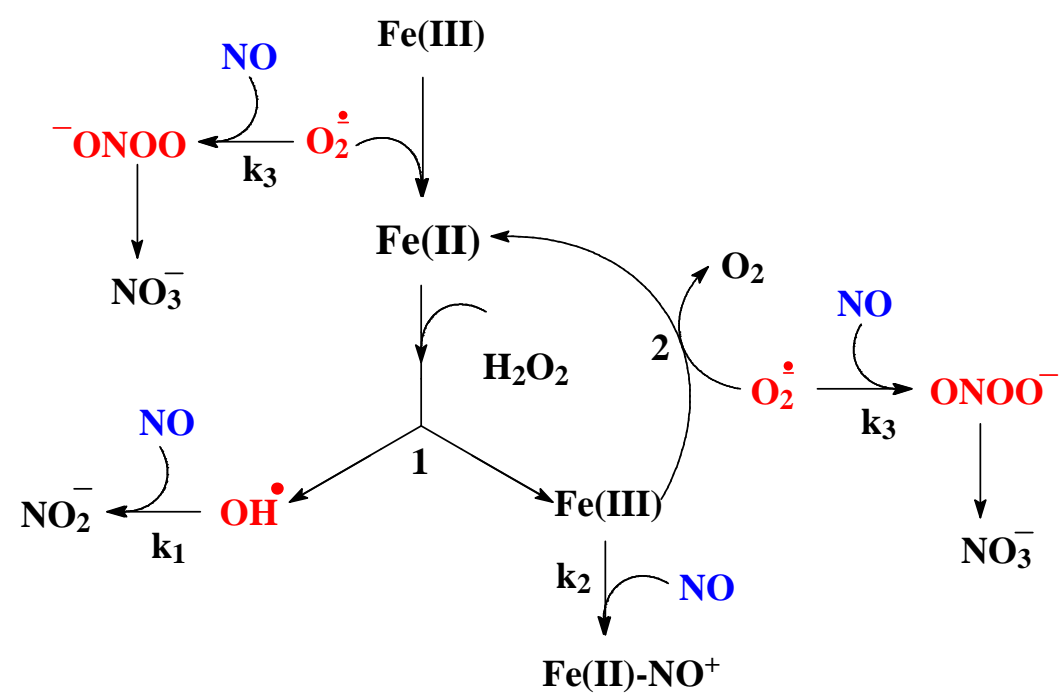

Figura 2 - Participação do NO como antioxidante nas reações envolvendo espécies reativas de oxigênio e dos íons $\mathrm{Fe}(\mathrm{II} / \mathrm{III})^{[29,34]}$.

A principal via pela qual o NO pode atuar como antioxidante é através da desativação das espécies oriundas da reação de Fenton (rota 1) e de Haber-Weiss (rota 2). Uma vez que espécies de Fe(III) são mais estáveis no meio fisiológico ${ }^{[29,34]}$, o impedimento de sua redução a $\mathrm{Fe}(\mathrm{II})$ pode levar a uma diminuição expressiva da formação do radical hidroxila. Além 
disso, a reação direta do radical $\mathrm{OH}^{\bullet}$ com o $\mathrm{NO}$ (reação 4) leva a formação do íon nitrito $\left(\mathrm{NO}_{2}{ }^{-}\right)$, que é consideravelmente menos tóxico ${ }^{[9]}$ que o radical $\mathrm{OH}^{\bullet}$. Por essa reação apresentar uma elevada constante de velocidade específica $\left(\mathrm{k}_{1} \approx 10^{9} \mathrm{M}^{-1} \mathrm{~s}^{-1}\right)^{[9]}$ esta pode constituir em uma via de desativação do radical $\mathrm{OH}^{\bullet}$.

$$
\mathrm{OH}^{\bullet}+\mathrm{NO} \stackrel{\mathrm{k}_{1}}{\longrightarrow} \mathrm{NO}_{2}^{-}+\mathrm{H}^{+}
$$

Reação 4 - Formação do íon nitrito pela reação do NO com o radical OH

Outra via importante de interrupção da formação de radicais sugerida na Figura 2, é através da formação de metalo-nitrosilos. A literatura reporta que íons de metais de transição tais como $\mathrm{Ni}^{2+}, \mathrm{Cu}^{2+}$ e principalmente íons de $\mathrm{Fe}^{2+/ 3+}$ seriam responsáveis pela formação do radical hidroxila ${ }^{[11]}$. O valor elevado da constante de velocidade específica $\left(\mathrm{k}_{2} \approx 10^{6} \mathrm{M}^{-1} \mathrm{~s}^{-1}\right)$ para a formação de nitrosilo complexos de ferro (reação 5) ${ }^{[38]}$ poderia levar a uma diminuição de íons $\mathrm{Fe}^{2+}$ (rota 2) no meio fisiológico e portanto a diminuição da formação de radicais $\mathrm{OH}^{\bullet}$.

$$
\mathrm{Fe}(\mathrm{III})+\mathrm{NO}^{0} \stackrel{\mathrm{k}_{2}}{\longrightarrow}[\mathrm{Fe}(\mathrm{NO})]^{2+}
$$

Reação 5 - Formação de nitrosilo complexos de ferro

A reação do radical $\mathrm{O}_{2}^{-\bullet}$ com o $\mathrm{NO}$ é ponto que exemplifica sobre a característica dual desta molécula em meio fisiológico. Em meios onde há elevada concentração de superóxido, elevadas concentrações de NO levam a formação do íon $\mathrm{ONOO}^{-}$(reação 5) com constante de velocidade específica bastante elevada $\left(\mathrm{k}_{3} \approx 1,9 \times 10^{10} \mathrm{M}^{-1} \mathrm{~s}^{-1}\right)^{[8,29]}$.

$$
\mathrm{O}_{2}^{\bullet}+\mathrm{NO} \stackrel{\mathrm{k}_{3}}{\longrightarrow} \mathrm{ONOO}^{-}(6)
$$

$$
\text { Reação } 6 \text { - Formação do íon peroxinitrito }
$$


Embora até o momento, a literatura ${ }^{[29]}$ não possua dados conclusivos sobre qual espécie, o radical $\mathrm{O}_{2}^{-\bullet}$ ou o íon $\mathrm{ONOO}^{-}$, seria mais danoso ao organismo foi sugerido que a atividade tripanomocida apresentada pelo óxido nítrico seria na verdade devido a formação in situ do íon $\mathrm{ONOO}^{-[8]}$.

\section{4 - Metais de transição: aplicações como fármacos e transportadores de óxido nítrico}

O estudo de complexos de metais de transição como fármacos, seja envolvendo diretamente o centro metálico ou o utilizando como transportadores de moléculas de interesse, tem sido alvo de várias investigações recentes, como descrito na literatura ${ }^{[39,40]}$. A cisplatina, cis- $\left[\mathrm{Pt}(\mathrm{Cl})_{2}\left(\mathrm{NH}_{3}\right)_{2}\right]$, o mais conhecido exemplo de metalofármaco em uso atualmente é um dos poucos fármacos com atividade contra tumores altamente agressivos como sarcomas e carcinomas $^{[39]}$. Exemplo mais recente é o complexo NAMI-A, trans-[RuCl$\left.{ }_{4}(\mathrm{DMSO}) \mathrm{HIm}\right] \mathrm{H}_{2} \mathrm{Im}$, o qual está em fase final de testes clínicos. Este complexo se demonstrou muito eficaz no tratamento de vários tipos de câncer principalmente quando envolvendo tumores sólidos ${ }^{[41]}$. Além disso, complexos metálicos contendo o íon nitrosilo $\left(\mathrm{NO}^{+}\right)$na esfera de coordenação estão sendo testados, no tratamento de diversas doenças dentre as quais câncer, doença de Chagas e leishmaniose $\mathrm{e}^{[27,42,43,44]}$.

Complexos metálicos de rutênio(II) têm sido estudados como possíveis liberadores de NO em meio fisiológico ${ }^{[31,45]}$. Podemos destacar a classe das tetraminas de rutênio(II) (trans- $\left.-\left[\mathrm{Ru}(\mathrm{NO})\left(\mathrm{NH}_{3}\right)_{4}(\mathrm{~L})\right]^{3+}\right)$, formalmente descritas na literatura como $\left[\mathrm{Ru}^{\mathrm{II}} \mathrm{NO}^{+}\right]^{[16]}$, onde $\mathrm{L}=$ isonicotinamida (isn), picolina (pic), nicotinamida (nic), piridina (py), pirazina (pz), LHistidina (L-Hist), imidazol (imN), 4-picolina (4-pic), trietilfosfito $\left(\mathrm{P}(\mathrm{OEt})_{3}\right) \quad$ e [Ru(NO)Hedta]. Estes complexos liberam óxido nítrico após redução monoeletrônica do íon 
nitrosônio coordenado ${ }^{[32]}$ (reação 7), seguido pela formação do aquocomplexo (reação 8) ou através da irradiação na banda de transferência de carga $\mathrm{Ru}_{4 \mathrm{~d} \pi} \rightarrow \mathrm{NO}_{\mathrm{p} \pi *}$ (reação 9)

$$
\begin{aligned}
& \operatorname{trans}-\left[\mathrm{Ru}(\mathrm{NO})\left(\mathrm{NH}_{3}\right)_{4}(\mathrm{~L})\right]^{3+}+\mathrm{e}^{-} \stackrel{\text { rápido }}{\longrightarrow} \operatorname{trans}-\left[\mathrm{Ru}(\mathrm{NO})\left(\mathrm{NH}_{3}\right)_{4}(\mathrm{~L})\right]^{2+}
\end{aligned}
$$

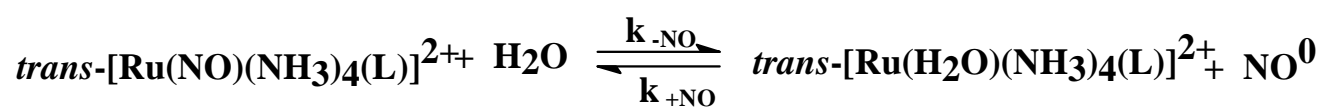

$$
\begin{aligned}
& \text { trans- }\left[\mathrm{Ru}(\mathrm{NO})\left(\mathrm{NH}_{3}\right)_{4}(\mathrm{~L})\right]^{2+} \stackrel{\mathrm{hv}}{\longrightarrow} \operatorname{trans}-\left[\mathrm{Ru}\left(\mathrm{H}_{2} \mathrm{O}\right)\left(\mathrm{NH}_{3}\right) 4(\mathrm{~L})\right]^{3+}+\mathrm{NO}^{0}
\end{aligned}
$$

Reações 7 a 9 - Reação de redução monoeletrônica e liberação de óxido nítrico via aquação dos nitrosilo complexos de rutênio(II) e liberação NO pela via fotoquímica ${ }^{[32]}$.

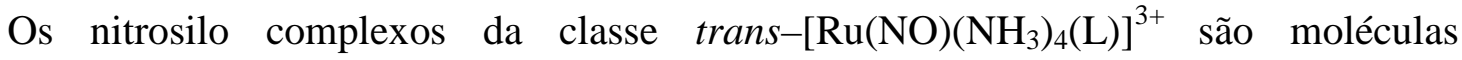
especialmente interessantes como metalofármacos em meio fisiológico, visto que apresentam: baixa toxicidade ${ }^{[26]}$, são solúveis em água ${ }^{[32]}$, suas soluções são estáveis no que diz respeito à exposição ao oxigênio, ${ }^{[32]}$ capacidade de modulação da liberação do óxido nítrico em função do efeito trans exercido pelos ligantes $(\mathrm{L})$ utilizados $^{[45,46]}$ e pelo potencial de redução do ligante $\mathrm{NO}^{+}$nestes compostos ser acessível a diversos redutores encontrados em meio biológico ${ }^{[32]}$. Dados de potencial de redução do ligante $\mathrm{NO}^{+}$e de constante específica de liberação de NO para os nitrosilo complexos encontram-se no Apêndice II.

Desta forma, os nitrosilo complexos de rutênio(II) poderiam agir como antioxidantes em meio fisiológico, por meio da reação de redução do ligante $\mathrm{NO}^{+}$a $\mathrm{NO}^{0}$ e posteriormente em reações onde o NO liberado pode estar envolvido. De acordo com estudos correlatos desenvolvidos em nossos Laboratórios, existem evidências de que estes nitrosilos podem, quando na presença de redutores que possuam potencial redox adequado, gerar nitroxila $\left(\mathrm{NO}^{-}\right)$, outro importante agente em meio fisiológico ${ }^{[47,48]}$. Ainda é plausível se supor que os aquo-complexos, trans- $\left[\mathrm{Ru}\left(\mathrm{H}_{2} \mathrm{O}\right)\left(\mathrm{NH}_{3}\right)_{4}(\mathrm{~L})\right]^{2+}$, gerados após a liberação do óxido nítrico possam agir como antioxidantes através da oxidação do centro metálico, gerando o correspondente complexo de $\mathrm{Ru}(\mathrm{III})$. 
Poucos trabalhos estão disponíveis na literatura tratando das reações entre metais de transição, contendo $\mathrm{NO}^{+} / \mathrm{NO}^{0}$ coordenado ou não, atuando como captadores de radicais. $\mathrm{O}$ fato do $\mathrm{NO}^{0}$ produzido pela redução do nitrosilo coordenado poderia atuar como um agente pró ou antioxidante ${ }^{[8,29]}$, visto que dependendo da concentração do $\mathrm{NO}^{0}$ e das espécies reativas de oxigênio e nitrogênio presentes, os produtos destas reações podem ser ainda mais danosos, contrapondo-se portanto aos efeitos benéficos do NO. Desta forma, o estudo das reações dos radicais superóxido e hidroxila com os nitrosilo complexos de rutênio(II) é por si só importante. 


\section{II - Objetivo e Justificativas}

Objetivo: Analisar a reatividade de nitrosilo complexos metálicos frente a radicais. Para tanto utilizou-se tetraaminas de rutênio (II) e os radicais $\mathrm{DPPH}^{\bullet}, \mathrm{OH}^{\bullet}$ e $\mathrm{O}_{2}^{-\bullet}$ como modelos.

As etapas deste trabalho envolveram:

- Investigar as reações dos nitrosilo complexos trans-[Ru(NO)(NH$\left.)_{4}(\mathrm{~L})\right](\mathrm{X})_{3}$, onde $\mathrm{L}=\mathrm{imN}$, isn, nic, py, 4-pic e $\mathrm{P}(\mathrm{OEt})_{3}$ e $\mathrm{X}=\mathrm{BF}_{4}^{-}$ou $\mathrm{PF}_{6}^{-}$e dos respectivos aquo complexos trans $-\left[\mathrm{Ru}\left(\mathrm{H}_{2} \mathrm{O}\right)\left(\mathrm{NH}_{3}\right)_{4}(\mathrm{~L})\right](\mathrm{X})_{3}$ com o radical DPPH ${ }^{\bullet}$ em meio aquoso.

- Investigar as reações dos nitrosilo complexos supracitados com o radical hidroxila $\left(\mathrm{OH}^{*}\right)$, gerado através da reação de Fenton.

- Investigar as reações dos nitrosilo complexos supracitados com o radical superóxido $\left(\mathrm{O}_{2}^{-\bullet}\right)$ e suas implicações na liberação de NO.

O radical $\mathrm{DPPH}^{*}$ é um modelo extensamente utilizado para verificação da capacidade antioxidante, e, portanto será utilizado como modelo de radical para os experimentos executados. Em relação aos radicais hidroxila e superóxido estes foram escolhidos por se tratarem de radicais de relevância biológica, formados principalmente em situações de estresse oxidativo. 


\section{III - Metodologia}

\section{1 - Instrumentação}

\subsection{1 - Espectrofotometria de UV-vis}

As medidas de espectrofotometria de UV-vis foram realizadas em um espectrofotômetro Hitachi, modelo U-3105. Foram utilizadas celas de quartzo de caminho óptico de 1,0 cm. Como referência foram utilizadas soluções aquosas em $\mathrm{pH}$ e condições específicas de cada protocolo de medida.

\subsection{2 - Medidas de eletrodo seletivo de NO}

As medidas utilizando eletrodo seletivo de NO foram realizadas com o equipamento da Innovative Instruments Inc., modelo inNO-T, cujo limite de detecção de NO em solução é de $1,0 \times 10^{-9} \mathrm{~mol} \mathrm{~L}^{-1}$. A corrente de fundo do eletrodo foi estabilizada durante uma hora imergindo o eletrodo nas respectivas soluções utilizadas em cada experimento. O tempo de monitoramento da liberação de NO foi de uma hora.

\subsection{3 - Infravermelho (IV)}

Os espectros de IV foram obtidos através de um espectrofotômetro BOMEM, modelo FT-IR MB - 102, na região de 4000 a $400 \mathrm{~cm}^{-1}$. Para obtenção das pastilhas foi utilizado brometo de potássio $(\mathrm{KBr})$. As pastilhas foram preparadas no momento das medidas utilizando-se concentração de complexo a 1\% em massa em relação ao KBr. 


\subsection{4 - Voltametria cíclica}

As medidas eletroquímicas foram efetuadas em um potenciostato AUTOLAB modelo PGSTAT100 ou em um potenciostato PAR modelo 264A. Foi utilizada uma cela de vidro encamisada de volume de 5,0 mL. O eletrodo de trabalho utilizado foi de diamante dopado com boro, fabricado pela Adamant Technologies S.A., La Chaux-de-Fonds, Suíça, com dopagem de 8.000 ppm de boro e área superficial de $6,25 \mathrm{~mm}^{2}$ ou eletrodo de carbono vítreo, de área superficial de $3,0 \mathrm{~mm}^{2}$. O contra-eletrodo utilizado foi uma placa de platina de área superficial de $8,0 \mathrm{~mm}^{2}$ e como eletrodo de referência o eletrodo de calomelano saturado $\left(\mathrm{Hg}_{2} \mathrm{Cl}_{2} / \mathrm{Hg} / \mathrm{KCl}_{\text {sat }}\right)$. As medidas foram realizadas em meio aquoso ácido $(\mathrm{pH}=3,0, \mu=0,1$ mol L $\left.\mathrm{L}^{-1} \mathrm{CF}_{3} \mathrm{CO}_{2} \mathrm{Na} / \mathrm{CF}_{3} \mathrm{CO}_{2} \mathrm{H}\right)$. A temperatura foi controlada por um banho termoestático $\left(25,0 \pm 0,5^{\circ} \mathrm{C}\right)$. As concentrações dos complexos utilizadas nestes experimentos foram de $5,0 \times 10^{-4} \mathrm{~mol} \mathrm{~L}^{-1}$. Todos os potenciais reportados nesta dissertação encontram-se convertidos para os valores relativos à ECS.

\subsection{5 - Medidas de espectroscopia de ressonância de elétrons (RPE)}

\subsubsection{1 - Medidas a temperatura ambiente utilizando o trapeador de} spin DMPO

As medidas de RPE foram efetuadas em um espectrômetro Bruker, modelo ESP300E, operando na faixa de micro-ondas entre 9,0 e 10,0 GHz (banda - X), utilizando parâmetros apresentados na Tabela 1 . 
Tabela 1 - Parâmetros utilizados para medidas de RPE a temperatura ambiente.

\begin{tabular}{cc}
\hline Parâmetro & Valor \\
\hline Modulação de amplitude & $0,1 \mathrm{G}$ \\
Modulação de freqüência & $100,0 \mathrm{KHz}$ \\
Campo central & $3430,0 \mathrm{G}$ \\
Campo varrido & $80,0 \mathrm{G}$ \\
Potência de micro-ondas & $20,0 \mathrm{~mW}$ \\
Ganho do receptor & $8,0 \times 10^{4}$ \\
\hline
\end{tabular}

Durante o experimento foi utilizado um sistema de fluxo contínuo, composto por uma bomba peristáltica, cânula de teflon para condução das soluções e capilar de quartzo (diâmetro interno $=1,0 \mathrm{~mm} ; \mathrm{V} \approx 80 \mu \mathrm{L}$ ) como cela para aquisição dos espectros. $\mathrm{O}$ sistema capilar foi utilizado em substituição a "flat-cell" devido a maior reprodutibilidade das medidas e maior praticidade no momento da troca das amostras. Após a mistura dos reagentes descritos na Tabela 3, o sistema foi agitado por 2 minutos em tubo eppendorf e depois bombeado até o centro da cavidade, onde o capilar de quartzo está localizado. O tempo total entre a mistura dos reagentes e a aquisição do primeiro espectro foi de 3 minutos.

\subsubsection{2 - Medidas de ressonância paramagnética de elétrons a baixa temperatura}

As medidas de RPE a baixa temperatura foram efetuadas em um espectrômetro Bruker, modelo ESP300E, alocado em nosso laboratório ou eventualmente em um espectrômetro Bruker Elexsys E580, no Instituto de Física de São Carlos (IFSC/USP). Estas 
últimas foram conduzidas sob supervisão do Prof. Dr. Cláudio José Magon, a quem agradecemos os préstimos.

Ambos os equipamentos contam com um sistema de criostato para medidas a temperatura variável. O equipamento alocado em nosso laboratório conta com um sistema Euroterm, modelo B-VT 2000, sendo capaz de atingir temperaturas na ordem de $100 \mathrm{~K}$ enquanto que o equipamento alocado no IFSC conta com um criostato ER 4112HV, capaz de atingir a temperatura de $4 \mathrm{~K}$. A Tabela 2 apresenta os parâmetros utilizados.

Tabela 2 - Parâmetros utilizados nos experimentos de RPE a baixa temperatura.

\begin{tabular}{lcc}
\hline \multicolumn{1}{c}{ Parâmetro } & \multicolumn{2}{c}{ Valor } \\
& IQSC & IFSC \\
\hline Temperatura & $115 \mathrm{~K}$ & $10 \mathrm{~K}$ \\
Modulação de amplitude & $1,0 \mathrm{G}$ & $1,0 \mathrm{G}$ \\
Modulação de freqüência & $100,0 \mathrm{KHz}$ & $100,0 \mathrm{KHz}$ \\
Campo central & $3430,0 \mathrm{G}$ & $3400,0 \mathrm{G}$ \\
Varredura de campo & $800 \mathrm{G}$ & $400 \mathrm{G}$ \\
Potência de microondas & $4,0 \mathrm{~mW}$ & $10,0 \mathrm{~mW}$ \\
Ganho do receptor & $1,0 \times 10^{5}$ & $5,0 \times 10^{3}$ \\
Número de médias & 32 & 8 \\
\hline
\end{tabular}

\subsection{6 - Experimentos utilizando fotólise por pulso de LASER}

Um Laser Continum, modelo Surelite-II, operando no $3^{\circ}$ harmônico $(355 \mathrm{~nm}$ ) foi utilizado para "bombear" um sistema de oscilação ótica paramétrica (cristal bi-refringente), também da Continum, para o ajuste do comprimento de onda em $440 \mathrm{~nm}$. A energia média de 
saída de cada pulso foi medida com auxílio de um medidor de energia, marca Coherent, modelo LASERMATE/P. Para determinar a energia média de cada pulso, foi efetuada a leitura e posteriormente a média de energia de um conjunto de 20 pulsos. Em geral, as amostras foram irradiadas com energia de $3,0 \pm 0,9 \mathrm{~mJ}$ por pulso.

\section{2 - Síntese e caracterização dos nitrosilo complexos de rutênio(II)}

\subsection{1 - Reagentes}

Todos os reagentes utilizados no processo de síntese dos complexos são de pureza analítica (P.A). Os solventes (acetona e etanol) foram destilados e tratados de acordo com a literatura $^{[49]}$. Éter etílico foi tratado com sódio metálico e sulfato ferroso amoniacal por uma noite, destilado e estocado em frasco escuro para evitar a formação de peróxido ${ }^{[49]}$. Os demais reagentes, $\mathrm{RuCl}_{3} \cdot \mathrm{XH}_{2} \mathrm{O}, \mathrm{NH}_{4} \mathrm{PF}_{6}, \mathrm{NaNO}_{2}, \mathrm{Na}_{2} \mathrm{~S}_{2} \mathrm{O}_{5}, \mathrm{HCl}, \mathrm{HBF}_{4}, \mathrm{CF}_{3} \mathrm{COOH}, \mathrm{NaHCO}_{3}$ e $\mathrm{H}_{2} \mathrm{O}_{2}$ foram utilizados sem prévia purificação, devido ao alto grau de pureza informado pelos fabricantes (Merck ou Sigma-Aldrich).

Os procedimentos de síntese que demandavam atmosfera inerte foram realizados utilizando-se como gás inerte argônio, procedência White Martins. Este foi purificado para retirada de oxigênio através de um sistema de via úmida composto de dois vasos lavadores contento solução ácida de $\mathrm{CrCl}_{3}$, juntamente com amálgama de $\mathrm{Zn}(\mathrm{Hg})^{[49]}$. Em seguida, o gás passou por um vaso contento $\mathrm{H}_{2} \mathrm{SO}_{4}$ concentrado para promover sua secagem ${ }^{[50]}$. Todos os procedimentos que demandavam ausência de oxigênio foram realizados em sistemas fechados, utilizando balões borbulhadores, balões de fundo redondo e cânulas de teflon para condução do gás e transferência das soluções. 


\subsection{2 - Caracterização dos compostos}

Os nitrosilo complexos obtidos foram submetidos a análises de IV (presença da banda em $v(\mathrm{NO})$ próximo a $\left.1900 \mathrm{~cm}^{-1}\right)^{[32]}$; UV-vis (bandas d-d e transferências de carga) ${ }^{[32]}$; voltametria cíclica (verificação do potencial $\left.\mathrm{NO}^{+} / \mathrm{NO}^{0}\right)^{[32]}$; análise elementar de carbono, hidrogênio, nitrogênio e rutênio sendo os dados obtidos comparados com os descritos na literatura $^{[32]}$.

\subsection{3 - Via de síntese dos complexos trans-[Ru(NO)(NH$\left.)_{4}(\mathrm{~L})\right]\left(\mathrm{BF}_{4}\right)_{3}$, onde} L = isn, 4-pic, nic, py, imN.

A rota de síntese para este conjunto de complexos segue procedimento descrito na literatura $^{[46,51]}$. A Figura 3 apresenta um fluxograma ilustrando as principais etapas do processo de síntese.

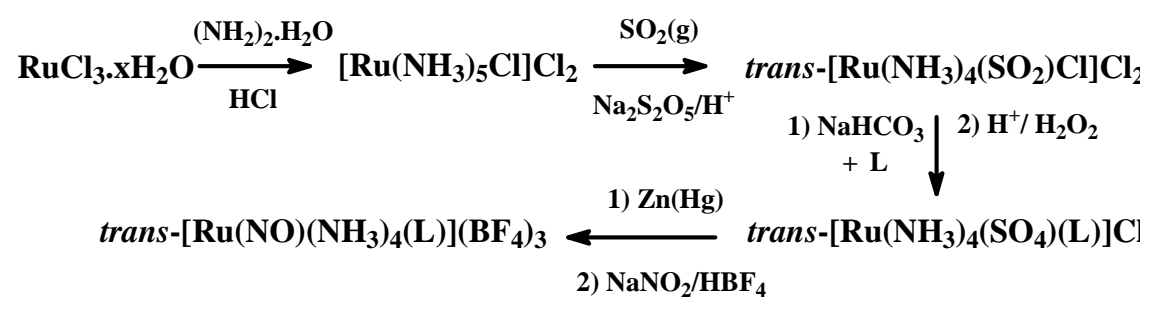

Figura 3 - Rota de síntese do complexo trans- $\left.-\mathrm{Ru}(\mathrm{NO})\left(\mathrm{NH}_{3}\right)_{4}(\mathrm{~L})\right]\left(\mathrm{BF}_{4}\right)_{3}{ }^{[46]}$.

Todos os complexos trans- $\left[\mathrm{Ru}\left(\mathrm{NH}_{3}\right)_{4}\left(\mathrm{SO}_{4}\right)(\mathrm{L})\right]\left(\mathrm{BF}_{4}\right)_{3}$ foram submetidos a recristalização seguindo o procedimento: dissolveu-se o produto da síntese no menor volume possível de solução de $\mathrm{HCl} 6,0 \mathrm{~mol} \mathrm{~L}^{-1}$, filtrou-se a solução obtida e esta foi reprecipitada com auxílio de acetona desaerada ${ }^{[46]}$. 


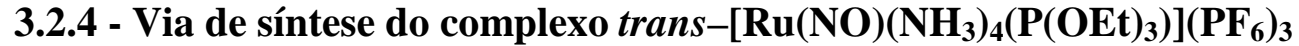

A rota de síntese para este complexo segue procedimento desenvolvido pelo nosso Grupo e reportado na literatura ${ }^{[52,53]}$. Abaixo é mostrado um fluxograma no qual os principais processos de síntese são apresentados (Figura 4).

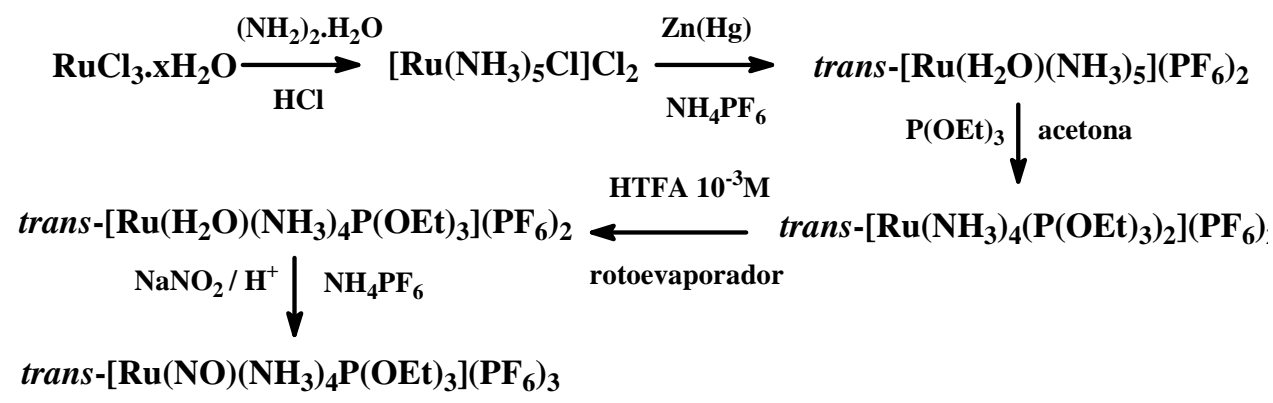

Figura 4 - Rota de síntese do complexo trans-[Ru(NO) $\left.\left(\mathrm{NH}_{3}\right)_{4}\left(\mathrm{P}(\mathrm{OEt})_{3}\right)\right]\left(\mathrm{PF}_{6}\right)_{3}{ }^{[53]}$.

$\mathrm{O}$ complexo trans- $\left[\mathrm{Ru}\left(\mathrm{NH}_{3}\right)_{4}\left(\left(\mathrm{P}(\mathrm{OEt})_{3}\right)_{2}\right)\right]\left(\mathrm{PF}_{6}\right)_{2}$ foi lavado várias vezes com água gelada para retirada do excesso de ligante $\mathrm{P}(\mathrm{OEt})_{3}$ retido no sólido. Por ser sensível a oxidação pelo oxigênio, os procedimentos empregando o complexo trans-[Ru( $\left.\left.\mathrm{H}_{2} \mathrm{O}\right)\left(\mathrm{NH}_{3}\right)_{5}\right]\left(\mathrm{PF}_{6}\right)_{2}$ foram efetuados em sistema de "glove-bag" em atmosfera de argônio, sendo que este complexo foi imediatamente utilizado na próxima etapa de síntese.

\subsection{5 - Síntese do complexo [Ru(NO)(Hedta)]}

O complexo $[\mathrm{Ru}(\mathrm{NO})(\mathrm{Hedta})]$ foi sintetizado conforme procedimento descrito na literatura $^{[54,55]}$ e descrito abaixo (Figura 5).

$\mathrm{RuCl}_{3} \cdot \mathrm{xH}_{2} \mathrm{O} \underset{\text { 2) } \mathrm{Hg} / \mathrm{KCl}}{\stackrel{\mathrm{HCl} \text { (conc.) }}{\longrightarrow}} \mathrm{K}_{2}\left[\mathrm{Ru}(\mathrm{Cl})_{5}\left(\mathrm{H}_{2} \mathrm{O}\right)\right] \underset{\mathrm{Na}_{2} \mathrm{H}_{2} \mathrm{EDTA}}{\stackrel{\mathrm{HCl}}{\longrightarrow}} \mathrm{K}[\mathrm{Ru}(\mathrm{Cl})(\mathrm{Hedta})] \underset{\mathrm{NO}_{\text {gas }}}{\stackrel{\mathrm{HCl}}{\longrightarrow}}[\mathrm{Ru}(\mathrm{NO})(\mathrm{Hedta})]$

Figura 5 - Rota de síntese do complexo $[\mathrm{Ru}(\mathrm{NO})(\text { Hedta })]^{[55]}$. 


\subsection{6 - Síntese do complexo trans- $\left[\mathrm{Ru}\left(\mathrm{H}_{2} \mathrm{O}\right)\left(\mathrm{NH}_{3}\right)_{4}\left(\mathrm{SO}_{2}\right)\right]\left(\mathrm{CF}_{3} \mathrm{SO}_{3}\right)_{2}$}

O complexo trans- $\left[\mathrm{Ru}\left(\mathrm{H}_{2} \mathrm{O}\right)\left(\mathrm{NH}_{3}\right)_{4}\left(\mathrm{SO}_{2}\right)\right]\left(\mathrm{CF}_{3} \mathrm{SO}_{3}\right)_{2}$ foi sintetizado conforme procedimento descrito na literatura ${ }^{[56]}$ e descrito na Figura 6.

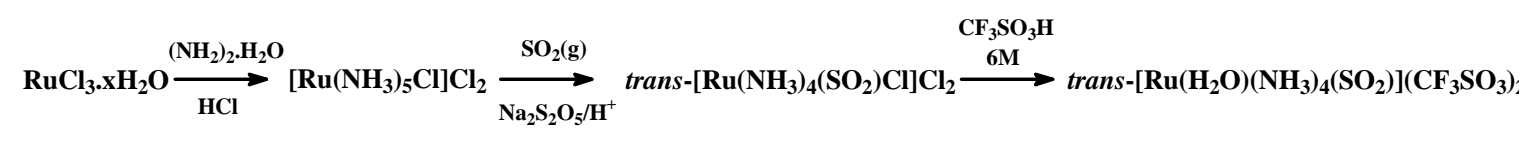

Figura 6 - Rota de síntese do complexo trans $-\left[\mathrm{Ru}\left(\mathrm{H}_{2} \mathrm{O}\right)\left(\mathrm{NH}_{3}\right)_{4}\left(\mathrm{SO}_{2}\right)\right]\left(\mathrm{CF}_{3} \mathrm{SO}_{3}\right)_{2}{ }^{[56]}$.

Os aquo complexos trans- $\left[\mathrm{Ru}\left(\mathrm{H}_{2} \mathrm{O}\right)\left(\mathrm{NH}_{3}\right)_{4}(\mathrm{~L})\right]^{2+}, \mathrm{L}=\mathrm{NH}_{3}$, isn e imN, foram preparados pela redução dos seus precursores utilizando amálgama de $\mathrm{Zn}(\mathrm{Hg})$ e utilizados imediatamente.

\section{3 - Reações envolvendo o radical DPPH}

\subsection{1 - Reagentes: procedência e pureza}

O radical $\mathrm{DPPH}^{\bullet}$ (2,2-difenil-1-picril-hidrazila; Sigma-Aldrich) teve sua pureza verificada através de espectroscopia de UV-vis. Para tanto utilizou-se uma solução de concentração 5,0 x $10^{-5} \mathrm{~mol} \mathrm{~L}{ }^{-1}$, calculou-se o coeficiente de absortividade molar e comparouse com o valor fornecido pela literatura $\left(\lambda_{\max }=520 \mathrm{~nm}, \varepsilon=12.000 \mathrm{~mol}^{-1} \mathrm{~L} \mathrm{~cm}^{-1}\right)^{[57]}$. As soluções utilizadas nas medidas foram preparadas imediatamente antes do seu uso. O surfactante Tween-20 (polioxietileno - monolaureto de sorbitol; Acros Organics) foi utilizado sem prévia purificação. 


\subsection{2 - Preparo das soluções}

Todas as soluções utilizadas foram preparadas em água Milli-Q (18,2 $\mathrm{M} \Omega \mathrm{cm}$; $\mathrm{T}=25^{\circ} \mathrm{C}$ ). Apesar de sua reportada estabilidade ${ }^{[32]}$, as soluções estoque dos nitrosilo complexos foram preparadas sempre imediatamente antes de sua utilização em ácido trifluoracético $(\mathrm{pH}=3,0)$ previamente deaerada. As soluções de $\mathrm{DPPH}^{\bullet}$ também foram preparadas nas mesmas condições descritas acima para os nitrosilo complexos, porém na presença de Tween-20, conforme o seguinte procedimento ${ }^{[57]}$ : dissolveu-se a massa requerida de $\mathrm{DPPH}^{\bullet}$ no mínimo volume de clorofórmio (grau de pureza HPLC), adicionou-se lentamente sobre agitação o volume requerido de uma solução $\mathrm{CF}_{3} \mathrm{COOH} /$ Tween-20 $\left(\mathrm{C}_{\mathrm{tween}-20}=0,04 \mathrm{~g} \mathrm{~mL}^{-1}\right)$. Evaporou-se o clorofórmio da solução através de fluxo de argônio sendo o volume corrigido posteriormente em balão volumétrico ${ }^{[57]}$. A concentração final de $\mathrm{DPPH}^{\bullet}$ na solução foi verificada através de espectroscopia UV-vis.

\section{4 - Reações envolvendo o radical hidroxila}

\subsection{1 - Reagentes: procedência e pureza}

$\mathrm{O}$ sal de cloreto férrico tetrahidratado $\left(\mathrm{FeCl}_{2} \cdot 4 \mathrm{H}_{2} \mathrm{O} ;\right.$ Merck) foi tratado conforme procedimento descrito na literatura ${ }^{[58]}$ e mantido em dessecador. Peróxido de hidrogênio 30\%, (Perhydrol - Merck) foi utilizado sem prévia purificação devido ao alto grau de pureza informado pelo fabricante, sendo estocado em geladeira e retirado somente no momento do preparo das soluções. O trapeador de spin DMPO (5,5-dimetil-1-pirrolidina-N-óxido; Aldrich), foi purificado conforme o seguinte procedimento ${ }^{[59,60]}: 500 \mu \mathrm{L}$ de DMPO foram adicionados a $1 \mathrm{~mL}$ de água Milli Q. A esta solução foi adicionado $250 \mathrm{mg}$ de carvão vegetal 
ativado seguido de agitação por 5 minutos. A solução resultante foi filtrada com auxílio de um sistema de membrana porosa (membrana de celulose regenerada, poro $0,25 \mu \mathrm{m}$; Sartorius). A concentração final da solução de DMPO foi verificada através de espectrofotometria de UVvis $\left(\lambda_{\max }=236 \mathrm{~nm}, \varepsilon=7.200 \mathrm{M}^{-1} \mathrm{~cm}^{-1}\right)^{[59,60]}$. O composto purificado foi guardado em freezer $\left(-15^{\circ} \mathrm{C}\right)$ até o momento do uso.

\subsection{2 - Preparação das soluções e protocolo de medida}

A solução estoque de $\mathrm{FeCl}_{2} \cdot 4 \mathrm{H}_{2} \mathrm{O}\left(\mathrm{C}_{\mathrm{Fe} 2+}=1,5 \times 10^{-3} \mathrm{~mol} \mathrm{~L}^{-1}\right)$ foi preparada utilizando solução de ácido trifluoroacético $(\mathrm{pH}=3,0)$ previamente deaerada. Após a dissolução do sal, a solução continuou em fluxo de argônio para evitar a oxidação de $\mathrm{Fe}($ II) à $\mathrm{Fe}(\mathrm{III})$; as soluções de $\mathrm{FeCl}_{2} \cdot 4 \mathrm{H}_{2} \mathrm{O}$ foram sempre preparadas no momento da medida.

A solução estoque de $\mathrm{H}_{2} \mathrm{O}_{2}\left(\mathrm{C}_{\mathrm{H} 2 \mathrm{O} 2}=1,0 \times 10^{-2} \mathrm{~mol} \mathrm{~L}^{-1}\right)$ foi preparada através da diluição do $\mathrm{H}_{2} \mathrm{O}_{2} 30 \%$. A solução foi renovada constantemente para garantir a concentração inicial de peróxido. A solução de DMPO utilizada foi proveniente do processo de purificação que este reagente foi submetido (item 3.4.1), sendo pipetada somente a quantidade necessária para a obtenção da concentração requerida.

Todas as medidas que envolveram a reação de Fenton seguiram o seguinte protocolo (Tabela 3) 
Tabela 3 - Protocolo utilizado para a reação com radical hidroxila.

\begin{tabular}{|c|c|c|c|}
\hline Reagente & $\begin{array}{c}\text { Volume }(\mu \mathrm{L}) \\
\text { Reações }\end{array}$ & $\begin{array}{c}\text { Volume }(\mu \mathrm{L}) \\
\text { Controle }\end{array}$ & $\begin{array}{c}\text { Concentração } \\
\text { Final } \\
\left(\mathrm{mol} \mathrm{L}^{-1}\right)\end{array}$ \\
\hline $\mathrm{H}_{2} \mathrm{O}$ & - & 160 & - \\
\hline trans $-\left[\mathrm{Ru}(\mathrm{NO})\left(\mathrm{NH}_{3}\right)_{4}(\mathrm{~L})\right]^{3+}$ & 160 & - & Variável \\
\hline $\mathbf{H}_{2} \mathbf{O}_{2}$ & 10 & 10 & $7,5 \times 10^{-4}$ \\
\hline $\mathrm{FeCl}_{2}$ & 15 & 15 & $1,1 \times 10^{-3}$ \\
\hline DMPO & 15 & 15 & $2,0 \times 10^{-3}$ \\
\hline Total & 200 & 200 & - \\
\hline
\end{tabular}

Foram pesadas massas dos complexos para que a concentração da solução estoque fosse igual à $1,5 \pm 0,2 \times 10^{-2} \mathrm{~mol} \mathrm{~L}^{-1}$. Com esta solução, efetuou-se a medida em excesso de 100 vezes de complexo em relação ao radical. Para as medidas de 1 e 50 vezes de excesso, foram feitas diluições apropriadas da solução estoque original, para se obter a concentração desejada. Todas as soluções dos complexos foram mantidas sob fluxo de argônio para evitar qualquer interferência de oxigênio.

O radical hidroxila, quando reage com o captor de spin DMPO gera um espectro de RPE com quatro linhas (intensidades relativas 1:2:2:1, $\mathrm{A}_{\mathrm{N}}=14.8 \mathrm{G}$ ), ilustrado na Figura 7, o qual é característico da formação do aduto DMPO-OH ${ }^{[60]}$. 


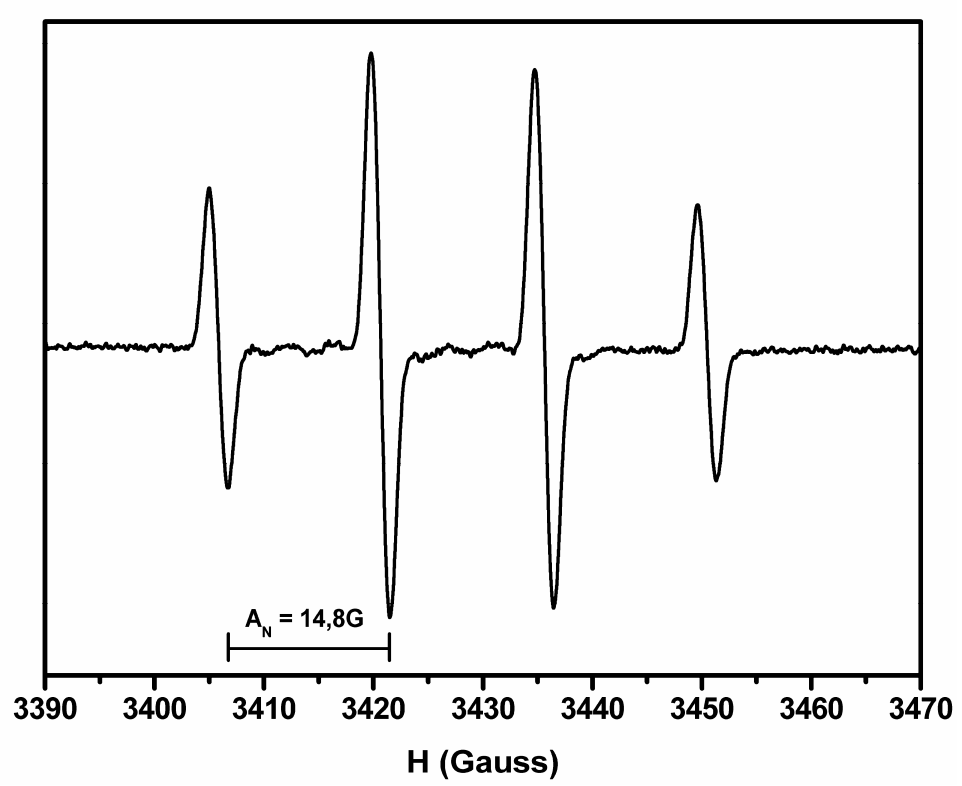

Figura 7 - Espectro de RPE do aduto DMPO-OH resultante da reação entre o radical hidroxila $\left(\mathrm{OH}^{*}\right)$ e o captador de spin DMPO.

Para a quantificação do radical hidroxila captado pelos nitrosilo complexos comparou-se as áreas dos sinais das reações de controle e das reações com os nitrosilo complexos de rutênio. A integração dos sinais foi efetuada no próprio software do equipamento.

\section{5 - Medidas envolvendo o radical superóxido $\left(\mathrm{O}_{2}^{-\bullet}\right)$}

\subsection{1 - Geração do radical $\mathrm{O}_{2}^{-\bullet}$ pela via fotoquímica}

O radical superóxido foi gerado fotoquimicamente utilizando ribloflavina como sensibilizador e DTPA (ácido dietileno-triamino-pentaacético) como doador de elétrons ${ }^{[61]}$. Em um experimento típico, uma solução contendo $1,0 \times 10^{-3} \mathrm{~mol} \mathrm{~L}^{-1}$ de riboflavina e $1,0 \times 10^{-2} \mathrm{~mol} \mathrm{~L}^{-1}$ de DTPA foi irradiada com luz de comprimento de onda de $440 \mathrm{~nm}$ (Reação 10). A solução foi irradiada por 4 minutos a uma taxa de 2 pulsos por segundo. 


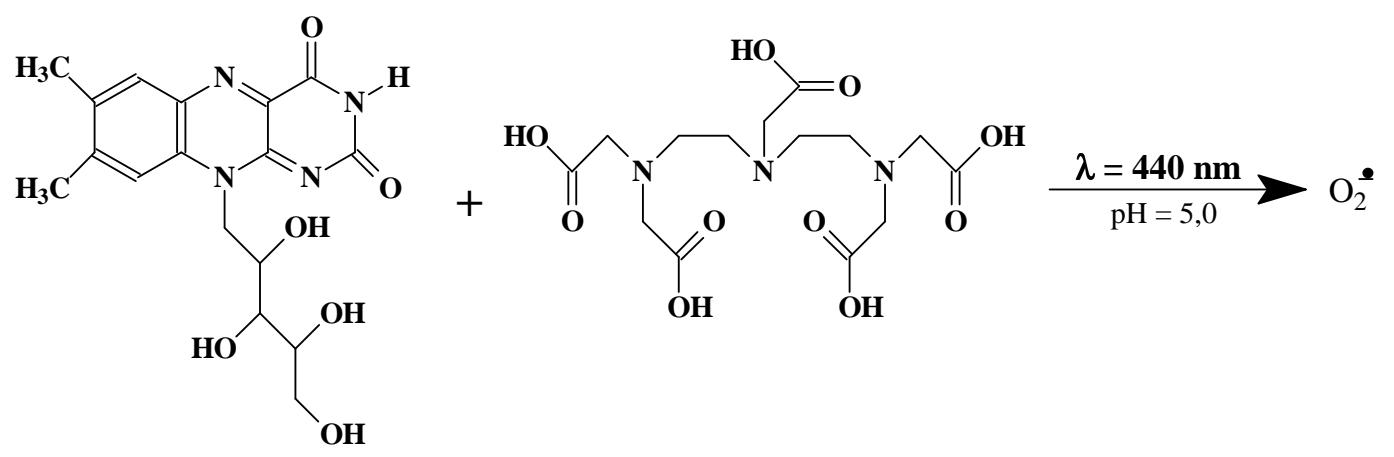

Riboflavina

DTPA

Reação 10 - Geração Fotoquímica do radical superóxido $\left(\mathrm{O}_{2}^{-\bullet}\right)$

Os nitrosilo complexos de rutênio utilizados neste trabalho podem apresentar fotolabilização do NO coordenado, quando os complexos são irradiados em comprimento de onda por volta de $350 \mathrm{~nm}$. Como o comprimento de onda utilizado foi de $440 \mathrm{~nm}$ e o rendimento quântico para a fotolabilização é muito pequeno $\left(\phi_{\text {médio }} \approx 0,1\right)^{[62]}$, reações fotoquímicas envolvendo os nitrosilo complexos podem ser descartadas.

\subsection{2 - Geração do radical $\mathrm{O}_{2}^{-\bullet}$ pela via enzimática}

O radical superóxido também foi obtido através da conversão do substrato xantina a hipoxantina ${ }^{[63]}$ pela enzima xantina oxidase segundo a Reação 11.<smiles>O=c1[nH]c(=O)c2nc[nH]c2[nH]1</smiles>

xantina

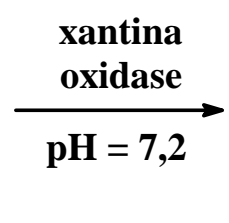

Reação 11 - Formação do radical superóxido $\left(\mathrm{O}_{2}^{-\bullet}\right)$ através da oxidação da xantina pela enzima xantina oxidase.

A reação foi efetuada em tampão fosfato $\left(\mathrm{pH}=7,2 ; \mu=0,1 \mathrm{~mol} \mathrm{~L}^{-1}\right)$ a temperatura de $25^{\circ} \mathrm{C}$. O tempo de incubação foi de 20 minutos. Como controle positivo da geração do radical 
$\mathrm{O}_{2}{ }^{\bullet}$ foi monitorada a produção de ácido úrico pela enzima $\left(\lambda_{\max }=290 \mathrm{~nm}\right.$, $\left.\varepsilon=9183 \mathrm{M}^{-1} \mathrm{~cm}^{-1}\right)^{[63]}$.

\subsection{3 - Protocolo de medida}

As medidas envolvendo o radical superóxido gerado fotoquimicamente foram executadas segundo o seguinte protocolo (Tabela 4).

Tabela 4 - Protocolo utilizado para geração fotoquímica do radical superóxido.

\begin{tabular}{|c|c|c|c|}
\hline Reagente & Volume $(\mu \mathrm{L})$ & Volume $(\mu \mathrm{L})$ & Concentração \\
\hline & Reações & Controle & $\begin{array}{c}\text { Final } \\
\left(\mathrm{mol} \mathrm{L}^{-1}\right)\end{array}$ \\
\hline $\operatorname{trans}-\left[\mathrm{Ru}(\mathrm{NO})\left(\mathrm{NH}_{3}\right)_{4}(\mathrm{~L})\right]^{3+}$ & variável & - & variável \\
\hline Cit $\mathrm{C}(\mathrm{Fe}(\mathrm{III}))$ & 200 & 200 & $2,0 \times 10^{-5}$ \\
\hline DTPA & 200 & 200 & $1,0 \times 10^{-2}$ \\
\hline Riboflavina & 200 & 200 & $1,0 \times 10^{-3}$ \\
\hline HTFA $(\mathrm{pH}=\mathbf{5 , 0})$ & - & variável & - \\
\hline Total & 800 & 800 & - \\
\hline
\end{tabular}

As concentrações dos nitrosilo complexos variaram entre 4,0 $\pm 0,2 \times 10^{-3}$ a 2,5 $\pm 0,2 \times 10^{-5} \mathrm{~mol} \mathrm{~L}^{-1}$, partindo-se de uma solução estoque de concentração 4,0 $\pm 0,2 \times 10^{-3} \mathrm{~mol} \mathrm{~L}^{-1}$. Para evitar problemas com a degradação dos complexos, as soluções estoques foram renovadas periodicamente.

As medidas envolvendo o radical superóxido gerado pela via enzimática foram executadas segundo o seguinte protocolo (Tabela 5). 
Tabela 5 - Protocolo utilizado para geração enzimática do radical superóxido.

\begin{tabular}{|c|c|c|c|}
\hline Reagente & Volume $(\mu \mathbf{L})$ & Volume $(\mu \mathbf{L})$ & Concentração \\
\hline & Reações & Controle & Final \\
\hline trans $-\left[\mathrm{Ru}(\mathrm{NO})\left(\mathrm{NH}_{3}\right)_{4}(\mathrm{~L})\right]^{3+}$ & 400 & - & variável \\
\hline Cit C (Fe(III)) & 200 & 200 & $2,0 \times 10^{-5(a)}$ \\
\hline Xantina & 100 & 100 & $1,0 \times 10^{-4(\mathrm{a})}$ \\
\hline Xantina Oxidase & 300 & 300 & $0,016^{(b)}$ \\
\hline T. $\mathbf{P}^{(*)}(\mathbf{p H}=7,2)$ & - & variável & - \\
\hline Total & 1000 & 1000 & - \\
\hline
\end{tabular}

(*) tampão fosfato; (a) mol L $\mathrm{L}^{-1}$; (b) unidades $\mathrm{mL}^{-1}$

A concentração dos nitrosilo complexos foram as mesmas relatadas para os experimentos utilizando a geração fotoquímica do radical.

\subsection{4 - Detecção e quantificação do radical $\mathrm{O}_{2}^{-\bullet}$}

O radical superóxido foi detectado e quantificado a partir de uma solução 2,0 $\times 10^{-5} \mathrm{~mol} \mathrm{~L}^{-1}$ de citocromo c (proveniente de fibra muscular de coração de cavalo, Sigma-Aldrich). A redução do citocromo c pelo superóxido foi monitorada através da formação de banda em $550 \mathrm{~nm}$ (Figura 8) sendo posteriormente quantificado $\left(\varepsilon=21.000 \mathrm{~cm}^{-1} \mathrm{~mol}^{-1}\right)^{[59]}$. Os experimentos foram conduzidos em solução de ácido trifluoroacético ( $\mathrm{pH}=5,0)$ ou em tampão fosfato $(\mathrm{pH}=7,2)$. 


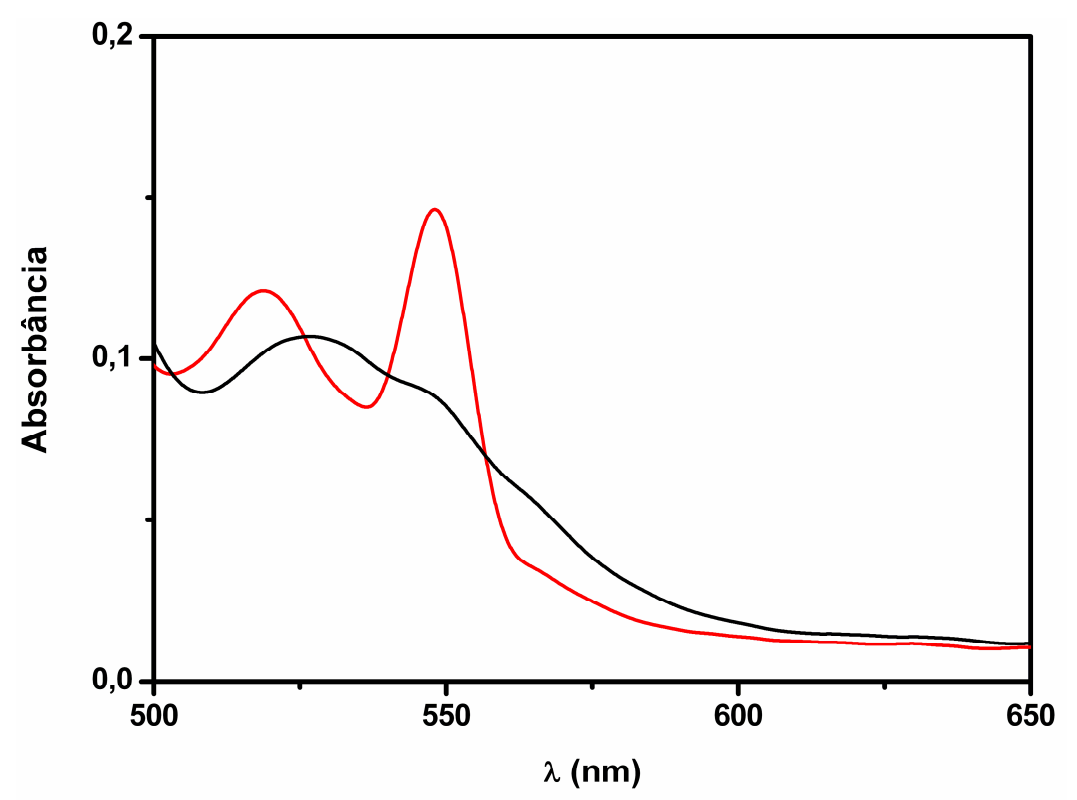

Figura 8 - Espectro de UV-vis típico para detecção do radical superóxido $\left(\mathrm{O}_{2}^{-\bullet}\right)$, utilizando como sonda citocromo c. Legenda: (一): controle (cit c Fe(III)); (—): após reação com superóxido (cit c Fe(II)). $\mathrm{T}=25^{\circ} \mathrm{C}$.

\section{6 - Medidas de cinética por competição}

Para a estimativa da constante de velocidade específica de segunda ordem para a captação do radical hidroxila e superóxido, foi utilizada a técnica de cinética por competição $^{[64,65]}$. Neste tipo de experimento, uma sonda (nos experimentos efetuados, citocromo c ou DMPO) e o composto que se deseja analisar (neste caso, os nitrosilo complexos) competem pelo radical superóxido formado, conforme ilustrado na Figura 9.

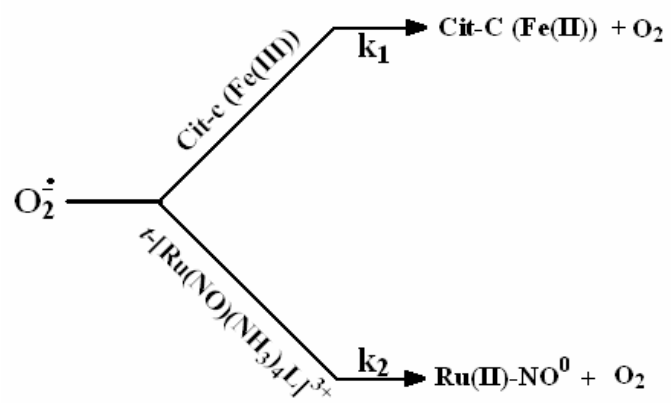

Figura 9 - Reação de competição entre o citocromo c e os nitrosilo complexos. 
O valor da constante de velocidade específica da reação entre o citocromo c e o radical superóxido está relatada na literatura ${ }^{[59]}$ com o valor de $1,4 \times 10^{6} \mathrm{M}^{-1} \mathrm{~s}^{-1}(\mathrm{pH}=5,0$; $\left.\mathrm{T}=25^{\circ} \mathrm{C}\right)$. Portanto, através da expressão:

$$
\left(\frac{\% \text { Cap }}{1-\% \text { Cap }}\right) \times\left(k_{1}\right) \times C_{\text {cit-c }}=\left(k_{2}\right) \times C_{\text {RuNO }}
$$

Onde: $\% \mathbf{C a p}=\mathbf{A b s}_{\text {reação }} / \mathrm{Abs}_{\text {controle }}$

é possível calcular a constante de velocidade específica $\mathrm{k}_{2}$ entre o radical superóxido e os nitrosilo complexos.

A dedução da expressão acima está demonstrada no Apêndice I. Como será discutido adiante, esse método não foi efetivo para o cálculo da constante específica de velocidade de captação do radical $\mathrm{OH}^{\bullet}$ pelos nitrosilo complexos. Portanto, nas equação e as deduções constam somente os parâmetros $\left(\mathrm{C}_{\text {cit-c }}\right.$ e $\left.\mathrm{k}_{1}\right)$ para o radical superóxido. 


\section{IV - Resultados e Discussão}

\section{1 - Comportamento voltamétrico dos nitrosilo complexos de rutênio(II)}

\subsection{1 - Aspectos gerais}

Os nitrosilo complexos de rutênio(II) de fórmula trans-[Ru(NO)( $\left.\left.\mathrm{NH}_{3}\right)_{4}(\mathrm{~L})\right]^{3+}$ apresentam dois processos eletroquímicos na faixa de potencial de - 1,0V a 1,0V. Observa-se a redução do ligante $\mathrm{NO}^{+}$a $\mathrm{NO}^{0}$ e posteriormente a formação do par trans- $\left[\mathrm{Ru}\left(\mathrm{H}_{2} \mathrm{O}\right)\left(\mathrm{NH}_{3}\right)_{4}(\mathrm{~L})\right]^{2+} /$ trans $-\left[\mathrm{Ru}\left(\mathrm{H}_{2} \mathrm{O}\right)\left(\mathrm{NH}_{3}\right)_{4}(\mathrm{~L})\right]^{3+}$ para os compostos da série utilizada neste trabalho. Para os compostos em que a constante de velocidade específica de liberação de NO ( $\mathrm{k}_{-\mathrm{NO}}$ ) apresenta valores inferiores a $0,2 \mathrm{~s}^{-1[32]}$ é possível observar também o processo de oxidação do ligante $\mathrm{NO}^{0}$. Os valores de potencial de redução para o processo $[\mathrm{Ru}(\mathrm{NO})]^{3+/ 2+}$ e de $\mathrm{k}_{-\mathrm{NO}}$ para os nitrosilo complexos utilizados neste trabalho encontram-se tabelados no Apêndice II. A Figura 10 mostra o voltamograma cíclico típico do complexo trans-[Ru(NO)(NH$\left.)_{4}\left(\mathrm{P}(\mathrm{OEt})_{3}\right)\right]^{3+}$ em solução aquosa ácida. Os processos indicados na Figura 10 demonstram a redução no nitrosil (b) e o par redox relativo ao aquo complexo (a). 


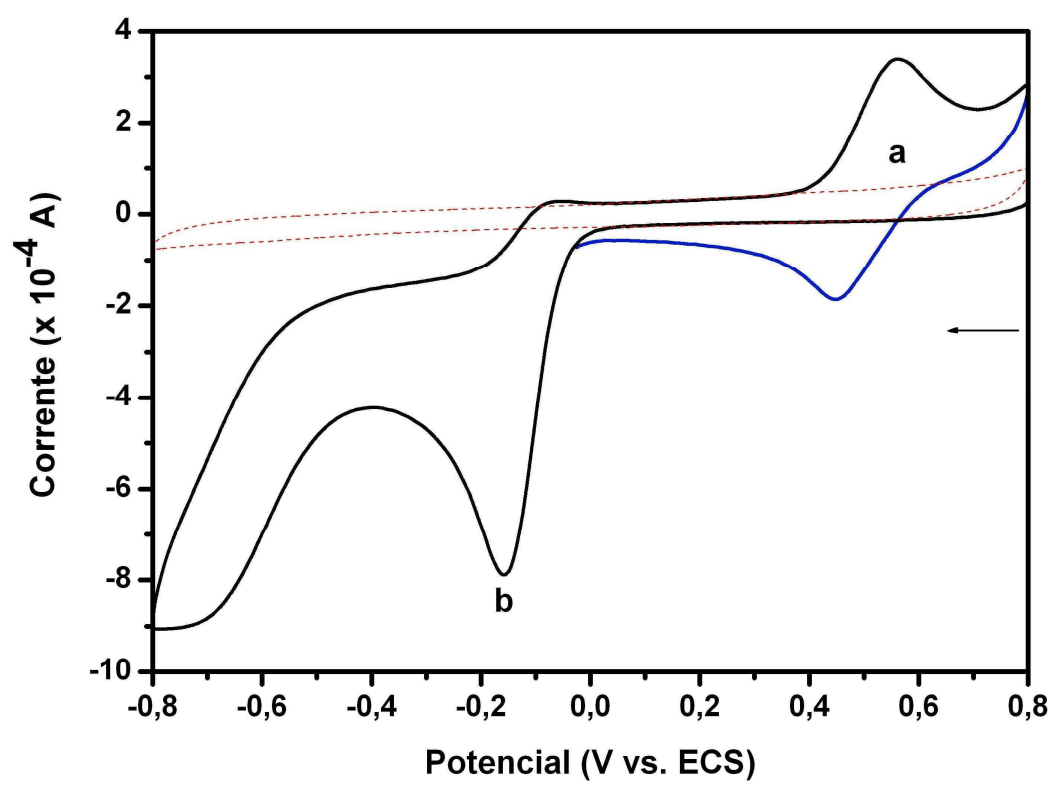

Figura 10 - Voltamograma cíclico do complexo trans- $\left[\mathrm{Ru}(\mathrm{NO})\left(\mathrm{NH}_{3}\right)_{4}\left(\mathrm{P}(\mathrm{OEt})_{3}\right)\right]^{3+}$. (一): complexo $1^{\circ}$ ciclo; (-): complexo $2^{\circ}$ ciclo; (-): eletrólito suporte; $\mathrm{CF}_{3} \mathrm{COONa} / \mathrm{CF}_{3} \mathrm{COOH} ; \mathrm{pH}=3,0 ; \mu=0,1 \mathrm{~mol} \mathrm{~L}{ }^{-1} ; \mathrm{T}=25^{\circ} \mathrm{C}$; $\mathrm{V}=100 \mathrm{mV} \mathrm{s}^{-1}$; eletrodo de trabalho carbono vítreo.

Como pode ser observado na Figura 10, não é possível identificar o par redox do centro metálico $\mathrm{Ru}(\mathrm{II}) / \mathrm{Ru}(\mathrm{III})$ no intervalo de potencial útil do eletrodo de carbono vítreo. Kain e colaboradores ${ }^{[66]}$ mostraram que para o complexo trans- $\left[\mathrm{Ru}(\mathrm{NO})(\mathrm{Cl})_{5}\right]^{2-}$ o par redox deste centro metálico encontra-se em $+1,52 \mathrm{~V}$ vs. ECS, utilizando como eletrólito n-butilnitrila e platina como eletrodo de trabalho. Como os cloretos são melhores doadores $\pi$ em relação às aminas espera-se, portanto que o par redox $\mathrm{Ru}(\mathrm{II}) / \mathrm{Ru}(\mathrm{III})$ para os complexos trans-[Ru(NO)(NH$\left.)_{4}(\mathrm{~L})\right]^{3+}$ sejam ainda mais positivos se comparado ao complexo trans- $\left[\mathrm{Ru}(\mathrm{NO})(\mathrm{Cl})_{5}\right]^{2-}$.

No entanto, não é possível efetuar medidas em meio aquoso em potenciais anódicos superiores a $+1,2 \mathrm{e}+1,1 \mathrm{~V}$, utilizando como eletrodo de trabalho carbono vítreo ou platina ${ }^{[67]}$, respectivamente. Nestas condições ocorre evolução de oxigênio molecular na superfície do eletrodo, fazendo com que a corrente medida aumente de forma exponencial, impedindo a realização de medidas eletroquímicas e até causando a degradação do material do eletrodo. 


\subsection{2 - Medidas voltamétricas utilizando eletrodos de diamante dopado

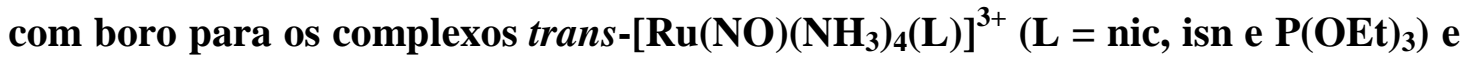 [Ru(NO)(Hedta)]}

Eletrodos de diamante sintético, dopados com materiais semicondutores, estão sendo estudados a mais de uma década por suportarem elevados potenciais anódicos e catódicos em meio aquoso ${ }^{[68]}$. Dentre os vários tipos de eletrodos de diamante dopados, destaca-se o dopado com boro EDDB (eletrodo de diamante dopado com boro). Uma das principais utilizações destes eletrodos é no processo de degradação eletroquímica de poluentes orgânicos em água contaminada, principalmente inseticidas ${ }^{[69]}$.

Os eletrodos EDDB varrem uma faixa de potencial bastante extensa, $-1,5$ à $+2,6 \mathrm{~V}$ vs. ECS com pequena evolução de hidrogênio e oxigênio, o que permite medidas voltamétricas em potenciais anódicos elevados. Além disso, existe a vantagem de utilizar eletrólito aquoso, dispensando uso de eletrólitos orgânicos.

Para observar o par redox $\mathrm{Ru}(\mathrm{II}) / \mathrm{Ru}(\mathrm{III})$ nos nitrosilo complexos, foi utilizado o EDDB em meio aquoso ácido, na faixa de potencial de $+1,7$ à $+2,6 \mathrm{~V}$. O eletrólito suporte utilizado foi $\mathrm{CF}_{3} \mathrm{COOH} / \mathrm{CF}_{3} \mathrm{COONa} 1,0 \times 10^{-3} \mathrm{~mol} \mathrm{~L}^{-1}\left(\mu=0,1 \mathrm{~mol} \mathrm{~L}^{-1}\right)$.

A Figura 11 ilustra o voltamograma cíclico obtido para o íon complexo trans-[Ru(NO) $\left.\left(\mathrm{NH}_{3}\right)_{4}(\mathrm{nic})\right]^{3+}$. Observa-se um processo eletroquímico (E1) centrado em $+2,5$ V, atribuído a componente anódica do par redox $\mathrm{Ru}(\mathrm{II}) / \mathrm{Ru}(\mathrm{III})$. Além disso, observam-se mais dois picos no voltamograma (E2 e E3). O pico E2 foi tentativamente atribuído como sendo a componente catódica do par redox $\mathrm{Ru}(\mathrm{II}) / \mathrm{Ru}(\mathrm{III})$, considerando-se que o sentido da corrente está invertido em relação ao componente anódico. Já o pico E3 pode ser atribuído a um processo anódico acoplado ao processo E2. Esta hipótese é plausível, uma vez que como pode ser observado no voltamograma da Figura 11 há a presença de uma histerese 
(cruzamento das linhas do gráfico), o que pode indicar processos eletroquímicos acoplados ou consecutivos ao processo E2.

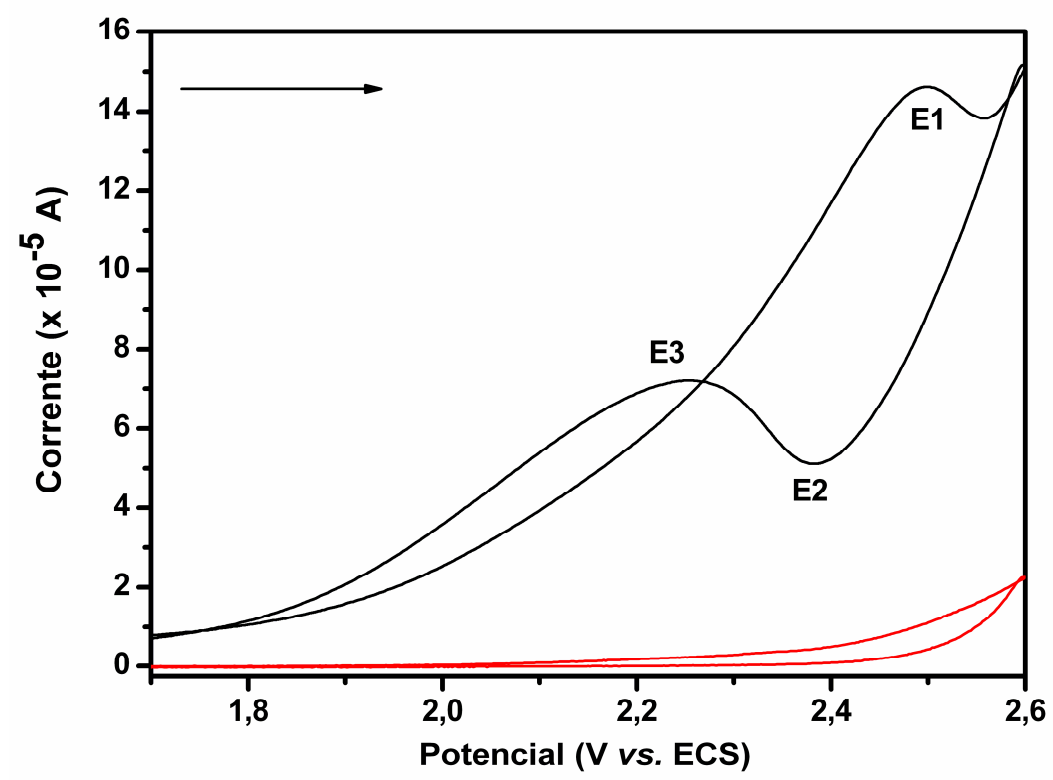

Figura 11 - Voltamograma cíclico utilizando eletrodo de trabalho EDDB. (一): complexo trans- $\left[\mathrm{Ru}(\mathrm{NO})\left(\mathrm{NH}_{3}\right)_{4}(\mathrm{nic})\right]^{3+} . \quad(-)$ : eletrólito suporte. $\mathrm{T}=25{ }^{\circ} \mathrm{C} ; \mathrm{pH}=3,0 ; \mu=0,1 \mathrm{~mol} \mathrm{~L}^{-1}$ $\mathrm{CF}_{3} \mathrm{COOH} / \mathrm{CF}_{3} \mathrm{COONa} ; \mathrm{V}=100 \mathrm{mV} \mathrm{s}^{-1}$.

Uma explicação tentativa para estes demais processos estaria relacionada, por analogia com outros casos discutidos na literatura, com a formação de espécies ativas de oxigênio na superfície do eletrodo ${ }^{[70]}$. Em um voltamograma cíclico apenas do eletrólito suporte utilizando EDDB pode-se observar um aumento discreto, porém gradual na corrente anódica a partir de $+2,1 \mathrm{~V}$ (Figura 11), tornando-se mais evidente em potenciais próximos a $+2,6 \mathrm{~V}$. Este fenômeno é conhecido como "evolução de oxigênio", e ocorre a diferentes potenciais em função do material constituinte do eletrodo de trabalho ${ }^{[67]}$. Reações na superfície do eletrodo geram oxigênio molecular a partir da quebra homolítica das ligações químicas da água, depois da adsorção desta na superfície do eletrodo ${ }^{[67]}$. Este comportamento ocorre com todos os eletrodos de trabalho de diferentes materiais (platina, ouro, carbono vítreo, dentre outros) quando usados em meio aquoso, porém em diferentes potenciais, devido à diferente força de 
interação entre as moléculas de água e a superfície do material do eletrodo. Como exemplo, a platina apresenta evolução de oxigênio em potenciais próximos de $+1,2 \mathrm{~V}^{[67]}$.

O mecanismo de formação de oxigênio molecular passa por vários estágios, dentre eles a formação de radicais $\mathrm{OH}^{\bullet}$ na superfície do eletrodo ${ }^{[33]}$, segundo as reações (Figura 12).

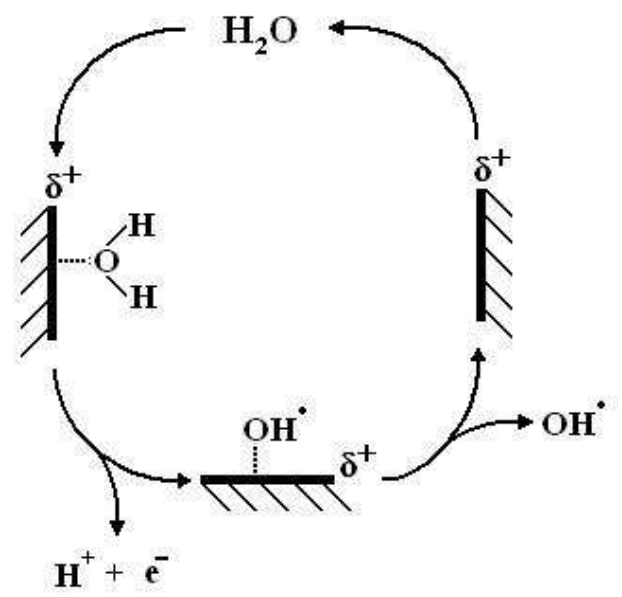

Figura 12 - Formação do radical $\mathrm{OH}^{*}$ pela adsorção da água na superfície de eletrodos submetidos a elevados potenciais anódicos ${ }^{[68]}$.

O processo E2 deve ser composto pela componente catódica do processo relativo ao processo E1. O processo E3 deve ser uma oxidação da espécie gerada no processo E2 pelos radicais $\mathrm{OH}^{\bullet}$ gerados na superfície do eletrodo. Há também a possibilidade de reações acopladas nos processos E2 e E3 com o radical $\mathrm{OH}^{*}$.

Assim, é bastante razoável considerar o processo eletroquímico E1 como sendo majoritariamente correspondente a componente anódica $[\mathrm{Ru}(\mathrm{II}) \mathrm{NO}]^{3+} /[\mathrm{Ru}(\mathrm{III}) \mathrm{NO}]^{4+}$. Foi efetuado um experimento com intuito de verificar se o potencial E1 seria apenas uma reação das espécies oxigenadas geradas na superfície do eletrodo ou então seria devido à transferência de elétrons entre eletrodo/complexo. Usando o mesmo eletrólito empregado nos experimentos envolvendo EDDB, foram obtidos voltamogramas utilizando platina com eletrodo de trabalho (Figura 13) até a região de evolução de oxigênio.

Como pode ser observado na Figura 13, na presença do nitrosilo complexo (gráfico em preto) não há o aparecimento de nenhuma espécie eletroativa na região de evolução de 
oxigênio do eletrodo. Logo é concebível que o processo E1 observado no EDDB seja majoritariamente oriundo da reação de transferência de elétrons entre o eletrodo e o complexo.

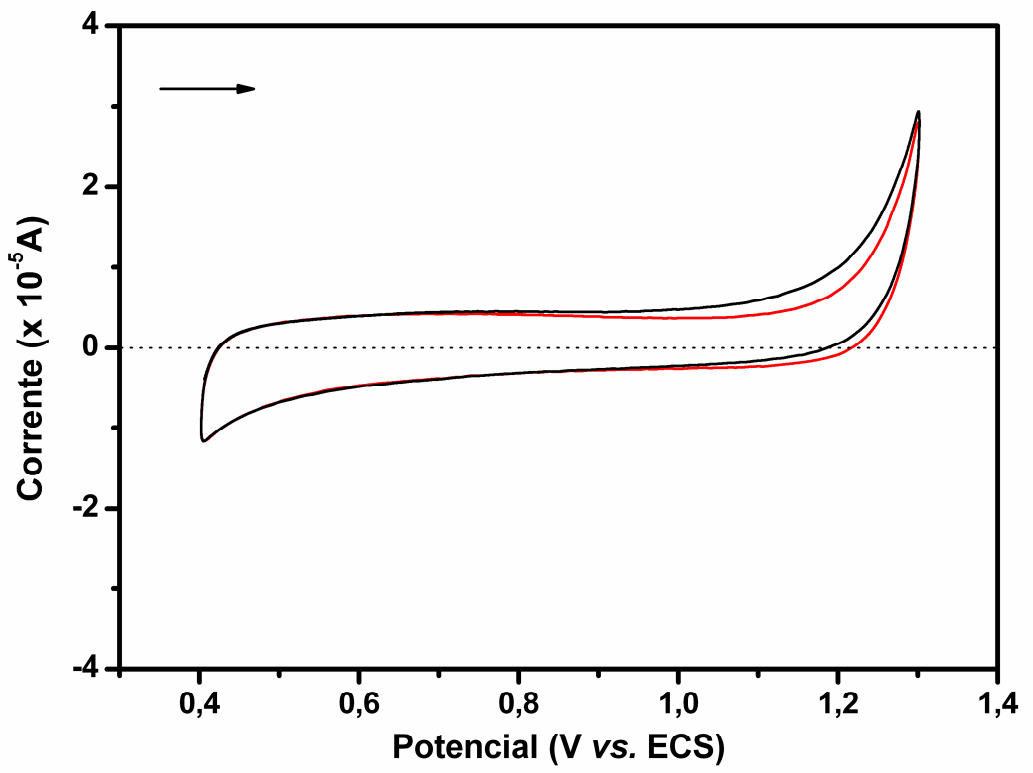

Figura 13 - Voltamograma cíclico utilizando platina como eletrodo de trabalho Pt para o complexo trans- $\left[\mathrm{Ru}(\mathrm{NO})\left(\mathrm{NH}_{3}\right)_{4}(\mathrm{nic})\right]^{3+}$. (-): complexo; (-): eletrólito suporte. $\mathrm{T}=25^{\circ} \mathrm{C} ; \mathrm{pH}=3,0 ; \mu=0,1 \mathrm{~mol} \mathrm{~L}^{-1}$ $\mathrm{CF}_{3} \mathrm{COOH} / \mathrm{CF}_{3} \mathrm{COONa} ; \mathrm{V}=100 \mathrm{mV} \mathrm{s}^{-1}$.

Além disso, a região de potencial de oxidação observada para o centro metálico nos nitrosilo complexos está coerente com dados correlatos reportados na literatura ${ }^{[66]}$. Comportamento análogo ao discutido para os complexos trans- $\left[\mathrm{Ru}(\mathrm{NO})\left(\mathrm{NH}_{3}\right)_{4}(\mathrm{~L})\right]^{3+}, \mathrm{L}=$ nic e isn, foi observado para o complexo $[\mathrm{Ru}(\mathrm{NO})(\mathrm{Hedta})]$. O pico para a oxidação do centro metálico neste último complexo está localizado em $+2,2 \mathrm{~V}$. Diferentemente do observado para os íons complexos trans-[Ru(NO)(NH$)_{4}($ nic $\left.)\right]^{3+}$ e trans- $\left[\mathrm{Ru}(\mathrm{NO})\left(\mathrm{NH}_{3}\right)_{4}(\mathrm{isn})\right]^{3+}, \quad$ o voltamograma cíclico utilizando EDDB como eletrodo de trabalho para o complexo trans-[Ru(NO) $\left.\left(\mathrm{NH}_{3}\right)_{4}\left(\mathrm{P}(\mathrm{OEt})_{3}\right)\right]^{3+}$ mostrou a presença de apenas uma espécie eletroativa, $\mathrm{E}_{\mathrm{pa}}=+2,1 \mathrm{~V}$. No entanto, foi possível observar no voltamograma algumas características semelhantes as observadas nos demais voltamogramas como a presença de histerese e o aumento da corrente anódica. 
A presença do $\mathrm{E}_{\mathrm{pa}}=+2,1 \mathrm{~V}$ para o complexo trans- $\left[\mathrm{Ru}(\mathrm{NO})\left(\mathrm{NH}_{3}\right)_{4}\left(\mathrm{P}(\mathrm{OEt})_{3}\right)\right]^{3+}$ indica mais uma vez que o potencial de oxidação do par $\left[\mathrm{Ru}(\mathrm{II}) \mathrm{NO}^{+}\right]^{3+} /\left[\mathrm{Ru}(\mathrm{III}) \mathrm{NO}^{+}\right]^{4+}$ para os nitrosilo complexos estudados neste trabalho encontra-se acima de $+2,0 \mathrm{~V}$.

Uma possível explicação para a observação de apenas um processo eletroquímico no complexo trans-[Ru(NO) $\left.\left(\mathrm{NH}_{3}\right)_{4}\left(\mathrm{P}(\mathrm{OEt})_{3}\right)\right]^{3+}$ pode estar relacionado com as diferentes estabilidades dos fragmentos $[\mathrm{Ru}(\mathrm{III}) \mathrm{NO}]^{4+}$ gerados no processo de oxidação dos compostos trans-[Ru(NO) $\left.\left(\mathrm{NH}_{3}\right)_{4}(\mathrm{~L})\right]^{3+}$. O elevado efeito trans do ligante de fósforo poderia induzir a dissociação do fragmento $\mathrm{NO}^{+}$da esfera de coordenação da espécie contendo $\mathrm{Ru}(\mathrm{III})$.

Portanto, o conjunto dos dados acima expostos nos permite afirmar que os pares redox

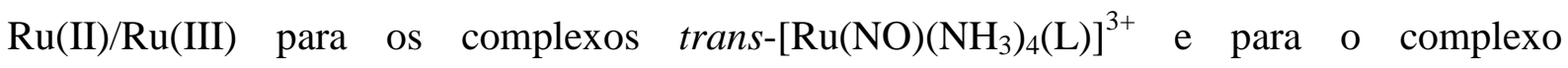
$\left[\mathrm{Ru}(\mathrm{NO})(\right.$ Hedta) $]$ encontram-se acima de 2,0 V vs. ECS em meio aquoso. Os valores de $\mathrm{E}_{\mathrm{pa}}$ para os complexos encontram-se na Tabela 6.

Tabela 6 - Potenciais de oxidação $\mathrm{Ru}(\mathrm{II}) / \mathrm{Ru}(\mathrm{III})$ para os complexos trans-[Ru(NO) $\left.\left(\mathrm{NH}_{3}\right)_{4}(\mathrm{~L})\right]^{3+}$ e $[\mathrm{Ru}(\mathrm{NO})($ Hedta $)]$.

\begin{tabular}{cc}
\hline Ligante & $\mathbf{E}^{\mathbf{0}} \mathbf{R u}(\mathbf{I I}) / \mathbf{R u}(\mathbf{I I I})$ \\
& $(v \boldsymbol{s} . \mathbf{E C S})$ \\
\hline Hedta & $+2,20$ \\
Isn & $+2,60$ \\
$\mathrm{Nic}$ & $+2,50$ \\
$\mathrm{P}(\mathrm{OEt})_{3}$ & $+2,10$ \\
\hline
\end{tabular}

O elevado valor de potencial encontrado para a oxidação do centro metálico reflete a elevada acidez $\pi$ do ligante $\mathrm{NO}^{+}$coordenado ao centro metálico de rutênio(II), fazendo com que o este possua caráter de rutênio(III) ${ }^{[31]}$, o que explica o elevado potencial necessário para sua oxidação. Este fato fica evidente quando é feita a comparação com os aquo complexos de 
rutênio(II) de fórmula trans-[Ru( $\left.\left.\mathrm{H}_{2} \mathrm{O}\right)\left(\mathrm{NH}_{3}\right)(\mathrm{L})\right]^{2+}$, precursores sintéticos dos nitrosilo complexos. Para estes complexos, o par redox $\mathrm{Ru}(\mathrm{II}) / \mathrm{Ru}(\mathrm{III})$ exibe valores na faixa de 0,1 a $0,6 \mathrm{~V}^{[71]}$, coerentemente com o fato do ligante $\mathrm{H}_{2} \mathrm{O}$ não exibir acidez $\pi$.

\section{2 - Experimentos envolvendo radical DPPH}

\subsection{1 - Aspectos gerais}

O radical estável DPPH` é um radical orgânico centrado no nitrogênio extensamente usado como modelo para se medir a capacidade antioxidante, principalmente moléculas orgânicas derivadas de produtos naturais ${ }^{[72,73]}$. Este radical apresenta um par redox com $\mathrm{E}_{1 / 2}=0,55 \mathrm{~V}$ em meio aquoso micelar ${ }^{[58]}$, sendo portanto uma molécula com caráter oxidante brando. Desta forma, uma das vias possíveis de desativação deste radical é através da transferência de elétron por redutores, como ácido ascórbico e cisteína.

$\mathrm{O} \mathrm{DPPH}^{\bullet}$ também pode reagir segundo mecanismo de transferência de átomo de hidrogênio $\left(\mathrm{H}^{\bullet}\right)^{[74,75]}$, através principalmente da quebra da ligação $\mathrm{C}-\mathrm{H}$ e O-H de moléculas insaturadas, como é o caso dos polifenóis. Neste caso, a fraca energia de ligação entre o átomo de hidrogênio e o átomo do carbono do anel aromático permite que a reação ocorra por esta via.

No entanto, outros mecanismos de desativação podem acontecer. Ingold $^{[74]}$ demonstrou que o radical $\mathrm{DPPH}^{\bullet}$ também pode reagir com antioxidantes através de mecanismos mais complexos, onde ocorrem reações acopladas de transferência de próton e de elétron, porém este mecanismo é fortemente dependente da polaridade do solvente e ocorre preferencialmente em meio orgânico. A Figura 14 ilustra as principais vias de desativação do radical DPPH*. 


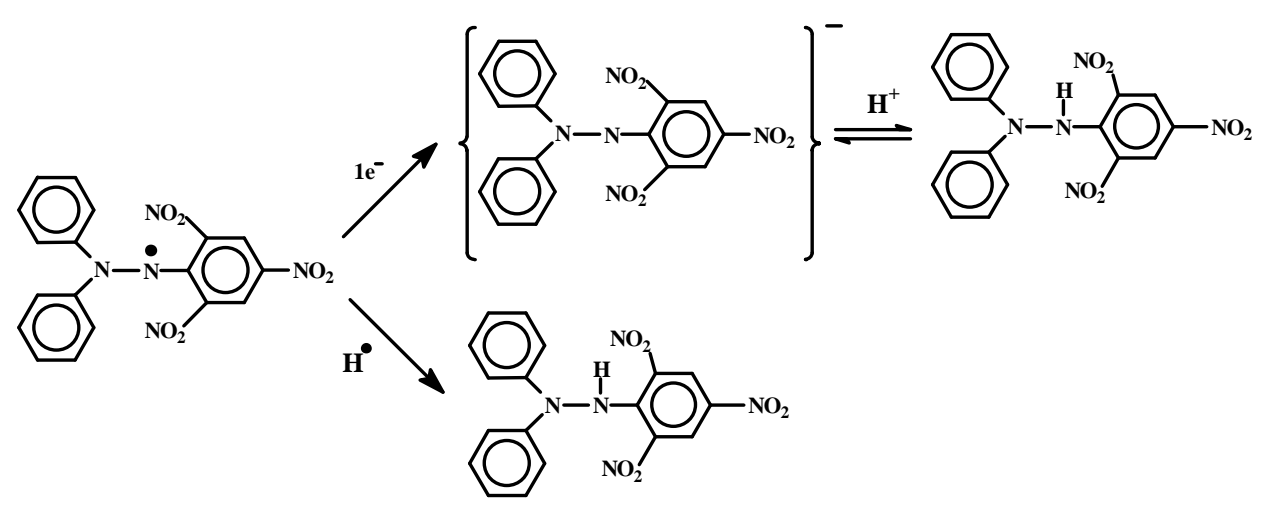

Figura 14 - Principais mecanismos de desativação do radical DPPH

Como mostrado no item anterior, os nitrosilo complexos de rutênio(II) apresentam potenciais de oxidação do centro metálico bastante elevados, impossibilitando que ocorra a transferência de elétron do metal para o radical $\mathrm{DPPH}^{\circ}$. A transferência de átomo de hidrogênio também se apresenta pouco provável. A amônia não é um bom doador de átomos de hidrogênio, visto que a ligação N-H é bastante forte e a coordenação do ligante no plano equatorial não leva a mudanças profundas na energia desta ligação. Já os ligantes N-heterocíclicos estudados neste trabalho apresentam energias de ligação dos átomos de hidrogênio menores, por se tratarem de sistemas insaturados. Além disso, a coordenação no centro metálico de $\mathrm{Ru}(\mathrm{II})$ leva a uma diminuição da energia de ligação dos átomos de hidrogênio do anel aromático, uma vez que a retrodoação $\mathrm{Ru}_{4 \mathrm{~d} \pi} \rightarrow \mathrm{L}_{\mathrm{p} \pi^{*}}{ }^{[46]}$ faz com que o anel aromático fique com maior densidade eletrônica. Porém a diferença de energia destas ligações também não é significativamente afetada. Deslocamentos químicos $\left(\delta_{1 \mathrm{H}}\right)$ para os átomos de hidrogênio dos ligantes N-heterocíclicos coordenados e livres são usualmente pequenos (da ordem de $1,0 \mathrm{ppm})^{[46]}$ indicando que as ligações de hidrogênio não são profundamente afetadas. Como a reação entre o radical $\mathrm{DPPH}^{\bullet}$ e os ligantes livres não foi observada, a reação dos nitrosilo complexos de rutênio(II) com o radical $\mathrm{DPPH}^{\bullet}$ via transferência de átomo de hidrogênio também não é esperada. 
Como esperado, as reações dos complexos trans- $\left[\mathrm{Ru}(\mathrm{NO})\left(\mathrm{NH}_{3}\right)_{4}(\mathrm{~L})\right]^{3+}$ onde $\mathrm{L}=$ isn, 4-pic, nic, py, imN e [Ru(NO)(Hedta)] com o radical DPPHºcorreram em pequena extensão (em torno de $5 \%$ de consumo do radical $\mathrm{DPPH}^{\circ}$ ), mesmo utilizando o complexo em excesso de 50 vezes em relação ao radical. A Figura 15 mostra o espectro de UV-vis da reação para o complexo [Ru(NO)(Hedta)]. Esperava-se a extinção completa da banda em $525 \mathrm{~nm}$, o que não ocorreu. Também não foi observada a reação entre o radical $\mathrm{DPPH}^{*}$, os ligantes livres e os sais relativos aos contra-íons nas mesmas condições experimentais utilizadas para os nitrosilo complexos.

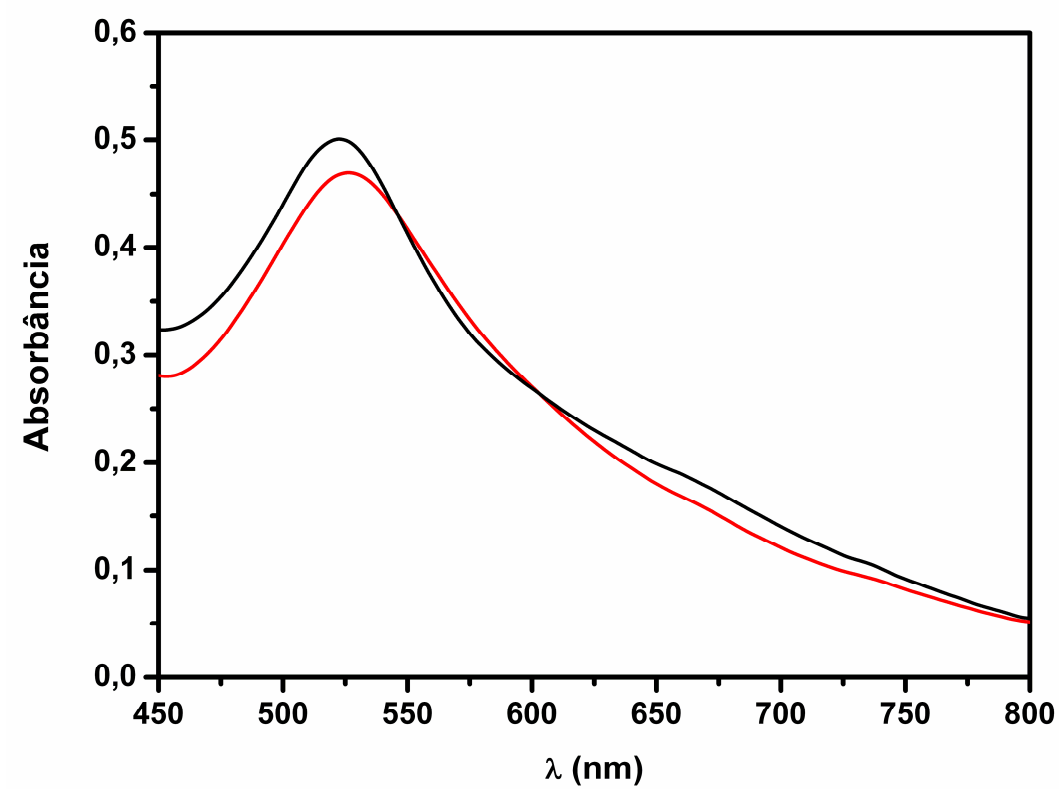

Figura 15 - Espectro de UV-vis da reação entre o radical DPPH e o complexo [Ru(NO)(Hedta)]. (一): controle; (一): $\left[\mathrm{Ru}(\mathrm{NO})(\right.$ Hedta) $]$ 1:50 (radical:complexo); $\mathrm{T}=25^{\circ} \mathrm{C} ; \mathrm{pH}=3,0 ; 30$ minutos de reação.

No entanto, foi observada a reação entre o radical DPPH $^{\circ}$ e o complexo trans-[Ru(NO) $\left.\left(\mathrm{NH}_{3}\right)_{4}\left(\mathrm{P}(\mathrm{OEt})_{3}\right)\right]^{3+}$. Monitorando a reação de desativação do DPPHं por um período de 30 minutos com um excesso de 50 vezes de complexo em relação ao radical foi possível observar o descaimento de $55 \%$ da concentração do radical, conforme ilustra o espectro Figura 16. Pode-se constatar a formação da espécie $\mathrm{DPPH}_{2}$ (ponto isosbéstico em $445 \mathrm{~nm})^{[73]}$. 


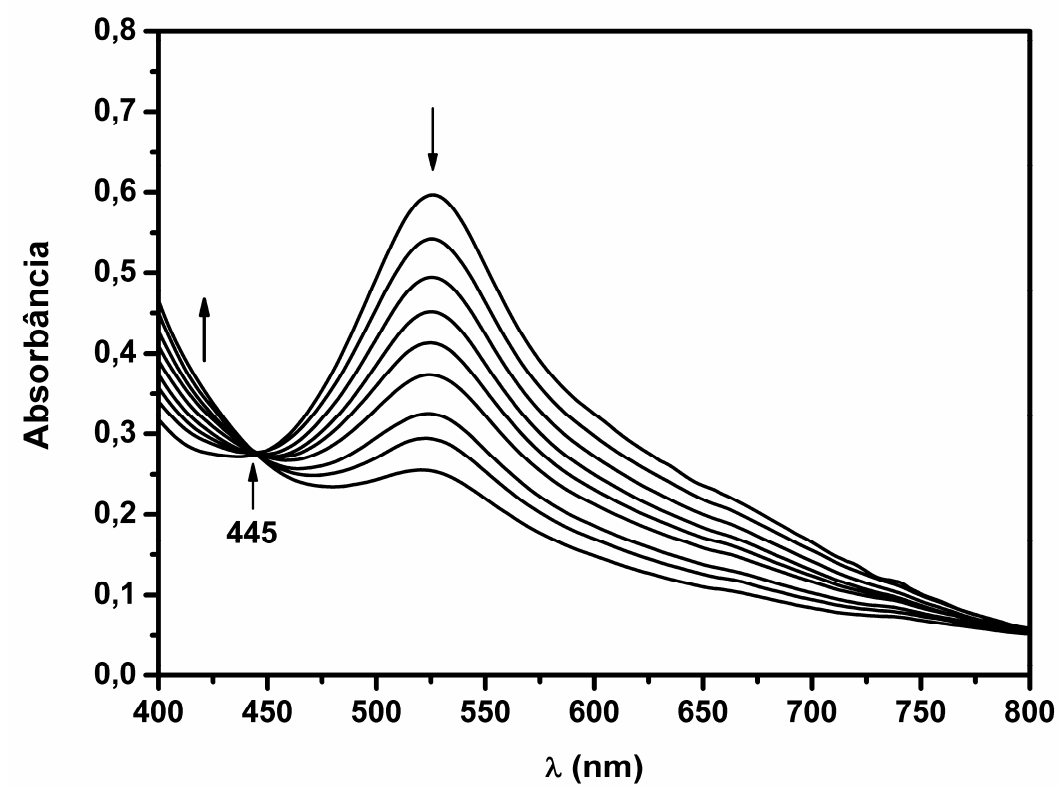

Figura 16 - Variação do espectro de UV-vis da reação entre o radical DPPH e o complexo trans- $\left[\mathrm{Ru}(\mathrm{NO})\left(\mathrm{NH}_{3}\right)_{4}\left(\mathrm{P}(\mathrm{OEt})_{3}\right)\right]^{3+} .1: 50$ (radical:complexo); $\mathrm{T}=25^{\circ} \mathrm{C} ; \mathrm{pH}=3,0 ; 30$ minutos de reação. $445 \mathrm{~nm}$ : ponto isosbéstico.

Não era esperado que houvesse reação entre este complexo e o radical $\mathrm{DPPH}^{\bullet}$. O potencial de oxidação do centro metálico para o complexo trans- $\left[\mathrm{Ru}(\mathrm{NO})\left(\mathrm{NH}_{3}\right)_{4}\left(\mathrm{P}(\mathrm{OEt})_{3}\right)\right]^{3+}$ é $+2,1 \mathrm{~V}$, inacessível ao DPPH. Medidas realizadas com eletrodo seletivo de $\mathrm{NO}^{0}$ mostram que durante esta reação não ocorre a liberação de óxido nítrico na solução indicando que a reação não ocorre com o ligante nitrosil. Ainda, espectro de RPE $(T=77 \mathrm{~K})$ obtido após 30 minutos de reação indica que não há formação de espécies paramagnéticas, e portanto não ocorre a oxidação do centro metálico.

Possivelmente, a reação observada ocorre com algum produto de degradação do complexo trans- $\left[\mathrm{Ru}(\mathrm{NO})\left(\mathrm{NH}_{3}\right)_{4}\left(\mathrm{P}(\mathrm{OEt})_{3}\right)\right]^{3+}$ em meio aquoso ou através da abstração de átomos de hidrogênio pelo radical $\mathrm{DPPH}^{\bullet}$ do ligante $\mathrm{P}(\mathrm{OEt})_{3}$. Estudos realizados pelo nosso Grupo $^{27}$ com o complexo trans $-\left[\mathrm{Ru}(\mathrm{NO})\left(\mathrm{NH}_{3}\right)_{4}\left(\mathrm{P}(\mathrm{OEt})_{3}\right)\right]\left(\mathrm{PF}_{6}\right)_{3}$ no estado sólido ${ }^{[76,77]}$ e em solução mostram que este pode sofrer hidrólise do ligante $\mathrm{P}(\mathrm{OEt})_{3}$, gerando o complexo trans- $-\left[\mathrm{Ru}(\mathrm{NO})\left(\mathrm{NH}_{3}\right)_{4}\left(\mathrm{P}(\mathrm{OH})(\mathrm{OEt})_{2}\right)\right]^{3+}$, etanol livre e outras espécies de fósforo livre, dentre elas o dietilfosfito e o dietilfosfonato. Existem relatos na literatura ${ }^{[78]}$, que ésteres de 
fósforo(III) e fosfonatos livres podem agir como captadores de radicais, com a formação de radicais alquila $\left(\mathrm{CH}_{3}{ }^{\circ}, \mathrm{CH}_{3} \mathrm{CH}_{2}{ }^{\circ}\right)$ e etoxila $\left({ }^{\circ} \mathrm{OCH}_{3},{ }^{\circ} \mathrm{OCH}_{3} \mathrm{CH}_{2}\right)$. Portanto, é viável que a reação observada possa ocorrer através do radical $\mathrm{DPPH}^{\bullet}$ abstraindo um átomo de hidrogênio do ligante trietilfosfito ou de seus produtos de degradação ou através da reação deste radical com o complexo gerado por esse processo de degradação. A constante de velocidade para a reação que ocorre entre o radical $\mathrm{DPPH}^{\bullet}$ e o complexo trans- $\left[\mathrm{Ru}(\mathrm{NO})\left(\mathrm{NH}_{3}\right)_{4}\left(\mathrm{P}(\mathrm{OEt})_{3}\right)\right]^{3+}$ foi estimada como sendo da ordem de $4,0 \times 10^{-1} \mathrm{M}^{-1} \mathrm{~s}^{-1}$.

\subsection{2 - Reação entre os aquo complexos e o radical DPPH}

A reação entre os aquo complexos e o radical $\mathrm{DPPH}^{\bullet}$ foi executada em atmosfera inerte, para evitar a oxidação do centro metálico pelo oxigênio molecular. Os complexos trans- $\left[\mathrm{Ru}\left(\mathrm{H}_{2} \mathrm{O}\right)\left(\mathrm{NH}_{3}\right)_{4}(\mathrm{~L})\right]^{2+}$, onde $\mathrm{L}=$ isn, imN e $\mathrm{P}(\mathrm{OEt})_{3}$, foram incubados na presença do radical $\mathrm{DPPH}^{\bullet}$, em excesso e em proporção estequiométrica. Em ambos os casos a reação de neutralização do radical ocorreu. A oxidação do centro metálico pode ser observada através da espectroscopia de RPE pela detecção de Ru(III), conforme ilustrado na Figura 18 para a reação entre o radical $\mathrm{DPPH}^{\bullet}$ e o aquo complexo onde $\mathrm{L}=\mathrm{P}(\mathrm{OEt})_{3}$. A estequiometria da reação entre o $\mathrm{DPPH}^{*}$ e os aquo complexos não foi 1:1, o que sugere que mais reações acopladas podem estar acontecendo.

A Figura 17 ilustra a reação entre o radical $\mathrm{DPPH}^{\bullet}$ e $\mathrm{o}$ complexo trans- $-\left[\mathrm{Ru}\left(\mathrm{H}_{2} \mathrm{O}\right)\left(\mathrm{NH}_{3}\right)_{4}\left(\mathrm{P}(\mathrm{OEt})_{3}\right)\right]^{3+}$. Como podemos observar no espectro da Figura 17, a reatividade do aquo complexo é em muito superior a observada para o experimento equivalente contendo o complexo com óxido nítrico (Figura 16). Quando a reação é conduzida na proporção 1:50 (radical:complexo), há uma diminuição de 73\% na absorbância do radical em $525 \mathrm{~nm}$ indicando a formação da espécie $\mathrm{DPPH}_{2}{ }^{[73]}$. 


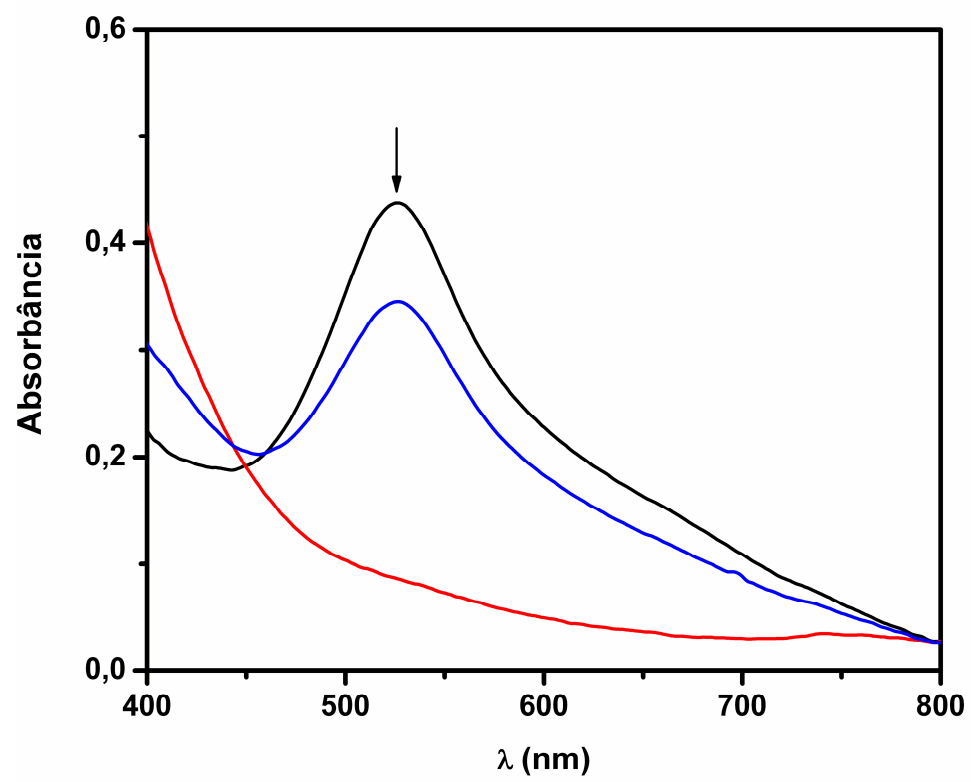

Figura 17 - Espectro de UV-vis da reação entre o complexo trans- $\left[\mathrm{Ru}\left(\mathrm{H}_{2} \mathrm{O}\right)\left(\mathrm{NH}_{3}\right)_{4}\left(\mathrm{P}(\mathrm{OEt})_{3}\right)\right]^{2+}$ e o radical DPPH $^{*}$. (一): controle; (一): 1:1; (一):1:50; (Radical:Complexo). T = 25 $5^{\circ} \mathrm{C} ; \mathrm{pH}=3,0$.

Este experimento indica que a reação de neutralização do radical $\mathrm{DPPH}^{\bullet}$ observado anteriormente (Figura 16) é devido à presença de ligantes do tipo $\mathrm{P}(\mathrm{III})$ e pelos produtos de sua degradação conforme sugerido pela literatura ${ }^{[78]}$ e não pelo nitrosil coordenado.

Após os 15 minutos de reação, foram efetuadas medidas de EPR a baixa temperatura (110K) para detecção de espécies metálicas paramagnéticas. Foi possível observar a presença de um sinal característico da espécie trans $-\left[\mathrm{Ru}\left(\mathrm{H}_{2} \mathrm{O}\right)\left(\mathrm{NH}_{3}\right)_{4}\left(\mathrm{P}(\mathrm{OEt})_{3}\right)\right]^{3+}$ conforme relato da literatura $^{[79]}$ (Figura 18). 


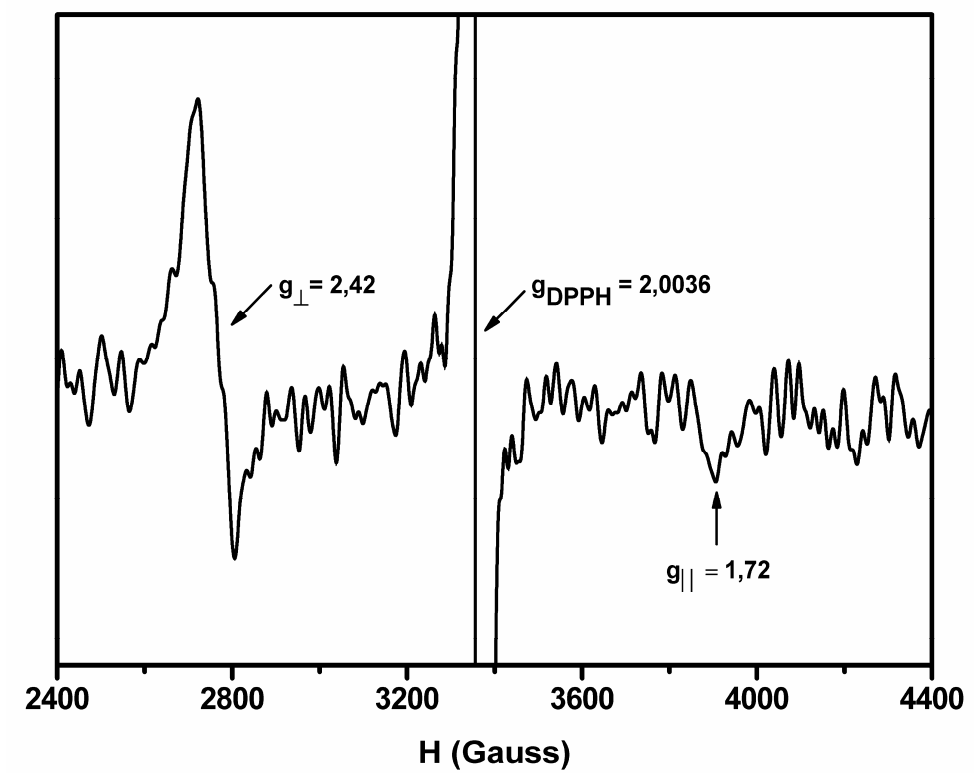

Figura 18 - Espectro de RPE da reação entre o complexo trans- $\left[\mathrm{Ru}\left(\mathrm{NH}_{3}\right)_{4}\left(\mathrm{H}_{2} \mathrm{O}\right)\left(\mathrm{P}(\mathrm{OEt})_{3}\right)\right]^{2+}$ e o radical DPPH gerando como produto trans $-\left[\mathrm{Ru}^{\text {III }}\left(\mathrm{NH}_{3}\right)_{4}\left(\mathrm{H}_{2} \mathrm{O}\right)\left(\mathrm{P}(\mathrm{OEt})_{3}\right)\right]^{3+} . \mathrm{C}_{\mathrm{Ru}}=\mathrm{C}_{\mathrm{DPPH}}=1,0 \times 10^{-3} \mathrm{~mol} \mathrm{~L}^{-1}, \quad \mathrm{pH}=3,0, \mathrm{~T}=$ $110 \mathrm{~K}$.

Assim, é concebível que ocorra a oxidação do centro metálico pelo radical $\mathrm{DPPH}^{\bullet}$, pois o potencial de oxidação do centro metálico neste complexo $\mathrm{E}_{\mathrm{Ru}(\mathrm{II}) / \mathrm{Ru}(\mathrm{III})}^{0}=0,5 \mathrm{~V}$ é acessível a esta reação. A variação da energia livre de Gibbs e o valor da constante de

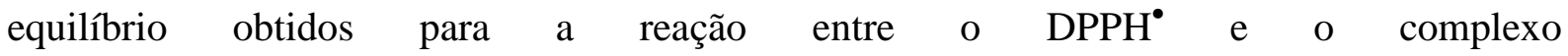
trans- $\left[\mathrm{Ru}\left(\mathrm{H}_{2} \mathrm{O}\right)\left(\mathrm{NH}_{3}\right)_{4}\left(\mathrm{P}(\mathrm{OEt})_{3}\right)\right]^{2+}$ foram respectivamente de $\quad-4,7 \quad \mathrm{KJ}^{-1} \mathrm{~mol}^{-1}$ e $\quad 6,8$ respectivamente.

Portanto, é plausível supor que o aquo-complexo possa reagir com o radical $\mathrm{DPPH}^{\bullet}$ quer através da abstração de um hidreto do ligante $\mathrm{P}(\mathrm{OEt})_{3}$ ou de seus produtos de degradação quer através da oxidação do centro metálico (Ru(II) a Ru(III)). 


\section{3 - Experimentos envolvendo radical hidroxila $\left(\mathrm{OH}^{\circ}\right)$}

\subsection{1 - Captação do radical hidroxila pelos nitrosilo complexos de rutênio}

Conforme demonstrado na seção 4.2, os nitrosilo complexos de rutênio(II) não são capazes de reduzir o radical $\mathrm{DPPH}^{\bullet}$ dado o elevado potencial de oxidação do centro metálico com exceção do complexo trans- $\left[\mathrm{Ru}(\mathrm{NO})\left(\mathrm{NH}_{3}\right)_{4}\left(\mathrm{P}(\mathrm{OEt})_{3}\right)\right]^{3+}$ o qual pode reagir segundo outros mecanismos de reação.

No entanto, existem outros radicais, tais como o radical hidroxila $\left(\mathrm{OH}^{\circ}\right)$, que possuem potenciais de oxidação mais elevados e que são subprodutos de reações bioquímicas no meio fisiológico.

O valor exato do potencial de oxidação do radical hidroxila é ponto controverso de discussão na literatura ${ }^{[10]}$. Estima-se que esteja em torno de $2,8 \mathrm{~V}$, em $\mathrm{pH} \approx 5,0 . \mathrm{O}$ valor do potencial de oxidação deste radical é muito sensível ao $\mathrm{pH}$, podendo ser alterado em mais de 1,0V em função da deprotonação do ácido conjugado $\mathrm{OH}_{2}{ }^{\bullet[10]}$.

Assim, o radical hidroxila possui potencial suficiente para oxidar o centro metálico nos complexos trans- $\left[\mathrm{Ru}(\mathrm{NO})\left(\mathrm{NH}_{3}\right)_{4}(\mathrm{~L})\right]^{3+}$ estudados neste trabalho sendo o processo termodinamicamente favorável $(\Delta \mathrm{G}<0)$. $\mathrm{O}$ radical $\mathrm{OH}^{\bullet}$ pode também ser desativado pela transferência de átomo de hidrogênio $\left(\mathrm{H}^{\bullet}\right)$. Porém, como discutido anteriormente para o radical $\mathrm{DPPH}^{\bullet}$, esta via de neutralização seria pouco favorecida levando-se em conta o meio em que as reações foram efetuadas. Bexendale e colaboradores ${ }^{[80]}$ demonstraram que o complexo trans- $\left[\mathrm{Ru}\left(\mathrm{NH}_{3}\right)_{6}\right]^{3+}$ reage com o radical $\mathrm{OH}^{\bullet}$, gerado através de radiólise de pulso, pela via de transferência de elétrons e não pela abstração de átomo de hidrogênio em meio aquoso ácido. 
De fato, os nitrosilo complexos mostraram-se capazes de reagir com o radical hidroxila, gerado através da reação de Fenton. Como forma de detecção indireta desta radical, foi utilizada a técnica de cinética por competição, utilizando o trapeador de spin DMPO, segundo a Reação 12:

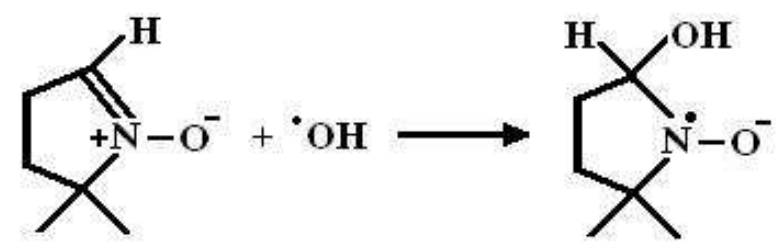

Reação 12 - Trapeamento do radical $\mathrm{OH}^{\bullet}$ pelo trapeador de spin DMPO.

A Figura 19 mostra um espectro típico de RPE obtido da solução após a reação entre os nitrosilo complexos e o captador de spin DMPO competindo pelo radical hidroxila.

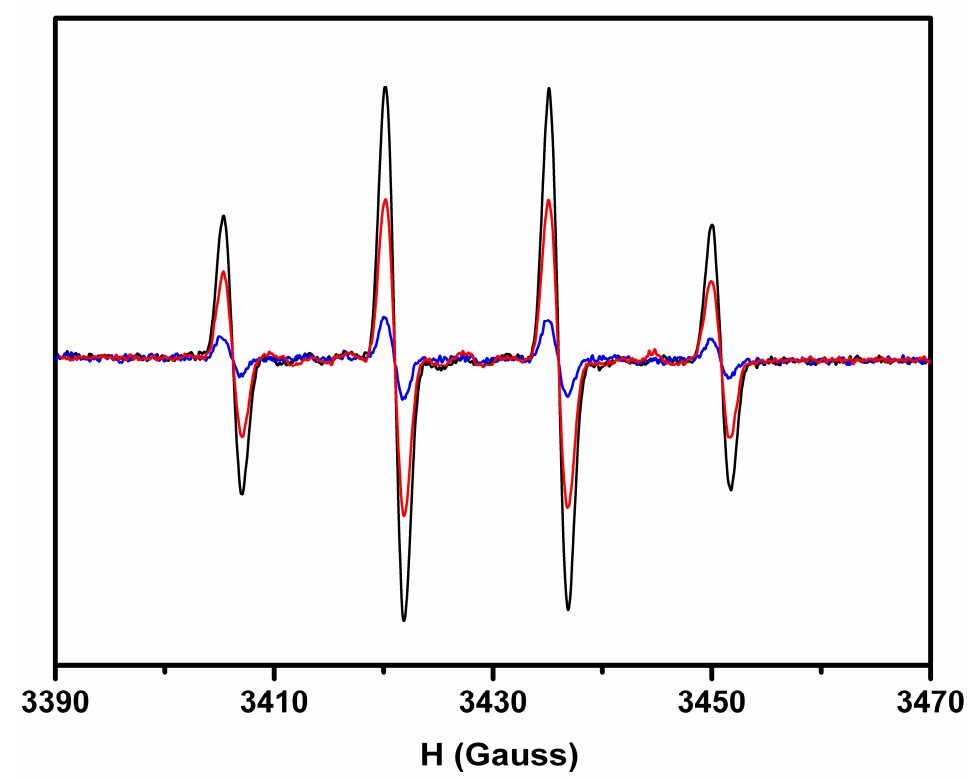

Figura 19 - Espectro de RPE da reação do complexo trans- $\left[\mathrm{Ru}(\mathrm{NO})\left(\mathrm{NH}_{3}\right)_{4}(\text { nic })\right]^{3+}$ e do captador de spin DMPO competindo pelo radical hidroxila. (-) controle; (-) $\mathrm{C}_{\mathrm{Ru}}=1,0 \times 10^{-3} \mathrm{~mol} \mathrm{~L}^{-1}$; (一) $\mathrm{C}_{\mathrm{Ru}}=1,0 \times 10^{-2} \mathrm{~mol} \mathrm{~L}^{-1}$; $\mathrm{T}=25^{\circ} \mathrm{C} ; \mathrm{CF}_{3} \mathrm{COOH} \mathrm{pH}=5,0 . \mathrm{C}_{\mathrm{DMPO}}=2 \times 10^{-3} \mathrm{~mol} \mathrm{~L}^{-1}$ 
A Tabela 7 resume os valores de eficiência de captação do radical em função da concentração dos nitrosilo complexos. Os ligantes livres bem como os contra-íons foram testados e não se mostraram capazes de captar o radical $\mathrm{OH}^{*}$.

Tabela 7 - Captação do radical $\mathrm{OH}^{\bullet}$ pelos complexos trans-[Ru(NO)(NH$\left.)_{4}(\mathrm{~L})\right]^{3+} \mathrm{e}$ $[\mathrm{Ru}(\mathrm{NO})(\mathrm{Hedta})]$.

\begin{tabular}{|c|c|c|c|}
\hline \multirow{3}{*}{$\mathbf{L}$} & \multicolumn{3}{|c|}{ \% Captação do Radical OH ${ }^{(*)}$} \\
\hline & \multicolumn{3}{|c|}{ Relação Radical: Complexo } \\
\hline & $1: 1$ & $1: 50$ & 1:100 \\
\hline Nic & 39,0 & 81,0 & 85,5 \\
\hline Isn & 58,0 & 66,0 & 70,0 \\
\hline $\operatorname{ImN}$ & 70,0 & 96,0 & 98,0 \\
\hline $\mathbf{P y}$ & 63,0 & 81,0 & 99,0 \\
\hline 4-pic & 68,0 & 79,0 & 84,0 \\
\hline $\mathbf{P}(\mathbf{O E t})_{3}$ & 70,0 & 100 & 100 \\
\hline Hedta & 8,0 & 13,5 & 20,0 \\
\hline
\end{tabular}

Como pode ser observado, a eficiência de captação do radical hidroxila apresenta variações significativas dependendo do nitrosilo complexo utilizado. Possivelmente, este fato está relacionado com a diferença no potencial de oxidação do centro metálico dos complexos trans-[Ru(NO) $\left.\left(\mathrm{NH}_{3}\right)_{4}(\mathrm{~L})\right]^{3+}$ quando se varia o ligante $\mathrm{L}$, visto que a influência trans exercida pelos ligantes trans posicionados ao NO pode acarretar mudanças significativas sobre o centro metálico.

Outro ponto importante a ser discutido, é a possibilidade de reações paralelas e consecutivas dos produtos da reação dos nitrosilo complexos com o radical $\mathrm{OH}^{*}$. Como o 
potencial de oxidação do radical hidroxila é muito elevado, após a primeira reação de oxidação do centro metálico de Ru(II), podem ocorrer reações com os produtos da reação. Experimentos utilizando os aquo complexos trans- $\left[\mathrm{Ru}\left(\mathrm{H}_{2} \mathrm{O}\right)\left(\mathrm{NH}_{3}\right)_{4}(\mathrm{~L})\right]^{2+}$, onde $\mathrm{L}=\mathrm{NH}_{3}, \mathrm{SO}_{2}$ e $\mathrm{P}(\mathrm{OEt})_{3}$ mostraram que estes complexos são capazes de reagir com o radical hidroxila.

Experimentos realizados com os precursores dos nitrosilo complexos, trans-[Ru( $\left.\left.\mathrm{SO}_{4}\right)\left(\mathrm{NH}_{3}\right)_{4}(\mathrm{~L})\right]^{+}$, onde $\mathrm{L}=$ isn e nic, que possuem o metal com estado de oxidação (III) foram efetuados. Nas condições experimentais que foram realizadas as medidas (excesso de complexo em relação ao radical de 50 vezes) não foi observada nenhuma reação entre os sulfato complexos e o radical $\mathrm{OH}^{*}$.

Esta observação experimental sugere duas interpretações. Primeiramente, nas condições experimentais utilizadas, a concentração de DMPO foi mantida igual a $2,0 \times 10^{-3} \mathrm{~mol} \mathrm{~L}^{-1}$, e a concentração de complexo trans- $\left[\mathrm{Ru}\left(\mathrm{SO}_{4}\right)\left(\mathrm{NH}_{3}\right)_{4}(\mathrm{~L})\right]^{+}$foi mantida igual a $3,0 \times 10^{-3} \mathrm{~mol} \mathrm{~L}^{-1}$. Como a constante de velocidade específica de captação do radical $\mathrm{OH}^{\bullet}$ pelo trapeador DMPO é igual a $2,1 \times 10^{9} \mathrm{M}^{-1} \mathrm{~s}^{-1[59]}$ é possível que a reação entre os sulfato complexos e o radical $\mathrm{OH}^{\bullet}$ não tenha sido observada pois a magnitude desta constante de velocidade seja muito menor que a constante de velocidade reportada para a formação do aduto DMPO`-OH.

Tentativas de variar a concentração do spin-trap DMPO para valores inferiores a 2,0 $\times 10^{-3} \mathrm{~mol} \mathrm{~L}^{-1}$ não conduziram e resultados de interesse, pois o sinal de RPE aproximou-se do nível de ruído. Portanto, as condições experimentais e o método de cálculo, baseado em valores de constantes de velocidade obtidas por reação de competição limita a investigação neste caso específico. A compreensão das reações que podem ocorrer entre os sulfato complexos e o radical $\mathrm{OH}^{\bullet}$ demandam mais experimentos, nos quais um dos reagentes possam ser monitorados de forma direta. 
Por outro lado, os resultados reforçam a hipótese que não ocorre a transferência de átomo de hidrogênio como via de desativação do radical $\mathrm{OH}^{\bullet}$ nestes sistemas. Caso isto ocorresse seria possível detectar esta reação para os sulfato complexos.

Até o momento, os resultados sugerem que os sulfato complexos trans-[Ru( $\left.\left.\mathrm{SO}_{4}\right)\left(\mathrm{NH}_{3}\right)_{4}(\mathrm{~L})\right]^{+}$não reagem com o radical $\mathrm{OH}^{\bullet}$ nas mesmas condições utilizadas para os nitrosilo complexos e que por conseqüência, a constante de velocidade desta reação caso exista, deve apresentar valor muito inferior que $1,0 \times 10^{9} \mathrm{M}^{-1} \mathrm{~s}^{-1}$.

A constante global de velocidade para a reação de captação do radical hidroxila pelos nitrosilo complexos de rutênio(II) pode estimada com base nos dados obtidos como estando situada entre $1,0 \times 10^{8}$ e $1,0 \times 10^{10} \mathrm{M}^{-1} \mathrm{~s}^{-1}$. Estes valores, que simplesmente definem um intervalo, estão próximos aos reportados na literatura por Bexandale ${ }^{[80]}$ para a reação entre os complexos metálicos de rutênio e o radical $\mathrm{OH}^{\bullet}\left(4,5 \times 10^{9} \mathrm{M}^{-1} \mathrm{~s}^{-1}\right)^{[80]}$.

\subsection{2 - Aspectos da reação entre o radical $\mathrm{OH}^{\bullet}$ e os nitrosilo complexos}

\section{utilizando RPE}

Os resultados reportados no item anterior indicam que a reação dos nitrosilo complexos com o radical $\mathrm{OH}^{\bullet}$ ocorre possivelmente através da oxidação do centro metálico. Para confirmar esta hipótese, foram conduzidos experimentos de RPE a baixa temperatura ( $\mathrm{N}_{2}$ e He líquido) para a detecção de centros metálicos de $\mathrm{Ru}(\mathrm{III})$.

Conforme descrito pela literatura ${ }^{[81,82]}$, centros metálicos de rutênio(III) com grupo pontual de simetria $\mathrm{C}_{4 \mathrm{v}}$ (como é dos complexos trans- $\left.\left[\mathrm{Ru}(\mathrm{NO})\left(\mathrm{NH}_{3}\right)_{4}(\mathrm{~L})\right]^{3+}\right)$ apresentam dois sinais distintos, com valores de g variando entre $2,2<\mathrm{g}_{\perp}<2,6$ e $1,2<\mathrm{g}_{\|}<1,6^{[82]}$.

Como pode ser observado na Figura 20, não foi possível de se detectar espécies de rutênio(III) através das medidas de RPE para a reação entre o radical $\mathrm{OH}^{\bullet}$ e os complexos 
trans $-[\mathrm{Ru}(\mathrm{NO})(\mathrm{Cl})(\text { ciclam })]^{2+}$ e trans- $\left[\mathrm{Ru}(\mathrm{NO})\left(\mathrm{NH}_{3}\right)_{4}(\mathrm{~L})\right]^{3+}$, em concentração da ordem de $1,0 \times 10^{-3} \mathrm{~mol} \mathrm{~L}^{-1}$. O complexo trans- $[\mathrm{Ru}(\mathrm{NO})(\mathrm{Cl})(\text { ciclam })]^{2+}$ foi escolhido por apresentar baixa constante de velocidade de liberação específica de NO e por já apresentar espectro de $\mathrm{NO}^{0}$ coordenado bem definido para a espécie trans- $[\mathrm{Ru}(\mathrm{NO})(\mathrm{Cl})(\text { ciclam })]^{+[81]}$.Os valores de $\mathrm{g}$ encontrados $\left(\mathrm{g}_{\mathrm{a}}\right.$ e $\left.\mathrm{g}_{\mathrm{b}}\right)$ estão próximos ao do eletron livre $(\mathrm{g} \approx 2,0)^{[83]}$. Além disso, o sinal de intensidade baixa nos espectros não permite conclusões mais aprofundadas.

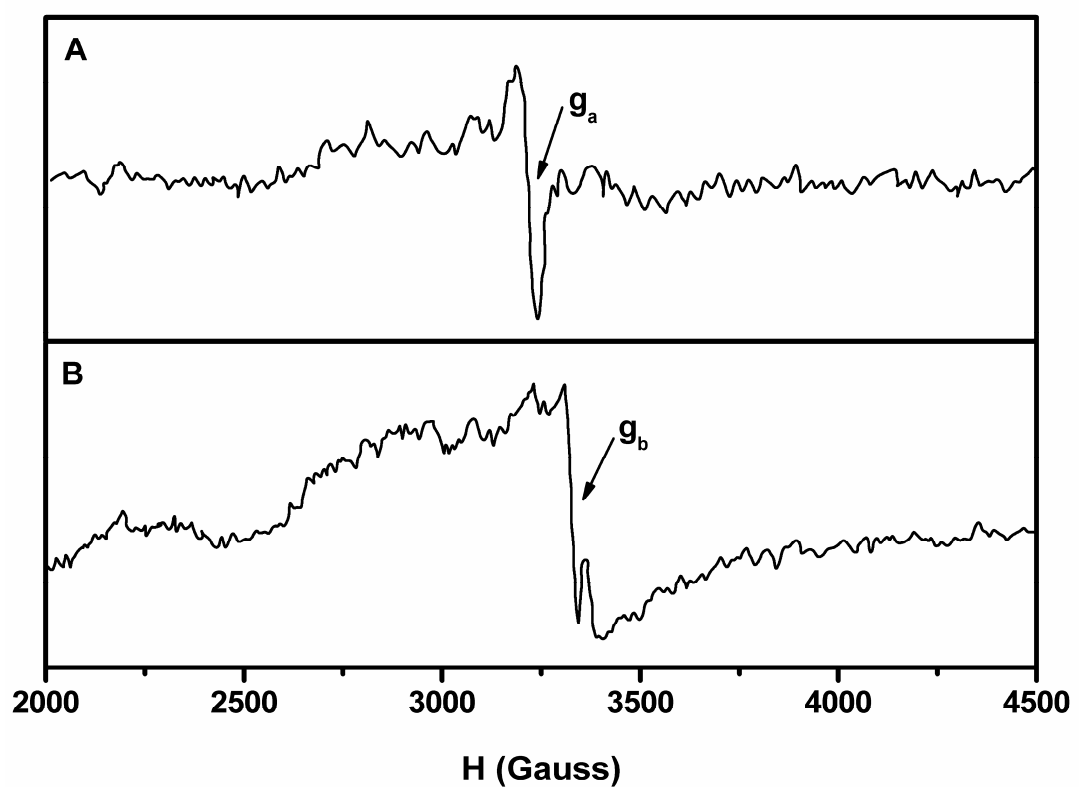

Figura 20 - Espectros de RPE em banda-X digitalizados para a reação entre o radical $\mathrm{OH}^{\bullet}$ e os complexos trans- $[\mathrm{Ru}(\mathrm{NO})(\mathrm{Cl})($ ciclam $)] \mathrm{Cl}_{2}(\mathrm{~A})$ e trans- $\left[\mathrm{Ru}(\mathrm{NO})\left(\mathrm{NH}_{3}\right)_{4}(\mathrm{isn})\right]^{3+}(\mathrm{B}) . \mathrm{T}=115 \mathrm{~K}, \mathrm{pH}=3,0 ; 35 \%$ etilenoglicol $(\mathrm{v} / \mathrm{v}), 32$ scans. $\mathrm{C}_{\mathrm{Ru}}=1,0 \times 10^{-3} \mathrm{~mol} \mathrm{~L}^{-1}$.

Nas mesmas condições experimentais, foram obtidos espectros utilizando hélio líquido como refrigerante da cavidade de RPE. Como pode ser observado na Figura 21, os espectros apresentam melhor relação sinal-ruído, e também melhor definição dos sinais. O complexo trans- $[\mathrm{Ru}(\mathrm{NO})(\text { ciclam }) \mathrm{Cl}]^{2+}$ apresenta três sinais distintos são com valores de $\mathrm{g}_{1}=2,02$, $\mathrm{g}_{2}=2,00$ e $\mathrm{g}_{3}=1,96$ respectivamente. Para $\mathrm{o}$ sistema envolvendo o complexo trans-[Ru(NO)(NH$\left.)_{4}(\mathrm{isn})\right]^{3+}$, o espectro de RPE obtido à $10 \mathrm{~K}$ também apresenta melhor resolução. Neste caso, é possível observar dois valores de $\mathrm{g}_{4}=2,02$ e $\mathrm{g}_{5}=1,98$. 


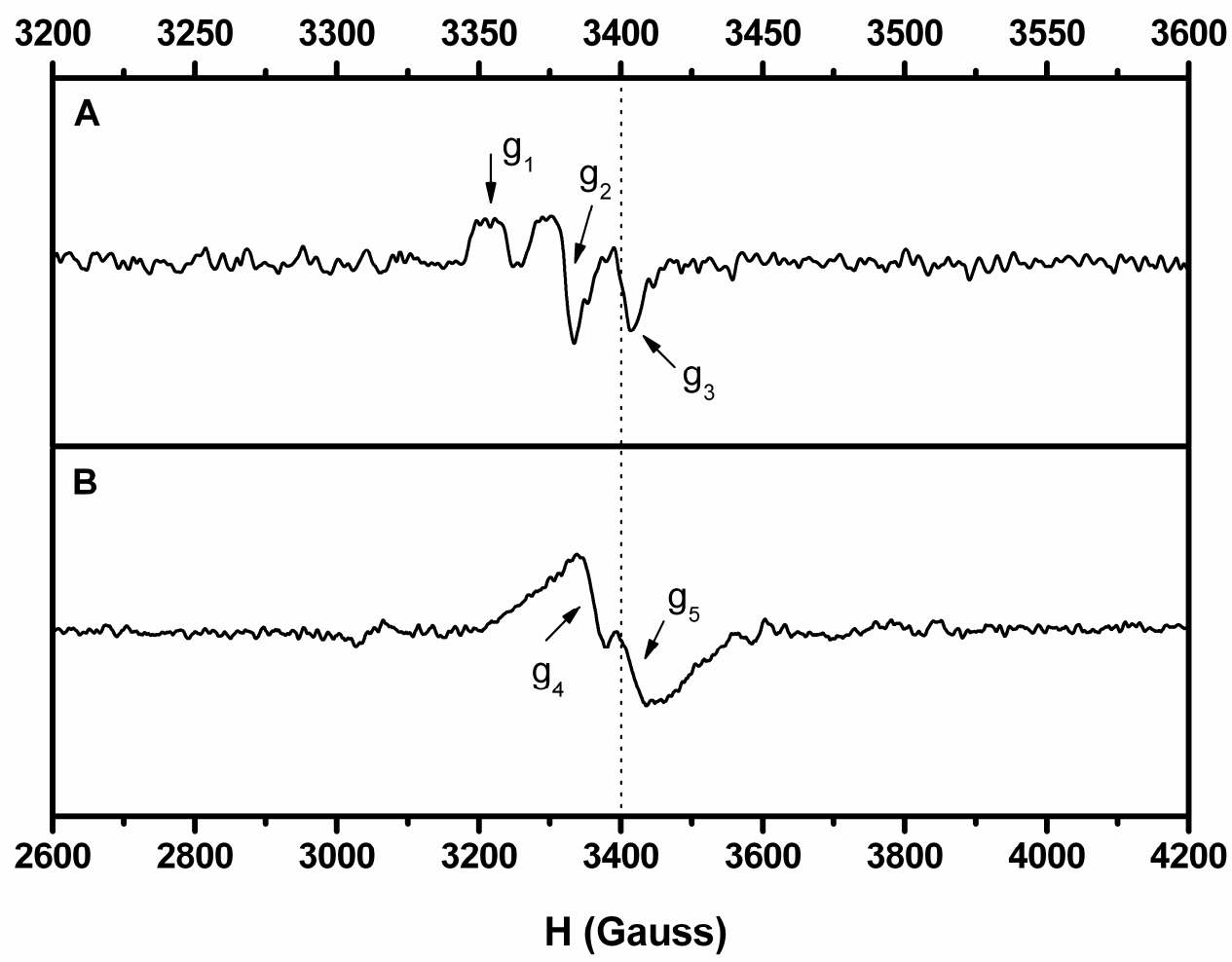

Figura 21 - Espectros de RPE banda-X digitalizados para a reação entre o radical $\mathrm{OH}^{\bullet}$ e os complexos trans- $\left[\mathrm{Ru}(\mathrm{NO}) \mathrm{CiclamCl}_{\mathrm{Cl}}(\mathrm{A})\right.$ e trans- $\left[\mathrm{Ru}(\mathrm{NO})\left(\mathrm{NH}_{3}\right)_{4}(\mathrm{Isn})\right]^{3+}(\mathrm{B}) . \mathrm{T}=10 \mathrm{~K}, \mathrm{pH}=3,0 ; 35 \%$ etilenoglicol $(\mathrm{v} / \mathrm{v})$, 8 scans. $\mathrm{C}_{\mathrm{Ru}}=1,0 \times 10^{-3} \mathrm{~mol} \mathrm{~L}^{-1}$.

Os valores de g para os dois casos, bem como o perfil de espectro e valores de constante de acoplamento hiperfina não são compatíveis com o espectro dos respectivos aquo $\operatorname{complexos}^{[81]}$.

$\mathrm{O}$ valor de g para o radical $\mathrm{NO}$ livre trapeado em cristal de $\mathrm{NH}_{3} \mathrm{OHCl}$ foi reportado na literatura por Ohigashi ${ }^{[84]}$ com valores de $\mathrm{g}_{\mathrm{x}}=1,998 ; \mathrm{g}_{\mathrm{y}}=1.999 ; \mathrm{g}_{\mathrm{z}}=1,886$. Também foi reportado os valores de g para o complexo $\left[\mathrm{Fe}(\mathrm{CO})_{2}(\mathrm{NO})_{2}\right]^{-}$com valores $\mathrm{g}_{\mathrm{x}}=1,999 ; \mathrm{g}_{\mathrm{y}}=$ 1,998; $\mathrm{g}_{\mathrm{z}}=1,9608$. Os espectros de RPE para o complexo trans- $[\mathrm{Ru}(\mathrm{NO})(\mathrm{Cl})(\text { ciclam })]^{+}$ previamente reduzidos com íons de $\mathrm{Eu}^{2+}$ foram obtidos a temperatura do nitrogênio líquido, apresentam os seguintes valores de $\mathrm{g}: \mathrm{g}_{\mathrm{x}}=1,995 ; \mathrm{g}_{\mathrm{y}}=2,035 ; \mathrm{g}_{\mathrm{z}}=1,88^{[81]}$. Segundo os dados expostos acima, nota-se uma similaridade entre os valores de $\mathrm{g}$ encontrados para os complexos trans- $[\mathrm{Ru}(\mathrm{NO})(\mathrm{Cl})(\text { ciclam })]^{2+}$ e trans- $\left[\mathrm{Ru}(\mathrm{NO})\left(\mathrm{NH}_{3}\right)_{4}(\text { isn })\right]^{3+}$ após a reação com o 
radical $\mathrm{OH}^{*}$. Assim, é possível supor que o sinal detectado seja referente a $\mathrm{NO}^{0}$ coordenado ao centro metálico.

Em primeira análise, esta hipótese seria descartada, pois a reação com o radical $\mathrm{OH}^{\bullet}$, uma entidade química estritamente oxidante, levaria a oxidação do centro metálico e não a redução do nitrosil coordenado. No entanto, como já foi discutido no item 4.3.1, múltiplas reações podem ocorrer neste sistema, sendo até possível espécies de rutênio(IV) agirem como redutoras $^{[80]}$. Outra possibilidade seria uma transferência de elétron do centro de $\mathrm{Ru}(\mathrm{III})$ para o NO, formando a espécie $[\mathrm{Ru}(\mathrm{IV})(\mathrm{NO})]^{3+}$. Caso este intermediário seja formado, seu tempo de meia vida seria muito curto, pois este seria instável devido ao elevado estado de oxidação do centro metálico. Shepherd e colaboradores ${ }^{[85]}$ propuseram a formação do fragmento $\left[\mathrm{Ru}(\mathrm{III})\left(\mathrm{NO}^{+}\right)\right]^{4+}$ no sistema $[\mathrm{Ru}(\mathrm{NO})($ Hedta)$]$, através de estudos de voltametria cíclica. Se este fragmento é passível de ser formado, o fragmento $[\mathrm{Ru}(\mathrm{IV})(\mathrm{NO})]^{3+}$ também poderia ser formado. Como pode ser observado pelo espectro de RPE (Figuras 20 e 21) a intensidade e a definição dos sinais dos espectros é bastante baixa, indicando que a quantidade de espécies paramagnéticas presentes no meio reacional é muito pequena. Isto pode ser explicado considerando-se que o tempo médio para o congelamento da reação foi de 2 segundos e que o $\mathrm{t}_{1 / 2}$ da reação de oxidação do centro metálico e da formação e decaimento da espécie $[\mathrm{Ru}(\mathrm{IV})(\mathrm{NO})]^{4+}$ é extremamente pequeno, possivelmente na ordem de mili ou micro segundos, com base na constante de velocidade estimada anteriormente para a reação entre o radical $\mathrm{OH}^{\bullet}$ e os nitrosilo complexos. 


\subsection{3 - Monitoramento da reação entre o radical $\mathrm{OH}^{*}$ e os nitrosilo complexos de Ru(II) utilizando eletrodo seletivo a NO}

Para auxiliar na interpretação dos experimentos de RPE envolvendo os nitrosilo complexos e o radical $\mathrm{OH}^{\bullet}$ foram efetuadas medidas envolvendo eletrodo seletivo à $\mathrm{NO}^{0}$. Uma vez que há a possibilidade de formação de $\mathrm{NO}^{0}$ pela reação entre os nitrosilo complexos e o radical $\mathrm{OH}^{\bullet}$, seria esperada a liberação de $\mathrm{NO}^{0}$ após a reação. No entanto, não foi detectado $\mathrm{NO}^{0}$ durante a reação entre os nitrosilo complexos e o radical $\mathrm{OH}^{\bullet}$.

Conforme reportado por Miranda e $\mathrm{Wink}^{[29]}$, a reação entre $\mathrm{NO}^{0}$ e o radical $\mathrm{OH}^{\bullet}$ tem constante de velocidade específica próximo ao limite da difusão (> $\left.1,0 \times 10^{9} \mathrm{M}^{-1} \mathrm{~s}^{-1}\right)$. Portanto a não detecção de $\mathrm{NO}^{0}$ pode ser consequiência desta reação. Essa reação faria com que o $\mathrm{NO}^{0}$ gerado pela oxidação do centro metálico de $\mathrm{Ru}(\mathrm{II})$ fosse consumido pelo radical $\mathrm{OH}^{\bullet}$ gerado no meio reacional, impedindo assim a detecção do óxido nítrico pelo eletrodo.

Também há a possibilidade da não liberação de $\mathrm{NO}^{0}$ após a reação dos nitrosilo complexos com o radical $\mathrm{OH}^{*}$, visto que a formação da espécie $\left[\mathrm{Ru}(\mathrm{III}) \mathrm{NO}^{+}\right]^{4+}$ pode levar a liberação de $\mathrm{NO}^{+}$no meio reacional.

\subsection{4 - Considerações sobre a reação entre os nitrosilo complexos e o radical $\mathbf{O H}^{\bullet}$}

Conforme discutido nas seções anteriores, o mecanismo de reação pelo qual o radical $\mathrm{OH}^{\bullet}$ interage com os nitrosilo complexos é complexo. Tomando como base os experimentos voltamétricos é possível supor que a reação ocorra através da oxidação do centro metálico, visto que o potencial encontrado em meio aquoso para o par $\mathrm{Ru}(\mathrm{II}) / \mathrm{Ru}(\mathrm{III})$ utilizando EDDB está em torno de $+2,1 \mathrm{~V}$ acessível portanto a oxidação pelo radical $\mathrm{OH}^{\bullet}$. 
No entanto, a não detecção de Ru(III) após a reação sugere que outras reações possam estar ocorrendo em seqüência ou de forma paralela. A detecção, mesmo que de forma precária, do sinal de radical nos espectros de RPE após a reação sugere que o ligante $\mathrm{NO}^{+}$é convertido a $\mathrm{NO}^{0}$ após a reação entre radical $\mathrm{OH}^{\bullet}$ e o centro metálico. Isso sugere uma pouco provável transferência de elétrons entre o metal e o ligante nitrosil. Portanto, seria plausível supor reação do ligante $\mathrm{NO}^{0}$ com o radical $\mathrm{OH}^{*}$. Esta pode ser uma explicação para a não detecção de $\mathrm{NO}^{0}$ via eletrodo seletivo à $\mathrm{NO}^{0}$.

Estudos realizados por Shepherd e colaboradores ${ }^{[85]}$ utilizando o complexo [Ru(NO)Hedta] indicam que este complexo quando submetido a potenciais anódicos superiores a 1,4 V em eletrólito orgânico pode formar a espécie $\left[\mathrm{Ru}(\mathrm{III}) \mathrm{NO}^{+}\right]^{+}$. Esta espécie poderia estar em equilíbrio com a espécie $\left[\mathrm{Ru}(\mathrm{IV}) \mathrm{NO}^{0}\right]$, instável, a qual rapidamente reagiria com outras espécies do meio.

Esta etapa da reação ainda demanda mais estudo. O uso de infra-vermelho resolvido no tempo seria uma alternativa, através do monitoramento da formação da banda de $\mathrm{NO}^{0}$ durante o curso da reação. Até o momento nossos resultados indicam a provável existência de mais reações após a captação do radical $\mathrm{OH}^{\bullet}$ pelos nitrosilo complexos de rutênio(II).

\section{4 - Reações entre os nitrosilo complexos e o radical superóxido $\left(\mathrm{O}_{2}^{-*}\right)$}

\subsection{1 - Captação do radical $\mathrm{O}_{2}^{-\bullet}$ pelos nitrosilo complexos}

A reação entre o radical $\mathrm{O}_{2}{ }^{-}$e os nitrosilo complexos foi monitorada via espectroscopia de UV-vis, utilizando como sonda para este radical o citocromo $\mathrm{c}^{[30]}$. Para quantificar o consumo do radical superóxido foram efetuados experimentos de cinética de competição ${ }^{[39]}$ entre os nitrosilo complexos e o citocromo c pelo radical $\mathrm{O}_{2}^{-\bullet}$ conforme 
ilustrado na Figura 22. $\mathrm{O}$ radical $\mathrm{O}_{2}^{-\bullet}$ foi gerado fotoquimicamente utilizando riboflavina como sensibilizador e o ácido DTPA como doador de elétrons ${ }^{[61]}$.

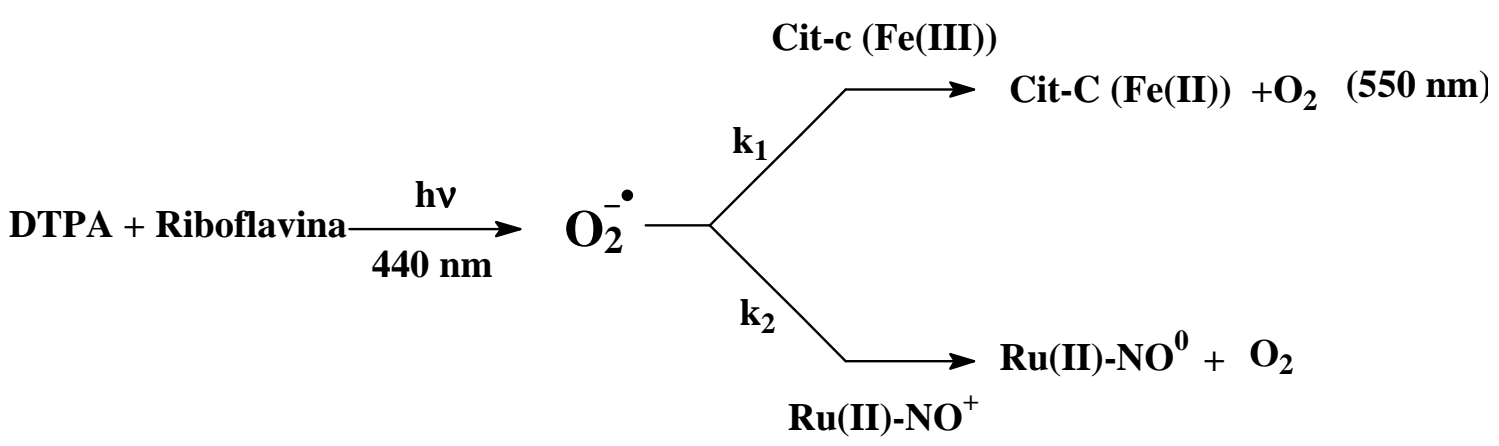

Fugura 22 - Geração do radical $\mathrm{O}_{2}^{\cdot}$ pela via fotoquímica e a sequiência de reações de competição entre os nitrosilo complexos e o citocromo c pelo radical $\mathrm{O}_{2}{ }^{*}$.

A Tabela 8 apresenta os resultados de captação do radical $\mathrm{O}_{2}{ }^{-}$em função da concentração dos nitrosilo complexos, conforme protocolo de reação descrito na seção 3.5. A Figura 23 ilustra os espectros de UV-vis típicos obtidos para as reações descritas acima.

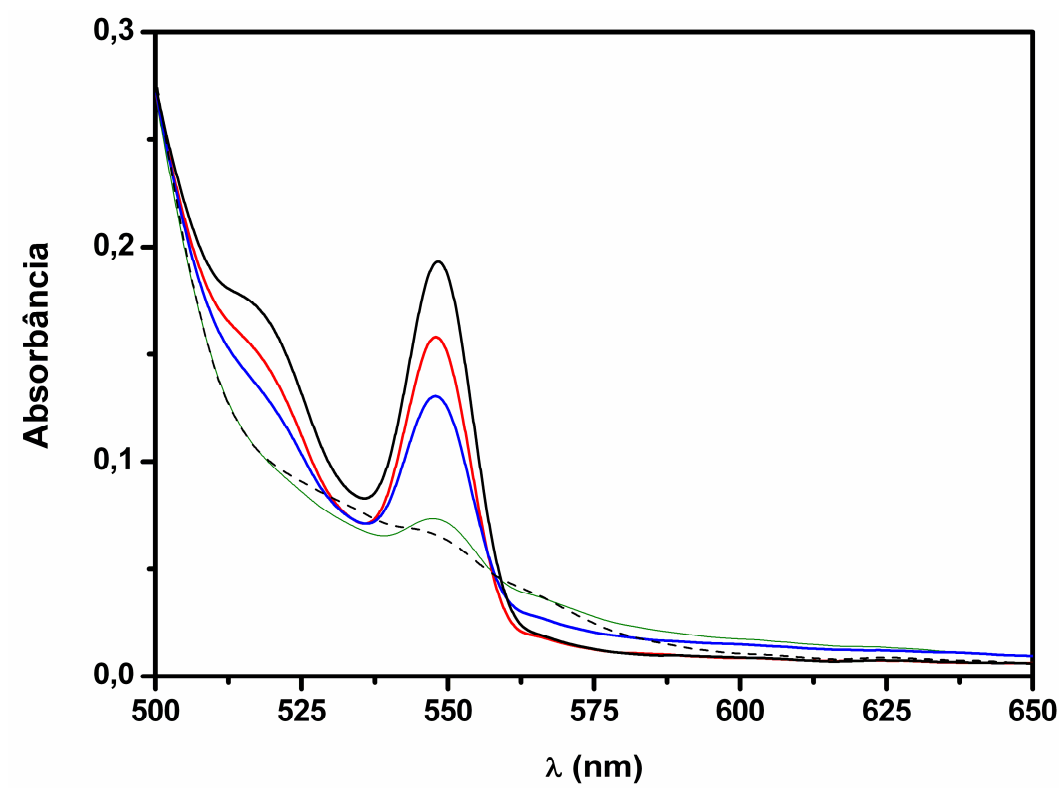

Figura 23 - Espectro de UV-vis da reação de competição entre o complexo trans-[Ru(NO) $\left.\left(\mathrm{NH}_{3}\right)_{4}(\mathrm{imN})\right]^{3+}$ e o citocromo c pelo radical $\mathrm{O}_{2}^{-} . \mathrm{T}=25^{\circ} \mathrm{C} ; \mathrm{pH}=5,0 ;(--)$ sem irradiar; $(-)$ controle; $(-) \mathrm{C}_{\mathrm{Ru}}=1,0 \times 10^{-4} \mathrm{~mol} \mathrm{~L}^{-1}$; (一) $\mathrm{C}_{\mathrm{Ru}}=5,0 \times 10^{-4} \mathrm{~mol} \mathrm{~L}^{-1} ;(-) \mathrm{C}_{\mathrm{Ru}}=1,0 \times 10^{-3} \mathrm{~mol} \mathrm{~L}^{-1}$. $\mathrm{C}_{\text {citocromo c }}=2,0 \times 10^{-5} \mathrm{~mol} \mathrm{~L}^{-1}$ 
Conforme se observa na Figura 23, a captação do radical superóxido pode ser monitorada pela diminuição da absorbância da banda em $550 \mathrm{~nm}$ quando na presença dos nitrosilo complexos (linhas vermelha, azul e verde) em relação ao controle sem a adição dos nitrosilo complexos (linha preta). A linha pontilhada representa a solução contendo riboflavia, DTPA, citocromo c e o complexo antes da irradiação com luz no comprimento de onda de $440 \mathrm{~nm}$.

Todos os nitrosilo complexos testados apresentaram-se capazes de captar o radical $\mathrm{O}_{2}{ }^{\bullet}$, em diferentes concentrações. Em concentrações menores que $1,0 \times 10^{-4} \mathrm{~mol} \mathrm{~L}^{-1}$ (excesso em relação ao radical formado menor que 10 vezes) nenhum dos nitrosilo complexos testados foi capaz de captar o radical $\mathrm{O}_{2}^{-\bullet}$ no modelo experimental utilizado.

Tabela 8 - Eficiência de captação do radical $\mathrm{O}_{2}{ }^{-}(\%)^{*}$ frente os complexos

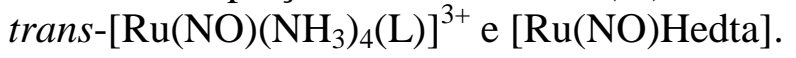

$\%$ Captação do Radical $\mathrm{O}_{2}^{-\bullet}$

L Relação Radical: Complexo

\begin{tabular}{cccc} 
& $\mathbf{1 : 1 0}$ & $\mathbf{1 : 5 0}$ & $\mathbf{1 : 1 0 0}$ \\
\hline imN & 1,0 & 28,5 & 88,7 \\
Nic & 0,0 & 14,9 & 58,2 \\
Py & 0,0 & 11,0 & 30,3 \\
4-pic & 8,7 & 19,0 & 34,4 \\
P(OEt) & 4,2 & 17,0 & 32,0 \\
Hedta & 13,8 & 100,0 & 100,0 \\
\end{tabular}

$(*): \mathrm{pH}=5,0 ; \mathrm{T}=25^{\circ} \mathrm{C} ; 4$ min de irradiação. $\mathrm{C}_{\text {citocromo }}=2,0 \times 10^{-5} \mathrm{~mol} \mathrm{~L}^{-1}$ 
Também foram testados os correspondentes sulfatos complexos trans- $\left[\mathrm{Ru}\left(\mathrm{NH}_{3}\right)_{4}\left(\mathrm{SO}_{4}\right)(\text { isn })\right]^{+}$e trans- $\left[\mathrm{Ru}\left(\mathrm{NH}_{3}\right)_{4}\left(\mathrm{SO}_{4}\right)(\text { nic })\right]^{+}$. Ambos não foram capazes de captar o radical $\mathrm{O}_{2}^{-\bullet}$

Os aquo complexos trans- $\left[\mathrm{Ru}\left(\mathrm{H}_{2} \mathrm{O}\right)\left(\mathrm{NH}_{3}\right)_{4}(\mathrm{~L})\right]^{2+}$, onde $\mathrm{L}=$ isn, imN e $\mathrm{P}(\mathrm{OEt})_{3}$, foram testados e de acordo com o esperado e mostraram-se incapazes de captar o radical $\mathrm{O}_{2}^{-\bullet}$. Estes experimentos foram realizados utilizando o protocolo de medida utilizando xantina oxidase para a geração de $\mathrm{O}_{2}^{-\bullet}$ conforme descrito no item 3.5.

Conforme pôde ser observado na Tabela 8 , o complexo trans- $\left[\mathrm{Ru}(\mathrm{NO})\left(\mathrm{NH}_{3}\right)_{4}\left(\mathrm{P}(\mathrm{OEt})_{3}\right)\right]^{3+}$ foi o mais eficiente captador do radical $\mathrm{O}_{2}{ }^{-\bullet}$. Pode-se correlacionar esta observação experimental com o potencial de redução do ligante nitrosil coordenado ao centro metálico de $\mathrm{Ru}(\mathrm{II})$. Este complexo apresenta o valor mais positivo de potencial de redução para o par $\mathrm{NO}^{+} / \mathrm{NO}^{0}$ na série de complexos estudados neste trabalho. No entanto, não foi possível se observar uma correlação direta, mas simplesmente uma tendência entre o potencial de redução do ligante $\mathrm{NO}$ e a porcentagem de captação do radical $\mathrm{O}_{2}{ }^{\bullet}$ para os demais nitrosilo complexos estudados conforme se observa na Figura 24.

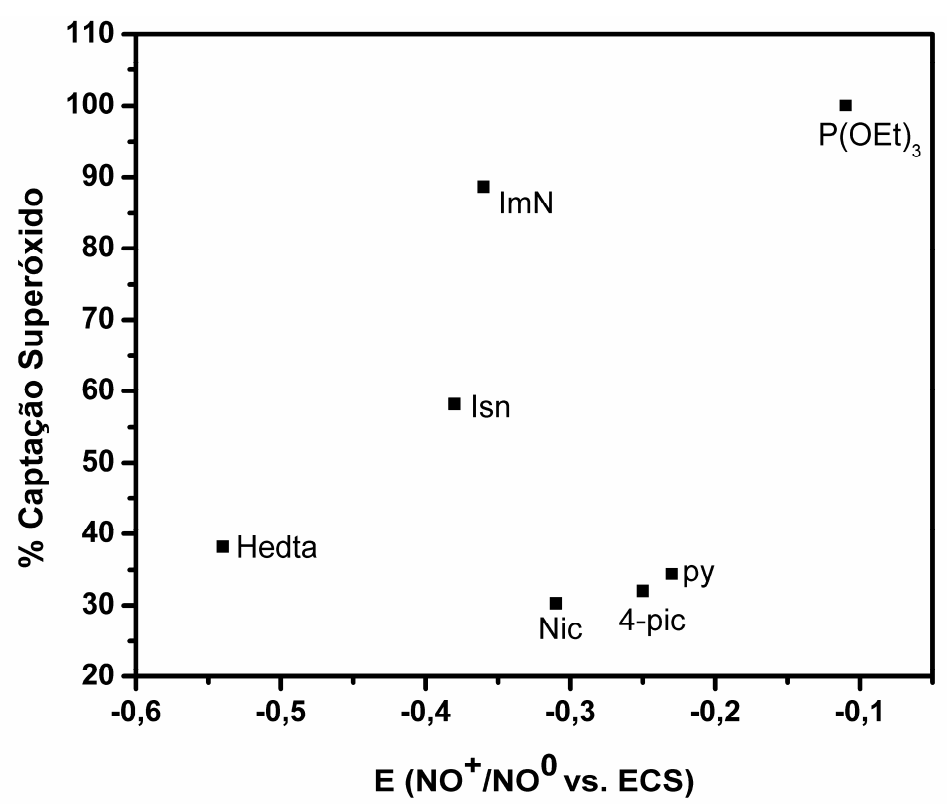

Figura 24 - Gráfico da porcentagem de captação do radical superóxido versus o potencial de redução $\mathrm{NO}^{+} / \mathrm{NO}^{0}$. 
Os resultados até agora obtidos indicam fortemente que a reação entre o radical superóxido e os nitrosilo complexos deve ocorrer preferencialmente pela redução do ligante $\mathrm{NO}^{+}$

\subsection{2 - Estimativa da constante de velocidade entre o radical superóxido e os nitrosilo complexos de rutênio(II)}

A constante de velocidade entre os nitrosilo complexos de rutênio e o radical $\mathrm{O}_{2}^{-\bullet}$ pode ser estimada utilizando uma expressão de constante de velocidade derivada para reações competitivas $^{[64,65]}$. Considerando que o conjunto de reações que ocorre no meio reacional seja o seguinte:

$$
\begin{aligned}
& \mathrm{O}_{2}^{-\dot{-}} \longrightarrow \mathrm{O}_{2}+\mathrm{e}^{-} \\
& \mathrm{Cit}-\mathrm{C}(\mathrm{FeIII})+\dot{\mathrm{O}_{2}} \longrightarrow \mathrm{Cit}-\mathrm{C}(\mathrm{FeII})+\mathrm{O}_{2} \\
& {\left[\mathrm{Ru}(\mathrm{II}) \mathrm{NO}^{+}\right]^{3+}+\dot{\mathrm{O}_{2}} \longrightarrow\left[\mathrm{Ru}(\mathrm{II}) \mathrm{NO}^{0}\right]^{2+}+\mathrm{O}_{2}}
\end{aligned}
$$

Reações 13 - 15 - Reações envolvidas na cinética de competição entre os nitrosilo complexos de rutênio(II) e o citocromo c pelo radical superóxido

Pode-se derivar ${ }^{[64,65]}$ a Equação 1 que correlaciona as constantes de velocidade de reação do radical $\mathrm{O}_{2}^{-\bullet}$ com os nitrosilo complexos e o citocromo c. Estas constantes podem ser relacionadas com as concentrações dos reagentes e a $\%$ de captação do radical $\mathrm{O}_{2}{ }^{\bullet}$ através da relação entre as absorbâncias do experimento de controle e do experimento contendo os nitrosilo complexos. Os valores de absorbância podem ser utilizados neste caso, pois a relação de absorbância entre o experimento de controle e o experimento contendo os nitrosilo complexos reflete diretamente as concentrações das espécies. 


$$
\begin{aligned}
& \left(\frac{\% \text { Cap }}{1-\% \text { Cap }}\right) \times\left(k_{1}\right) \times C_{\text {cit-c }}=\left(k_{2}\right) \times C_{\text {RuNO }} \\
& \text { Onde: \% Cap }=\mathrm{Abs}_{\text {reação }} / \mathrm{Abs}_{\text {controle }}
\end{aligned}
$$

Equação 1 - Expressão derivada para a estimativa da constante de velocidade de reação dos nitrosilos complexos com o radical $\mathrm{O}_{2}{ }^{-}$. \%Cap = porcentagem de captação do radical $\mathrm{O}_{2}{ }^{-} ; \mathrm{C}_{\text {cit-c }}$ : concentração de citocromo c; $\mathrm{C}_{\mathrm{RuNO}}$ : concentração do complexo. $\mathrm{T}=25^{\circ} \mathrm{C}, \mathrm{pH}=5,0$. Abs: absorbância.

A constante de velocidade para a reação entre o citocromo c e o radical $\mathrm{O}_{2}^{-{ }^{-}}$tem seu valor relatado na literatura de $\mathrm{k}_{1}=1,4 \times 10^{6} \mathrm{M}^{-1} \mathrm{~s}^{-1},\left(\mathrm{pH}=5,0 ; \mathrm{T}=25^{\circ} \mathrm{C}\right)^{[59,86]}$. Para calcular a constante de velocidade de captação do radical $\mathrm{O}_{2}^{-\bullet}$ pelos nitrosilo complexos, foi plotado um gráfico de $\%$ de captação de $\mathrm{O}_{2}{ }^{-\bullet}$ versus a concentração dos nitrosilos complexos utilizada. Pela correlação linear encontrada, foi interpolado o valor onde a captação do radical é igual a 50\%. Nesta condição, a relação (\%Cap/1-\%Cap) na Equação 1 se iguala a 1, podendo assim ser obtido o valor de $\mathrm{k}_{2}$. $\mathrm{O}$ valor da constante de velocidade específica $\mathrm{k}_{2}$ entre os nitrosilo complexos e o radical $\mathrm{O}_{2}^{-}$calculada como estando entre $5,0 \pm 1,0 \quad$ x $10^{4}$ e 4,2 $\pm 0,8 \times 10^{5} \mathrm{M}^{-1} \mathrm{~s}^{-1}$. Foram obtidas boas correlações lineares para o gráfico \% captação $v s$. concentração de nitrosilo para os complexos estudados. Porém a reta obtida não cruzou a origem, indicando que reações paralelas ocorrem durante as medidas. Umas das possibilidades é a dismutação do radical superóxido. Seu consumo via dismutação explicaria o coeficiente linear positivo obtido (Figura 25). Para o calculo das constantes foram utilizadas 4 concentrações diferentes dos complexos listados na Tabela 8. A Figura 25 ilustra o gráfico obtido para o cálculo da constante de velocidade entre o radical $\mathrm{O}_{2}^{-\bullet}$ e o complexo trans$\left[\mathrm{Ru}(\mathrm{NO})\left(\mathrm{NH}_{3}\right)_{4}\left(\mathrm{P}(\mathrm{OEt})_{3}\right)\right]^{3+}$. 


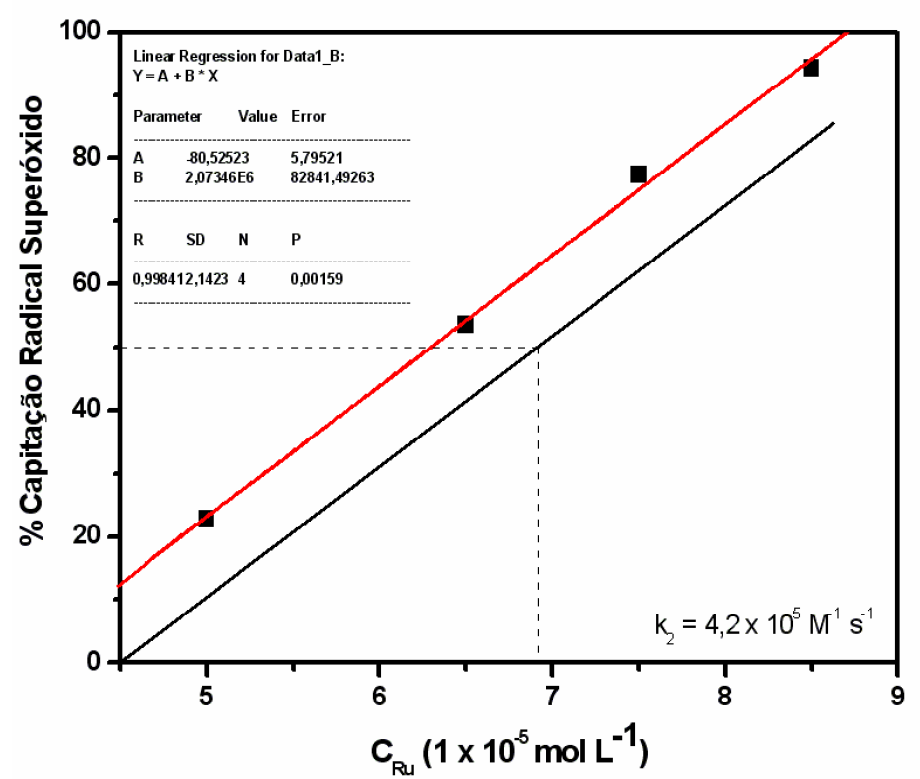

Figura 25 - Gráfico da captação do radical $\mathrm{O}_{2}^{-\bullet}$ versus a concentração do complexo trans- $\left[\mathrm{Ru}(\mathrm{NO})\left(\mathrm{NH}_{3}\right)_{4}\left(\mathrm{P}(\mathrm{OEt})_{3}\right)\right]^{3+}$. (-): reta experimental; $(-)$ : reta teórica. $\mathrm{k}_{2}$ é o valor da constante específica de velocidade obtida utilizando a Equação1.

Este valor estimado de constante de velocidade específica encontrado é compatível com valores reportados na literatura ${ }^{[5]}$ (na ordem de $10^{4}$ a $10^{6} \mathrm{~mol}^{-1} \mathrm{~s}^{-1}$ ) para complexos metálicos de $\mathrm{Fe}(\mathrm{II})\left\{\left(\mathrm{e}_{\mathrm{g}}\right)^{0}\left(\mathrm{t}_{2 \mathrm{~g}}\right)^{6}\right\}$ e $\mathrm{Mn}(\mathrm{II})\left\{\left(\mathrm{e}_{\mathrm{g}}\right)^{0}\left(\mathrm{t}_{2 \mathrm{~g}}\right)^{3}\right\}^{[13]}$.

Uma possível explicação para a maior velocidade de reação entre o radical superóxido e a o citocromo c se comparado aos nitrosilo complexos de rutênio pode estar relacionada ao potencial de redução em cada caso.

O potencial de oxidação do radical $\mathrm{O}_{2}{ }^{\bullet}$ é de $-0,60 \mathrm{~V}$, em $\mathrm{pH}=5,0^{[86]}$. Os potenciais de redução do ligante $\mathrm{NO}^{+} / \mathrm{NO}^{0}$ nos nitrosilo complexos variam entre $-0,54 \mathrm{~V}$ e $-0,11 \mathrm{~V}$. Para o citocromo c, o potencial de redução do par $\mathrm{Fe}(\mathrm{III}) / \mathrm{Fe}(\mathrm{II})$ é de $-0,01 \mathrm{~V}$. Analisando a viabilidade termodinâmica das reações, podemos concluir que a reação entre o citocromo c e o radical $\mathrm{O}_{2}{ }^{\bullet}$ é termodinamicamente mais viável pelo maior valor de $\Delta \mathrm{E}$ se comparado à reação entre os nitrosilo complexos e o radical $\mathrm{O}_{2}{ }^{-}$. Com respeito ao aspecto cinético, podemos relacionar o maior valor em módulo de $\Delta \mathrm{G}$ com uma menor energia de ativação para a reação de transferência de elétrons, via relação linear de energia livre. 
Foram calculadas as variações da energia livre de Gibbs e as constantes de equilíbrio para os complexos $\left[\mathrm{Ru}(\mathrm{NO})(\right.$ Hedta) $]$ e trans- $\left[\mathrm{Ru}(\mathrm{NO})\left(\mathrm{NH}_{3}\right)_{4}\left(\mathrm{P}(\mathrm{OEt})_{3}\right)\right]^{3+}$ na reação com o radical $\mathrm{O}_{2}^{-\bullet}$. Os valores obtidos foram $-5,8 \mathrm{KJ} \mathrm{mol}^{-1} / 10,4 \mathrm{e}-41,5 \mathrm{KJ} \mathrm{mol}^{-1} / 1,8 \times 10^{7}$ respectivamente. Para a reação entre o radical $\mathrm{O}_{2}^{-\bullet}$ e o citocromo c, os valores de $\Delta \mathrm{G}$ e $\mathrm{K}_{\mathrm{eq}}$ são $-57 \mathrm{KJ} \mathrm{mol}^{-1}$ e $9,8 \times 10^{9}$ respectivamente.

Desta forma, é coerente o resultado encontrado onde o valor da constante de velocidade específica de reação entre os nitrosilo complexos e o radical $\mathrm{O}_{2}^{-\bullet}$ é inferior ao da constante de velocidade da reação entre o citocromo c e o radical $\mathrm{O}_{2}{ }^{-}$.

\subsection{3 - Liberação de $\mathrm{NO}^{0}$ após a reação entre o radical $\mathrm{O}_{2}^{-\bullet}$ e os nitrosilo complexos}

Para verificar se a reação entre o radical $\mathrm{O}_{2}{ }^{-\bullet}$ e os nitrosilo complexos ocorre preferencialmente sobre o ligante $\mathrm{NO}^{+}$coordenado, gerando $\mathrm{NO}^{0}$ que posteriormente pode ser liberado, a reação foi executada na presença de eletrodo seletivo à $\mathrm{NO}^{0}$.

A utilização da via fotoquímica para a geração de $\mathrm{O}_{2}{ }^{\bullet}$ é comprometida neste caso devido às dificuldades de um controle preciso da concentração de oxigênio dissolvida no meio reacional. Este fato dificulta a medida direta de $\mathrm{NO}^{0}$ liberado, visto que as reações:

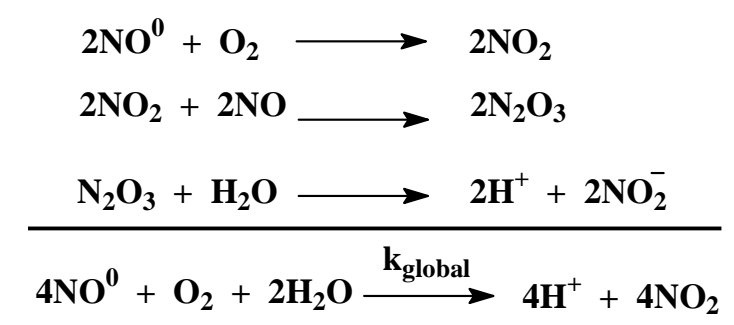

Reações 14 - 17 - Reações do $\mathrm{NO}^{0}$ com oxigênio molecular 
ocorrem no meio na presença de $\mathrm{NO}^{0}$ e $\mathrm{O}_{2}$. Como a constante $\mathrm{k}_{\text {global }}=2,1 \pm 0,4 \times 10^{6} \mathrm{M}^{-2} \mathrm{~s}^{-1}$ é elevada ${ }^{[87]}$, a detecção de $\mathrm{NO}^{0}$ via eletrodo seletivo ficaria impossibilitada pela resposta lenta que o eletrodo apresenta.

Portanto para a execução deste experimento foi utilizado para a geração de $\mathrm{O}_{2}{ }^{\bullet} \mathrm{o}$ sistema xantina/xantina oxidase. Para a utilização da enzima xantina oxidase em meio contendo os nitrosilo complexos foram executados experimentos para verificar se a presença destes complexos poderia inibir a atividade desta enzima. Para tanto, foi monitorada espectrofotometricamente a formação de ácido úrico $\left(\lambda_{\max }=290 \mathrm{~nm}\right)$, produto da reação entre a enzima e o substrato. A presença dos complexos supracitados não inibiu a produção de superóxido uma vez que foi detectada a formação de ácido úrico.

No entanto, a enzima xantina oxidase necessita de $\mathrm{pH}$ fisiológico (próximo a 7,2) para que possa converter o substrato com máxima eficiência. $\mathrm{O}$ complexo trans-[Ru(NO) $\left.\left(\mathrm{NH}_{3}\right)_{4}\left((\mathrm{POEt})_{3}\right)\right]^{3+}$ que dentre as tetraminas estudadas apresenta a maior constante de liberação de $\mathrm{NO}^{0}$, e portanto seria ideal para este teste, não pode ser utilizado nesse modelo experimental. Isto porque esse complexo em $\mathrm{pH}$ fisiológico forma o nitrito complexo correspondente ${ }^{[88]}$ e também sofre ataque nucleofílico no ligante de fósforo pelos íons $\mathrm{OH}^{-}$do meio.

Assim, para este experimento, foram utilizados os complexos trans-[Ru(NO)(NH$\left.)_{4}(\mathrm{isn})\right]^{3+}$ e $[\mathrm{Ru}(\mathrm{NO})$ Hedta]. Para o primeiro complexo, foi possível observar a liberação de $\mathrm{NO}^{0}$ conforme ilustrado na Figura 26. Para o complexo [Ru(NO)Hedta] a liberação de $\mathrm{NO}^{0}$ pode ser observada mas como a constante de velocidade específica de liberação é muito baixa $\left(\mathrm{k}-\mathrm{NO}=0,02 \mathrm{~s}^{-1}\right)$, a variação da corrente medida pelo eletrodo foi muito pequena, conforme ilustrado no gráfico menor na Figura 26. A diferença na escala de tempo entre os dois complexos é claramente visível. Para o complexo trans$\left[\mathrm{Ru}(\mathrm{NO})\left(\mathrm{NH}_{3}\right)_{4}(\mathrm{isn})\right]^{3+}$ a variação na corrente começa a ocorrer em aproximadamente 40 
segundos após a adição da enzima. Já para o complexo [Ru(NO)Hedta] essa variação ocorre somente 800 segundos após a adição da enzima e a variação da corrente observada é muito menor (aproximadamente 10 vezes) em relação ao observado para o complexo contendo isonicotinamida como ligante.

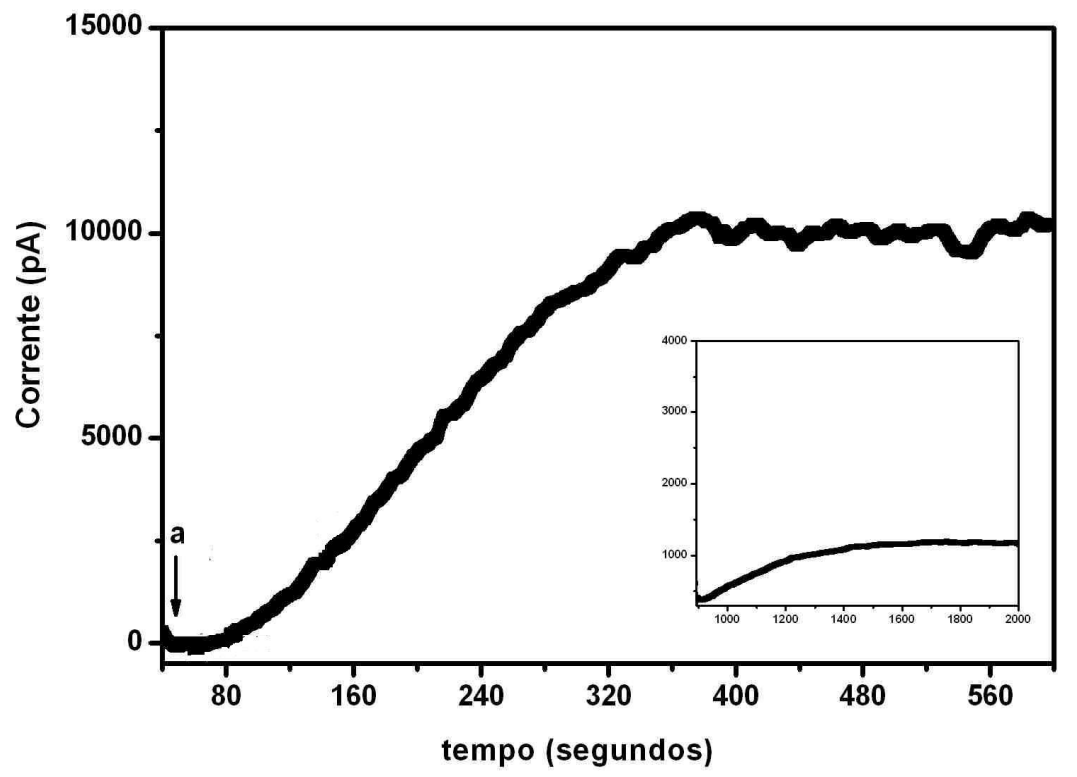

Figura 26 - Cronoamperometria utilizando eletrodo seletivo à $\mathrm{NO}^{0}$ para monitoramento da reação entre o complexo trans- $\left[\mathrm{Ru}(\mathrm{NO})\left(\mathrm{NH}_{3}\right)_{4}(\text { isn })\right]^{3+}$ e o radical $\mathrm{O}_{2}^{-\bullet}$. Gráfico menor: mesma reação com o complexo $[\mathrm{Ru}(\mathrm{NO}) \mathrm{Hedta}]$ (a): adição da enzima xantina oxidase. $\mathrm{C}_{\mathrm{Ru}}=5,0 \times 10^{-4} \mathrm{~mol} \mathrm{~L}^{-1} ; \mathrm{pH}=7,2 ; \mathrm{T}=25^{\circ} \mathrm{C}$.

A liberação de NO após a redução pelo superóxido também pode ser constatada através da formação da espécie [citc(FeII) - NO], conforme ilustra o gráfico da Figura 27. Para este experimento, foi utilizado excesso de nitrosilo de rutênio em relação ao citocromo c (150 vezes) e ao radical $\mathrm{O}_{2}^{-\bullet}(200$ vezes) para favorecer somente a via de reação entre o citocromo c e o NO liberado. 


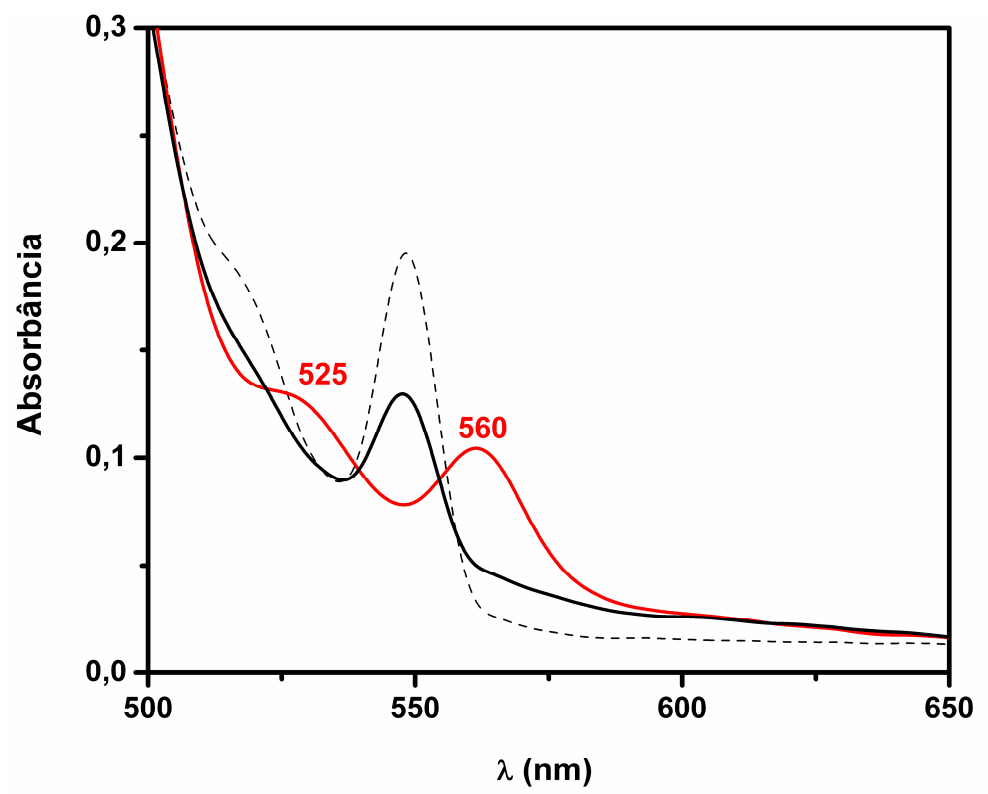

Figura 27 - Reação entre o citocromo c e o complexo trans-[Ru(NO) $\left.\left(\mathrm{NH}_{3}\right)_{4}(\mathrm{imN})\right]^{3+}$ após a reação com $\mathrm{O}_{2}^{-{ }^{*}}$. (--) controle; (-) $\mathrm{C}_{\mathrm{Ru}}=1,0 \times 10^{-4} \mathrm{~mol} \mathrm{~L}^{-1} ;(-) \mathrm{C}_{\mathrm{Ru}}=3,0 \times 10^{-3} \mathrm{~mol} \mathrm{~L}^{-1} . \mathrm{T}=25^{\circ} \mathrm{C}$; HTFA; $\mathrm{pH}=5,0$.

O espectro representado na Figura 27 em vermelho é característico do produto [citc(FeII) - NO], com $\lambda_{\max }$ em 525 e $560 \mathrm{~nm}^{[89]}$. Também pode ser observado que o produto citc(FeII), proveniente da reação entre o radical $\mathrm{O}_{2}{ }^{-}$(espectros em preto) não é observado, evidenciando o favorecimento da via de reação entre o citocromo c e o NO.

Esses experimentos, somados com os experimentos de captação de $\mathrm{O}_{2}{ }^{-\bullet}$ demonstrados no item 4.5.1 nos levam fortemente a acreditar que a reação entre o radical superóxido e o nitrosilo complexos ocorre sobre o ligante $\mathrm{NO}^{+}$, com posterior liberação no $\mathrm{NO}^{0}$.

\subsection{4 - Sobre a formação de peroxinitrito $\left(\mathrm{ONOO}^{-}\right)$}

Uma importante questão envolvendo o radical $\mathrm{O}_{2}^{-\bullet}$ é a formação do íon peroxinitrito $\left(\mathrm{ONOO}^{-}\right)^{[8]}$. A liberação de $\mathrm{NO}^{0}$ em meios onde o radical $\mathrm{O}_{2}^{-\bullet}$ está presente em excesso pode levar a formação do íon $\mathrm{ONOO}^{-}$, com constante de velocidade específica $\left(\mathrm{k}_{\mathrm{p}}\right)$ próximas a $10^{8}$ $\mathrm{M}^{-1} \mathrm{~s}^{-1}$, espécie extremamente reativa conforme ilustrado na Reação $18^{[29]}$. 


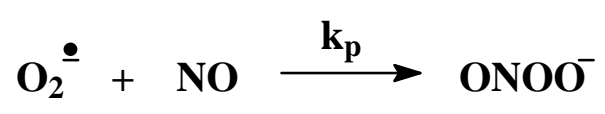

Reação 18 - Formação do íon peroxinitrito

Utilizando o modelo experimental enzimático, para a geração do radical $\mathrm{O}_{2}{ }^{-\bullet}$ foram efetuados ensaios para se verificar a possibilidade de formação do íon $\mathrm{ONOO}^{-}$, utilizando-se como sonda o radical tirosina. $\mathrm{O}$ íon $\mathrm{ONOO}^{-}$pode reagir com a tirosina, gerando como produto a nitrotirosina ${ }^{[90]}$, que pode ser identificada via HPLC ou espectrometria de massas. Os testes realizados com os compostos trans- $\left[\mathrm{Ru}(\mathrm{NO})\left(\mathrm{NH}_{3}\right)_{4}(\mathrm{~L})\right]^{3+}, \mathrm{L}=\mathrm{imN}$ e isn, mostraram que não há a formação de peroxinitrito na escala de tempo utilizada no experimento.

Esta observação experimental pode estar relacionada com a constante de liberação de NO pelos nitrosilo complexos. Após a redução do ligante $\mathrm{NO}^{+}$coordenado a $\mathrm{NO}^{0}$, a liberação de NO é relativamente lenta frente ao tempo de meia vida do radical $\mathrm{O}_{2}^{-\bullet}$ em solução.

No entanto, é esperado que em situações onde a concentração de $\mathrm{O}_{2}{ }^{-\bullet}$ é constante, exista a possibilidade de formação do íon $\mathrm{ONOO}^{-}$após a liberação de $\mathrm{NO}$ pelos nitrosilo complexos. Esta reação poderia ocorrer após a redução do ligante $\mathrm{NO}$ pelo radical $\mathrm{O}_{2}^{-\bullet}$ ou mesmo por redutores biológicos.

Dados reportados na literatura ${ }^{[91]}$ indicam que esta seria uma das vias pelas quais o óxido nítrico poderia causar a morte de parasitas, como o Tripanossoma cruzi. A formação de peroxinitrito in lócus nas células do parasita poderia causar danos irreversíveis ao parasita, levando a sua morte. 


\subsection{5 - Considerações entre as reações entre o radical $\mathrm{O}_{2}^{-\bullet}$ e os nitrosilo complexos de rutênio(II)}

Analisando de forma conjunta os resultados obtidos podemos inferir que o radical superóxido age como redutor do nitrosil coordenado nos complexos trans-[Ru(NO)(NH$\left.)_{4}(\mathrm{~L})\right]^{3+}$ implicando na liberação de $\mathrm{NO}^{0}$ por estes complexos A julgar pela ordem de grandeza entre $10^{4}$ e $10^{5} \mathrm{M}^{-1} \mathrm{~s}^{-1}$ da constante de velocidade específica estimada para esta reação é muito provável que essa reação possa ser importante no meio fisiológico. Os nitrosilo complexos de rutênio têm sido utilizados como modelo de metalofarmaco em testes em culturas de células de câncer, leishimaniose e doença de Chagas com bons resultados. Nestes casos, há uma elevada concentração de radicais, principalmente $\mathrm{O}_{2}{ }^{-}$ caracterizando uma situação de estresse oxidativo. Neste aspecto, os complexos poderiam agir como captadores de $\mathrm{O}_{2}^{-\bullet}$ e liberadores de $\mathrm{NO}$, que como descrito anteriormente possui diversas funções fisiológicas. Portanto, a redução do $\mathrm{NO}^{+}$coordenado poderia ocorrer não somente pela reação destes complexos por redutores químicos encontrados em altas concentrações em meio fisiológico (cisteína, ácido ascórbico, NADH), mas também pela ação do radical $\mathrm{O}_{2}{ }^{-}$. 
O conjunto dos dados expostos nos itens anteriores nos permite algumas considerações:

Os potenciais de oxidação do centro metálico nos complexos trans-[Ru(NO)(NH$\left.)_{4}(\mathrm{~L})\right]^{3+}$ encontram-se acima de 2,0V. Estes potenciais são muito positivos se comparados com outros compostos de rutênio(II) que não apresentam o nitrosil coordenado, mostrando de acordo com o fato deste ligante ser um forte ácido $\pi$. Os voltamogramas na região de $2,0 \mathrm{~V}$ apresentaram características distintas dependendo do complexo utilizado nos experimentos, porém nenhum dos pares redox encontrados podem ser formalmente considerados como reversíveis.

Os complexos trans-[Ru(NO)(NH$\left.)_{4}(\mathrm{~L})\right]^{3+}$ não se mostraram ativos para a captação do radical DPPH', pois não são capazes de reagir pela via de transferência de elétrons (potencial de oxidação do centro metálico é muito positivo) e também não são capazes de reagir pela via de transferência de átomo de hidrogênio $\left(\mathrm{H}^{\bullet}\right)$. Portanto, os nitrosilo complexos não podem ser considerados como antioxidantes para modelos de radicais que são desativados por redução. No entanto, os aquo complexos mostraram-se capazes de captar o radical $\mathrm{DPPH}^{\bullet}$ pela oxidação do centro metálico.

A reação dos complexos trans-[Ru(NO) $\left.\left(\mathrm{NH}_{3}\right)_{4}(\mathrm{~L})\right]^{3+}$ e o radical hidroxila indica que estes complexos são capazes de captar este radical em meio aquoso. No entanto, o mecanismo pelo qual a reação se processa é bastante complexo. Foi possível identificar via RPE um intermediário de reação que indica a presença de $\mathrm{NO}^{0}$ coordenado ao centro metálico. Em relação ao estado de oxidação de centro metálico após as reações, não foi observada a presença de Ru(III) via RPE. Não foi possível utilizando o método de cinética de competição calcular a constante da reação, possivelmente pela presença de reações paralelas e consecutivas entre o radical $\mathrm{OH}^{\bullet}$ e os produtos da reação com os nitrosilo complexos. Porém, 
a julgar pelos dados obtidos, estima-se de forma muito qualitativa que esta constante possa estar entre $1,0 \times 10^{8}$ e $1,0 \times 10^{10} \mathrm{M}^{-1} \mathrm{~s}^{-1}$.

Os nitrosilo complexos também se mostraram capazes de captar o radical $\mathrm{O}_{2}^{-\bullet}$, através da redução do ligante nitrosil coordenado. A liberação de NO após a reação foi monitorada via eletrodo seletivo à NO. A constante de velocidade para a reação foi calculada para a série de compostos utilizada, sendo que os valores estão na faixa de $1,0 \times 10^{4}$ a $4,5 \times 10^{5} \mathrm{M}^{-1} \mathrm{~s}^{-1}$. Utilizando tirosina como sonda, não foi detectada a formação do íon peroxinitrito após a redução no ligante nitrosil coordenado pelo radical $\mathrm{O}_{2}^{-\bullet}$. Os valores de constante de velocidade indicam que a reação entre os nitrosilo complexos e o radical $\mathrm{O}_{2}{ }^{-}$poderia ter importância no meio fisiológico, visto que a reação é relativamente rápida e poderia captar o radical em meio acometido pelo estresse oxidativo. 
1. LEFFLER, J.E. An introduction to free radicals. New York: John Wiley, 1993. p. 1-7.

2. IGNARO, L.J. Nitric oxide: biology and pathobiology. San Diego: Academic Press, 2000. p. 38-65

3. HALLIWELL, B.; GUTTERIDGE, J.M.C. Free radicals in biology and medicine. New York: Oxford University Press, 2007. p. 291-380.

4. AHMAD, S. Oxidative stress and antioxidant defenses in biology. New York: Chapman \& Hall, 1995. p. 2-27.

5. BEDARD, K.; KRAUSE, K.H. The NOX family of ROS-generating NADPH oxidases: physiology and pathophysiology. Physiological Reviews, v. 87, p. 245-313, 2007.

6. HALLIWELL, B.; GUTTERIDGE, M.C.; Oxygen toxicity, oxygen radicals, transition metals and disease. Biochemical Journal, v. 214, p. 1-14, 1984.

7. CARLSEN, C.U.; MOLLER, J.K.S.; SKIBSTED, L.H. Heme-iron in lipid peroxidation. Coordination Chemistry Reviews, v. 249, p. 485-498, 2005.

8. PACHER, P.; BECKMAN, J.S.; LIUDET, L. Nitric oxide and peroxynitrite in health and disease. Physiological Reviews, v. 37, p. 315-412, 2007.

9. MERKOFER, M.; KISSNER, R.; HIDER, R.C.; BRUNK, U.T.; KOPPENOL, W.H. Fenton chemistry and iron chelation under physiologically relevant conditions: electrochemistry and kinetics. Chemical Research in Toxicology, v. 19, n. 10, p. 1263-1269, 2006.

10. KOPPENOL, W. H.; LIEBMAN, J. F. The oxidizing nature of the hydroxyl radical. A comparison with the ferryl ion $\left(\mathrm{FeO}_{2}{ }^{+}\right)$. Journal of Physical Chemistry, v. 88, p. 99-101, 1984.

11. BENEDET, J.A.; SHIBAMOTO, T. Role of transition metals, $\mathrm{Fe}(\mathrm{II}), \mathrm{Cr}(\mathrm{II}), \mathrm{Pb}(\mathrm{II})$, and Cd(II) in lipid peroxidation. Food Chemistry, v. 107, p. 165-168, 2008.

12. DUNFORD, H.A. Oxidations of iron(II)/(III) by hydrogen peroxide: from aquo to enzyme. Coordination Chemistry Reviews, v. 233, p. 311-318, 2002.

13. AFANAS'EV, I.B. Superoxide ion: chemistry and biological implications. Boca Raton: CRC, 1989. v.1

14. SAWYER, D.T.; VALENTINE, J.S. How super is superoxide. Accounts of Chemical Reserch, v. 14, p. 393-400, 1981.

15. ZANICHELLI, P.G.; ESTRELA, H.F.G.; SPADARI-BRATFISCH, R.C.; GRACIKASSISSE, D.M.; FRANCO, D.W. The effects of ruthenium tetramine compounds on vascular smooth muscle. Nitric Oxide Biology and Chemistry, v. 16, n. 2, p. 189-196, 2007.

16. SAYRE, L.M.; PERRY, G.; SMITH, M.A. Oxidative stress and neurotoxicity. Chemical Research in Toxicology, v. 21, p. 172-18, 2008. 
17. ZANA, M.; JANKA, Z.; KALMAN, J. Oxidative stress: a bridge between Down's syndrome and Alzheimer's disease. Neurobiology of Aging, v. 28, p. 648-676, 2007.

18. IGNARRO, L.J. Endothelium-derived nitric oxide - actions and properties. FASEB Journal, v. 3, p. 31-36, 1989.

19. WINK, D.A.; MITCHEL, J.B. Nitric oxide and cancer: an introduction. Free Radical Biology \& Medicine, v. 34, n. 8, p. 951-954, 2003.

20. MOREIRA, P.I.; NUNOMURA, A.; NAKAMURA, M.; TAKEDA, A.; SHENK, J.C.; ALIEV, G.; SMITH, M.A.; PERRY, G. Nucleic acid oxidation in Alzheimer disease. Free Radical Biology \& Medicine, v. 44, p. 1493-1505, 2008.

21. LEE, I.K.; JANG, Y.W.; YU, S.H.; YUN, B.S. New triterpene glucosides, oligoporins A$\mathrm{C}$, from oligoporus tephroleucus protect DNA from Fenton reaction. Bioorganic \& Medicinal Chemistry Letters, v. 17, p. 4906-4909, 2007.

22. FINKEL, T.; HOLBROOK, N.J. Oxidants, oxidative stress and the biology of ageing. Nature, v. 408, n. 9, p. 239-247, 2000.

23. Chun, O.K.; Kim, D.; Lee, C.Y. Superoxide radical scavenging activity of the major polyphenols in fresh plums. Journal of Agriculture and Food Chemistry, v. 51, n. 27, p. 8067-8072, 2003.

24. MCCLEVERTY, J.A. Chemistry of nitric oxide relevant to biology. Chemical Reviews, v. 104, n. 2, p. 403-418, 2004.

25. PALMER, R.M.J.; ASHTON, D.S.; MONCADA, S. Vascular endothelial cells synthesize nitric oxide. Nature, v. 333, p. 664-666, 1988.

26. BARROS, B. F.; TOLEDO JR, J.C.; FRANCO, D.W.; TFOUNI, E.; KRIEGER, M.H. A new inorganic vasodilator, trans-[Ru(NO) $\left.\left(\mathrm{NH}_{3}\right)_{4}(\mathrm{POEt})_{3}\right]\left(\mathrm{PF}_{6}\right)_{3}$ : hypotensive effect of endothelium-dependent and -independent vasodilators in different hypertensive animals models. Nitric Oxide Biology and Chemistry, v. 7, p. 50, 2002.

27. SILVA, J.J.N.; OSAKABE, A.L.; PAVANELLI, W.R.; SILVA, J.N.; FRANCO, D.W. In vitro and in vivo antiproliferative and trypanocidal activities ruthenium NO donors. British Journal of Pharmacology, v. 152, p. 112-121, 2007.

28. NUNOSHIBA, T.; DeROJAS-WALKER, T.; TANENBAUM, S.R.; DEMPLE, B. Activation by nitric oxide of an oxidative-stress response that defends Escherichia coli against macrophages. Proceeding of the National Academy of Science, v. 90, p. 9993-9997, 1993.

29. WINK, D.A.; MIRANDA, K.M.; ESPEY, M.G.; PLUTA, R.M.; HEWETT, S.J.; COLTON, C. VITEK, M.; FEELISCH, M.; GRISHAM, M.B. Mechanisms of the antioxidant effects of nitric oxide. Antioxidants \& Redox Signaling, v. 3, n. 2, p. 203-213, 2001.

30. KIM, Y.M.; BERGONIA, H., LANCASTER, J. Jr. Nitrogen-oxide induced autoprotection in isolated rat hepatocytes. FEBS Letters, v. 374, p. 288-232, 1995. 
31. TOLEDO, J.C.; LIMA NETO, B.S.; FRANCO, D.W. Mutual effects in the chemical properties of the ruthenium metal center and ancillary ligands upon coordination.

Coordination Chemistry Reviews, v. 249, p. 419-431. 2005.

32. TFOUNI, E.; KRIEGER, M.; MCGARVEY, B.R.; FRANCO, D.W. Structure, chemical and photochemical reactivity and biological activity of some ruthenium amine nitrosyl complexes. Coordination Chemistry Reviews, v. 236, p. 57-69, 2003.

33. LANCASTER JUNIOR, J. Nitric oxide: principles and actions. San Diego: Academic Press, 1996. p. 37-46.

34. MIRANDA, K.M.; ESPEY, M.G.; WINK, D.A. A discussion of the chemistry of oxidative and nitrosative stress in cytotoxicity. Journal of Inorganic Biochemistry, v. 79, p. 237-240, 2000.

35. MIRANDA, K.M. The chemistry of nitroxyl (HNO) and implications in biology. Coordination Chemistry Reviews, v. 249, p. 433-455, 2005.

36. RIDNOUR, L.A.; THOMAS, D.D.; SWITZER, C.; FLORES-SANTANA, W.; ISENBERG, J.S.; AMBS, S.; ROBERTS, D.D.; WINK, D.A. Molecular mechanisms for discrete nitric oxide levels in câncer. Nitric Oxide, v. 19, p. 73-76, 2008.

37. FUKUTO, J.M.; BARTBERGER, M.D.; DUTTON, A.S.; PAOLOCCI, N.; WINK, D.A.; HOUK, K.N. The physiological chemistry and biological activity of nitroxyl (HNO): the neglected, misunderstood, and enigmatic nitrogen oxide. Chemical Research in Toxicology, v. 18, p. 790-801, 2005.

38. OLABE, J.A. The coordination chemistry of nitrosyl in cyanoferrates: an exhibit of bioinorganic relevant reactions. Dalton Transactions, v. 28, p. 3633-3648, 2008.

39. CLARKE, M.J. Ruthenium metallopharmaceuticals. Coordination Chemistry Reviews, v. 236, p. 209-233, 2003.

40. SAKURAI, H.; KOJIMA, Y.; YOSHIKAWA, Y.; KAWABE, K.; YASUI, H. Antidiabetic vanadium(IV) and zinc(II) complexes. Coordination Chemistry Reviews, v. 226 p. 187-198, 2002.

41. RADEMAKER-LAKHAI, J.M.; VAN DEN BONGARD, D.; PLUIM, D.; BEIJNEN, J.H.; SCHELLENS, J.H.M. A Phase I and pharmacological study with imidazolium-transDMSO-imidazole-tetrachlororuthenate, a novel ruthenium anticancer agent. Clinical Cancer Research, v. 10, p. 3717-3727, 2004.

42. SILVA, J. J. N.; PAVANELLI, W.; SALAZAR GUTIERREZ, F.R ; LIMA, F. C. A.; SILVA, F.B.A; SILVA, J. S.; FRANCO, D W . Complexation of the anti-trypanosoma cruzi drug benznidazole improves solubility and efficacy. Journal of Medicinal Chemistry, v. 51, p. 4104-4114, 2008. 
43. PEREIRA, J. C. M.; Carregaro, V.; COSTA, D. L.; SILVA, J. S.; CUNHA, F. Q.; FRANCO, D. W. Antileishmanial effect of ruthenium NO-donors. In: BRAZILIAN MEETING ON INORGANIC CHEMISTRY, 14., 2008, Foz do Iguaçu. Livro de Resumos... Foz do Iguaçu: Brazilian Meeting on Inorganic Chemistry, 2008. ref. OL-12.

44. VALDEZ, C.A.; SAAVEDRA, J.E.; SHOWALTER, B.M.; DAVIES, K.M.; WILDE, T.C.; CITRO, M.L.; BARCHI JUNIOR., J.J.; DESCHAMPS, J.R.; PARRISH, D.; ELGAYAR, S.; SCHLEICHER, U.; BOGDAN, C.; KEEFER, L.K. Hydrolytic reactivity trends among potential prodrugs of the $\mathrm{O}_{2}$-glycosylated diazeniumdiolate family. targeting nitric oxide to macrophages for antileishmanial activity. Journal of Medicinal Chemistry, v. 51, p. 3961-3970, 2008.

45. TOLEDO JUNIOR, J. C.; SILVA, H.A.S.; SCARPELLINI, M.; MORI, V.; CAMARGO, A.J.; BERTOTTI, M.; FRANCO, D.W . Ruthenium tetraammines as a model of nitric oxide donor compounds. European Journal Of Inorganic Chemistry, p. 1879-1885, 2004.

46. BORGES, S.S.S.; DAVANZO, C.U.; CASTELLANO, E.E.; SCHPECTOR, J.Z.; SILVA, S.C.; FRANCO, D.W. Ruthenium nitrosyl complexes with N-Heterocyclic ligands. Inorganic Chemistry, v. 37, p. 2670-2677, 1998.

47. STEFANELI, E.V. Sobre a redução do óxido nítrico em complexos de tetraaminas de rutênio (II). 2007. 82f. Dissertação (Mestrado) - Instituto de Química de São Carlos, Universidade de São Paulo, São Carlos, 2007.

48. MIRANDA, K.M. The chemistry of nitroxyl (HNO) and implications in biology. Coordination Chemistry Reviews, v. 249, p. 433-455, 2005.

49. PERRIN, D.D.; ALMARGE, W,L.; PERRIN, D.P. Purification of laboratory chemicals. New York: Pergamon Press. New York, 1983. p. 56

50. SHRIVER, D. F.; Drezdzon, M.A. The manipulation of air-sensitive compounds. New York : Wiley, 1986. p. 22-57.

51. ISIED, S.; TAUBE, $\mathrm{H}$. Effects of $\mathrm{SO}_{2}, \mathrm{HSO}_{3}{ }^{-}$and $\mathrm{SO}_{3}{ }^{-}$as auxiliary ligands on the reactivity of ammineruthenium(II)-ligands bonds. Inorganic Chemistry, v. 13, n. 17, p. 1545-1551, 1974.

52. LOPES, L.G.F.; CASTELLANO, E.E.; FERREIRA, A.G.; DAVANZO, C.U.; CLARKE, M.J.; FRANCO, D.W Reactivity of trans- $\left[\mathrm{Ru}\left(\mathrm{NH}_{3}\right)_{4} \mathrm{P}(\mathrm{OEt})_{3} \mathrm{NO}\right] \mathrm{X}_{3}\left(\mathrm{X}=\mathrm{PF}_{6}^{-}, \mathrm{CF}_{3} \mathrm{COO}^{-}\right)$: modulation of release of NO by trans-effect. Inorganica Chimica Acta, v. 358, p. 28832890, 2005.

53. FRANCO, D.W.; TAUBE, H. Triethyl phosphite as a ligand on ruthenium (II). Inorganic Chemistry, v. 17, p. 571-577, 1978.

54. BAJAJ, H. C; VAN ELDIK, R. Kinetics and mechanism of the ligand substitution reactions of ethylenediaminetetraacetate complexes of ruthenium(III) in aqueous solution. Inorganic Chemistry, v. 27, p. 4052-4055, 1988. 
55. DIAMANTIS, A. A.; DUBRAWSKY, J. V. Preparation and structure of ethylenediaminetetraacetate complexes of ruthenium(II) with dinitrogen, carbon monoxide, and other p-acceptor ligands. Inorganic Chemistry, v. 20, p. 1142-1150, 1981.

56. VOGT JR, L.H.; KATZ, J.L.; WIBERLEY, S.E. The crystal and molecular structure of ruthenium-sulfur dioxide coordination compounds. i. chlorotetraammine (su1fur dioxide) ruthenium(ii) chloride. Inorganic Chemistry, v. 4, p. 1157-1163, 1965.

57. CARDOSO, D.R.; FREDERIKSEN, A.M.; SILVA, A.A.; FRANCO, D.W.; SKIBSTED, L.H. Sugarcane spirit extracts of oak and Brazilian woods: antioxidant capacity and activity. European Food Research Technology, v. 1, p. 1-2, 2008.

58. LIXING, L.; ABE, Y.; KANAGAWA, K.; SHOJI, T.; MASHINO, T.; MOCHIZUKI, M.; TANAKA, M.; MIYATA, N. Iron-chelating agents never suppress Fenton reaction but participate in quenching spin-trapped radicals. Analytica Chimica Acta, v. 599, p. 315-319, 2007.

59. ROSEN, G.M.; BRITIGAN, B.E.; HALPEN, H.J.; POU, S. Free radicals: biology and detection by spin trapping. New York: Oxford University Press, 1999. p. 122-167.

60. BERR, D. A step-by-step procedure for spin trapping the hydroxyl radical. Billerica: Bruker Instruments Inc. EPR division, 2005. 4 p. (Relatório Técnico).

61. ROUBAUD, V.; SANKARAPANDI, S.; KUPPUSAMY, P.; TORDO, P.; ZWEIER, J.L. Quantitative measurement of superoxide generation using the spin trap 5-

(diethoxyphosphoryl)-5-methyl-1-pyrroline-n-oxide. Analytical Biochemistry, v. 247, p. 404-411, 1997.

62. CARLOS, R.M.; FERRO, A.A.; SILVA, H.A.S.; GOMES, M.G.; BORGES, S.S.S.; FORD, P.C.; TFOUNI, E.; FRANCO, D.W. Photochemical reactions of trans-[Ru $\left.{ }^{\mathrm{II}}\left(\mathrm{NO}^{+}\right)\left(\mathrm{NH}_{3}\right)_{4}(\mathrm{~L})\right]^{3+}$ complexes. Inorganica Chimica Acta, v. 357, p. 1381-1388, 2004.

63. ESPEY, M.G.; THOMAS, D.D.; MIRANDA, K.M.; WINK, D.A. Focusing of nitric oxide mediated nitrosation and oxidative nitrosylation as a consequence of reaction with superoxide. Proceedings of the National Academy of Sciences, v. 99, n. 17, p. 11127-11132 2002.

64. OGUSUCU, R.; RETTORI, D.; MUNHOZ, D.C.; NETTO, L.E.S.; AUGUSTO, O; Reactions of yeast thioredoxin peroxidases I and II with hydrogen peroxide and peroxynitrite: Rate constants by competitive kinetics. Free Radical Biology and Medicine, v. 42, p. 326334, 2007.

65. BALK, J.M.; BAST, A.; HAENEN, G.R.M.M. Evaluation of the accuracy of antioxidant competition assays. Free Radical Biology and Medicine, v. 47, p. 135-144, 2009.

66. SIEGER, M.; SARKAR, B.; ZÁLIŠ, S.; FIEDLER,J.; ESCOLA, N.; DOCTOROVICH, F.; OLABE, J.A.; KAIM, W. Establishing the NO oxidation state in complexes $[\mathrm{Cl} 5(\mathrm{NO}) \mathrm{M}] \mathrm{n}-, \mathrm{M}=\mathrm{Ru}$ or Ir, through experiments and DFT calculations. Dalton Transactions, p. 1797-1 800, 2000. 
67. BOCKRIS, J. O. Modern electrochemistry: fundamentals of electrodics. New York: Academic Press, 2000. v.2A

68. KAPAŁKA, A.; FÓTI, G.; COMNINELLIS, C. Investigations of electrochemical oxygen transfer reaction on boron-doped diamond electrodes. Electrochimica Acta, v. 53, p. 19541961, 2007.

69. OLIVEIRA JUNIOR, R.T.S.; SALAZAR-BANDA, G.R.; SANTOS, M.C.; CALEGARO, M.L.; MIWA, D.W.; MACHADO, S.A.S.; AVACA, L.A. Electrochemical oxidation of benzene on boron-doped diamond electrodes. Chemosphere, v. 66, p. 2152-2158, 2007.

70. KAPAŁKA, A.; FÓTI, G.; COMNINELLIS, C. The importance of electrode material in environmental electrochemistry formation and reactivity of free hydroxyl radicals on borondoped diamond electrodes. Electrochimica Acta, v. 54, n. 7, p. 2018-2023, 2009.

71. NASCIMENTO FILHO, J.C.; FRANCO, D.W. Isonicotinamide as entering ligand on trans $-\left[\mathrm{Ru}\left(\mathrm{NH}_{3}\right)_{4} \mathrm{P}(\mathrm{OR})_{3}\left(\mathrm{H}_{2} \mathrm{O}\right)\right]^{2+},(\mathrm{R}=\mathrm{Me}, \mathrm{Pr}, \mathrm{Pr}$ and $\mathrm{Bu})$. Inorganica Chimica Acta, v. 113 , p. 55-60, 1986.

72. MILARDOVIC, S.; IVEKOVIC, D.; RUMENJAK, V.; GRABARIC, B. Use of DPPH /DPPH redox couple for biamperometric determination of antioxidant activity.

Electroanalysis, v. 17, n. 20, p. 1847-1853, 2005.

73. YORDANOV, N.D.; CHRISTOVA, A.G.; Quantitative spectrophotometric and EPR determination of 1,1-diphenil-2-picryl-hydrazyl (DPPH). Fresenius Journal of Analytical Chemsitry, v. 358, p. 610-613, 1997.

74. LITWINIENKO, G.; INGOLD, K. U. Solvent effects on the rates and mechanisms of reaction of phenols with free radicals. Accounts of Chemical Research, v. 40, p. 222-230, 2007.

75. VLEESCHOUWER, F.; SPEYBROECK, V.V.; WAROQUIER, M.; GEERLINGS,P.; PROFT, F. Electrophilicity and nucleophilicity index for radicals. Organic Letters, v. 9, p. $2721-2724,2007$.

76. METZKER, G.; TOLEDO JUNIOR, J. C.; MAGALHÃES, A.; CARDOSO, D. R.; FRANCO, D. W. Hydrolysis of trans-[Ru(NO)(NH$\left.)_{4} \mathrm{P}(\mathrm{OEt})_{3}\right]\left(\mathrm{PF}_{6}\right)_{3}$ : $\mathrm{NO}$ as an activation agent for nucleophilic attack. In: BRAZILIAN MEETING ON INORGANIC CHEMISTRY, 14., 2008, Foz do Iguaçu. Livro de Resumos... Foz de Iguaçu: Brazilian Meeting on Inorganic Chemistry, 2008. ref. PB-29.

77. TOLEDO JUNIOR, J.C. Aspectos da reatividade de complexos de rutênio contendo óxido nítrico como ligante. 2004. 119f. Tese (Doutorado) - Instituto de Química de São Carlos, Universidade de São Paulo, São Carlos, 2004.

78. SCHAFER, K.; ASMUS, K-D. Phosphite radicals and their reactions: examples of redox, substitution and addition reactions. Journal of Physical Chemistry, v. 84, p. 2156-2160, 1980. 
79. MAZZETO, S.E.; RODRIGUES, E.; FRANCO, D.W. Synthesis, characterization and reactivity of trans- $\left[\mathrm{Ru}\left(\mathrm{NH}_{3}\right)_{4}\left(\mathrm{P}(\mathrm{OEt})_{3}\right)_{2}\right]^{3+}$ ions. Polyhedron, v. 12, n. 8, p. 971-975, 1993.

80. BAXENDALE, J.H.; RODGERS, M.A.J.; WARD, M.D. Radiolysis of aqueous solution of ruthenium(III) hexa-ammine chloro-penta-ammine. Journal of Chemical Society (A), p. 1246-1250, 1970.

81. FERRO, A.A.; TFOUNI, E.; BEZERRA, C.W.B.; BAGATIN, I.; FRANCO, D.W.; MCGARVEY, B.R. Detection of the EPR Spectra of NO in ruthenium(II) Complexes. Inorganic Chemistry, v. 39, p. 3577-3581, 2000.

82. SILVA, H. A. S.; McGARVEY, B. R.; SANTOS, R. H. A.; BERTOTTI, M.; MORI, V.; FRANCO, D. W. Sulfate as a ligand in ruthenium (II) and (III) ammines. Canadian Journal of Chemistry, v. 79, p. 679-687, 2001.

83. WEIL, J.A.; BOLTON, J.R. Electron paramagnetic resonance: elementary theory and practical applications. New York: John Wiley, 1999. p. 34-76.

84. OHIGASHI, H.; KURITA, Y. Electron spin resonance of Vk centers, radical pairs, and $\mathrm{NO}$ trapped in $\mathrm{X}$-irradiated single crystals of $\mathrm{NH}_{3} \mathrm{OHCl}$. Journal of the Physical Society of Japan, v. 24, p. 654. 1968.

85. CHEN, Y.; LIN, F.T.; SHEPHERD, R.E. ${ }^{15} \mathrm{~N}$ NMR and electrochemical studies of [Ru ${ }^{\text {II }}(\text { Hedta) }]^{-}$complexes of $\mathrm{NO}, \mathrm{NO}^{+}, \mathrm{NO}_{2}^{-}$, and $\mathrm{NO}^{-}$. Inorganic Chemistry, v. 38 ,p. 973 983, 1999.

86. CRILLY, S.; MAGNER, E. Reversible increase in the redox potential of cytochrome $\mathrm{c}$ in methanol. Chemical Communications, n. 8, p. 535-537, 2009.

87. LEWIS, R.S.; DEEN, W.M. Kinetics of the reaction of nitric oxide with oxygen in aqueous solutions. Chemical Research Toxicology, v. 7, n. 4, p. 568-574, 1994.

88. OSTI, R.Z.; FRANCO, D.W. Aspects of nitrite association with trans- $\left[\mathrm{Ru}\left(\mathrm{H}_{2} \mathrm{O}\right)\left(\mathrm{NH}_{3}\right)_{4} \mathrm{P}(\mathrm{OEt})_{3}\right]^{2+}$. Polyhedron, v. 26, p. 4746-4750, 2007.

89. SHARPE, M.A.; COOPER, C.R. Reactions of nitric oxide with mitochondrial cytochrome c: a novel mechanism for the formation of nitroxyl anion and peroxynitrite. Biochemical Journal, v. 332, p. 9-19, 1998.

90. KRAINEV, A.G.; WILLIAMS, T.D.; BIGELOW, D.J. Enzymatic reduction of 3nitrotyrosine generates superoxide. Chemical Research in Toxicology, v. 11, p. 495-502, 1998.

91. DENICOLA, A.; RUBBO, H.; RODRIGUEZ, D.; RADI, R.; Peroxynitrite-mediated cytotoxicity to trypanosoma cruzi. Archives of Biochemistry and Biophysics, v. 304, p. 279286, 1993. 


\section{Apêndice I}

Assumindo-se que as reações abaixo (1 e 2) como os processos cineticamente majoritários durante o processo de captação do radical superóxido:

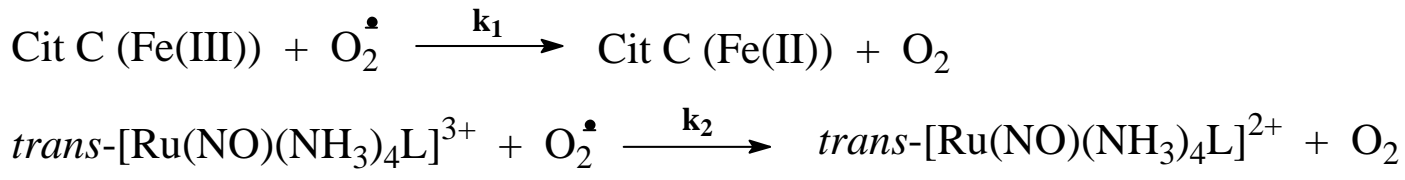

Podemos resumir as seguintes equações de velocidade para o consumo do radical superóxido:

$$
\begin{aligned}
& -\frac{\mathrm{d}\left[\mathrm{O}_{2}^{\bullet}\right]}{\mathrm{dt}}=\mathrm{k}_{1} \cdot\left[\mathrm{Cit} \mathrm{C}(\mathrm{Fe}(\mathrm{III})] \cdot\left[\mathrm{O}_{2}^{\circ}\right]\right. \\
& -\frac{\mathrm{d}\left[\mathrm{O}_{2}^{\circ}\right]}{\mathrm{dt}}=\mathrm{k}_{2} \cdot[\mathrm{Ru}(\mathrm{NO})] \cdot\left[\mathrm{O}_{2}^{\circ}\right]
\end{aligned}
$$

Quando a captação do íon superóxido pelos nitrosilo complexos é igual a 50\% ( $\mathrm{IC}_{50}$ concentração inibitória de 50\%) temos as velocidades de consumo do íon superóxido iguais para as equações de velocidade 3 e 4 . Portanto, podemos escrever a seguinte equação que expressa a relação entre $\mathrm{k}_{1} \mathrm{e} \mathrm{k}_{2}$.

$$
\begin{aligned}
& \left(\frac{\% \text { Cap }}{1-\% \text { Cap }}\right) \times\left(k_{1}\right) \times C_{\text {cit-c }}=\left(k_{2}\right) \times C_{\text {RuNO }} \\
& \text { Onde: \% Cap }=\mathrm{Abs}_{\text {reação }} / \mathrm{Abs}_{\text {controle }}
\end{aligned}
$$

Assim, a porcentagem de captação é obtida através das absorbâncias do experimento de controle $\left(\mathrm{Abs}_{\text {controle }}\right)$ e de experimentos variando-se a concentração analítica dos nitrosilo complexos. Para se obter o $\mathrm{IC}_{50}$ lança-se um gráfico de porcentagem de captação do radical versus concentração do nitrosilo complexo utilizada, conforme mostra a Figura 25. O valor de $\mathrm{IC}_{50}$ é obtido por interpolação da curva. Calcula-se assim o valor de $\mathrm{k}_{2}$. 


\section{Apêndice II}

Valores de potencial de redução $\left(\mathrm{E}_{\mathrm{NO}+/ \mathrm{NO} O}\right)$ e constante específica de liberação de $\mathrm{NO}\left(\mathrm{k}_{-\mathrm{NO}}\right)$ para os nitrosilo complexos de rutênio(II).

\begin{tabular}{lcc}
\hline Complexo & $\mathbf{k}_{-\mathbf{N O}}\left(\mathbf{s}^{-1}\right)$ & $\mathbf{E}_{\mathbf{N O}+/ \mathrm{NO}}(\mathbf{V}$ vs. ECS $)$ \\
\hline trans $-\left[\mathrm{Ru}(\mathrm{NO})\left(\mathrm{NH}_{3}\right)_{4}(\mathrm{imN})\right]^{3+}$ & 0,160 & $-0,36$ \\
trans $-\left[\mathrm{Ru}(\mathrm{NO})\left(\mathrm{NH}_{3}\right)_{4}(4-\mathrm{pic})\right]^{3+}$ & 0,090 & $-0,25$ \\
trans $-\left[\mathrm{Ru}(\mathrm{NO})\left(\mathrm{NH}_{3}\right)_{4}(\mathrm{py})\right]^{3+}$ & 0,060 & $-0,23$ \\
trans $-\left[\mathrm{Ru}(\mathrm{NO})\left(\mathrm{NH}_{3}\right)_{4} \mathrm{P}(\mathrm{OEt})_{3}\right]^{3+}$ & 0,987 & $-0,11$ \\
trans $-\left[\mathrm{Ru}(\mathrm{NO})\left(\mathrm{NH}_{3}\right)_{4}(\mathrm{isn})\right]^{3+}$ & 0,043 & $-0,38$ \\
trans $-\left[\mathrm{Ru}(\mathrm{NO})\left(\mathrm{NH}_{3}\right)_{4}(\mathrm{nic})\right]^{3+}$ & 0,025 & $-0,31$ \\
{$[\mathrm{Ru}(\mathrm{NO}) \mathrm{Hedta}]$} & 0,020 & $-0,54$ \\
\hline
\end{tabular}

